\title{
Navigating from quality management to quality culture
}

Citation for published version (APA):

Bendermacher, G. (2021). Navigating from quality management to quality culture. [Doctoral Thesis, Maastricht University]. Ipskamp. https://doi.org/10.26481/dis.20210702gb

Document status and date:

Published: 01/01/2021

DOI:

10.26481/dis.20210702gb

Document Version:

Publisher's PDF, also known as Version of record

\section{Please check the document version of this publication:}

- A submitted manuscript is the version of the article upon submission and before peer-review. There can be important differences between the submitted version and the official published version of record.

People interested in the research are advised to contact the author for the final version of the publication, or visit the DOI to the publisher's website.

- The final author version and the galley proof are versions of the publication after peer review.

- The final published version features the final layout of the paper including the volume, issue and page numbers.

Link to publication

\footnotetext{
General rights rights.

- You may freely distribute the URL identifying the publication in the public portal. please follow below link for the End User Agreement:

www.umlib.nl/taverne-license

Take down policy

If you believe that this document breaches copyright please contact us at:

repository@maastrichtuniversity.nl

providing details and we will investigate your claim.
}

Copyright and moral rights for the publications made accessible in the public portal are retained by the authors and/or other copyright owners and it is a condition of accessing publications that users recognise and abide by the legal requirements associated with these

- Users may download and print one copy of any publication from the public portal for the purpose of private study or research.

- You may not further distribute the material or use it for any profit-making activity or commercial gain

If the publication is distributed under the terms of Article $25 \mathrm{fa}$ of the Dutch Copyright Act, indicated by the "Taverne" license above, 
Navigating from Quality Management to Quality Culture 


\section{Maastricht University 4 Maastricht UMC+}

in the School of Health Professions Education

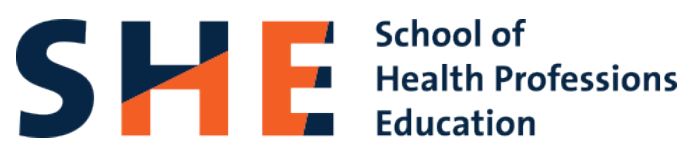

(C) Guy Bendermacher, 2021, Maastricht.

ISBN: 97894642 I 3522

Editing and Printing: Ipskamp Printing Maastricht.

Cover design: Guy Bendermacher 


\section{Navigating from Quality Management to Quality Culture}

\section{Dissertation}

to obtain the degree of Doctor at Maastricht University,

on the authority of the Rector Magnificus Prof. dr. Rianne M. Letschert

in accordance with the decision of the Board of Deans,

to be defended in public on Friday 2 July 2021, at 10:00 hours

by

Guy Bendermacher 


\section{Supervisors:}

Prof. dr. Mirjam oude Egbrink

Prof. dr. Diana Dolmans

\section{Co-supervisor:}

Dr. Ineke Wolfhagen

Assessment Committee:

Prof. dr. Pim Teunissen (chair)

Prof. dr. Lia Fluit, Radboud UMC Nijmegen

Dr. Dries Berings, Katholieke Universiteit Leuven

Prof. dr. Wim Gijselaers

Dr. Renée Stalmeijer 


\section{Table of Contents}

Chapter I

Introduction

Chapter II

Unravelling quality culture in higher education institutions: a realist review Higher Education (2017); 73: 39-60.

Chapter III

Reinforcing pillars for quality culture development: a path analytic model Studies in Higher Education (2019); 44: 643-662.

Chapter IV

Shaping a culture for continuous quality improvement in undergraduate medical education

Academic Medicine (2020); 95: 1913-1920.

Chapter V

Advancing quality culture in health professions education: experiences and perspectives of educational leaders

Advances in Health Sciences Education (2020); online publication ahead of print.

Chapter VI

Discussion

Chapter VII

Appendices

Summary

138

Samenvatting

Impact addendum

Dankwoord (acknowledgements)

About the author

SHE Dissertation series 

Chapter I

\section{Introduction}


The myriad of ideas brought forward by quality management gurus such as Crosby, Deming, Juran, and Ishikawa mark a shore from which a broad spectrum of quality evaluation and improvement approaches have departed - now more than four decades ago.' Many of these ideas and their underpinning philosophies are still embodied in attempts of organisations to continuously enhance the quality of their products and services today. ${ }^{2}$ That is, organisational investments to prevent mistakes, to set and measure strict performance criteria, and to increase the focus on client, patient, or customer demands are considered worthwhile, since the benefits derived from the generated quality of outputs are believed to outweigh the dedicated efforts and costs. ${ }^{3}$ The theory behind quality improvement approaches has however also evolved over the years: in this introductory chapter, a number of trends and characteristics particular to the higher education domain are described which have contributed to the understanding that educational quality enhancement requires more than the implementation of systems and processes. To safeguard and enhance educational quality, an organisational culture should be in place that builds on shared values, a mastering of change, the nurturing of professional ownership, and a focus on learning and development. ${ }^{4}$ Although the interpretation of quality as part of the organisational culture has gained more importance, to this date there is a lack of research and conceptual clarity on the exact interrelation between educational quality and organisational culture(s). ${ }^{5}$ The studies conducted in the line of this dissertation address this research gap and signal ways to push quality improvement approaches out of their mainstream. The performed studies coincide with an emerging awareness that the typical features of educational quality improvement demand that we navigate in another direction: from quality management to quality culture.

\section{A managerial take on educational quality}

Among the major driving forces behind the increased attention to quality management in higher education institutions (HEls) are rising student numbers, intensified competition between institutions, rapid advances in educational technology, expanded pressure on governmental funding and growing public and political demands for institutional accountability. ${ }^{6-9}$ While still topical at present, the onset of these trends took place against a backdrop of accelerated internationalisation following the Bologna process (which kicked-off in 1999). Moreover, at that time, new ideas of public management were introduced that brought integration, decentralisation and responsibility structures into sharper focus. ${ }^{10}$ More specifically, the adoption of a common European framework for educational quality assurance placed a profound emphasis on HEls' accountability. The main areas of attention targeted in this framework were systematic reviews of study programme contents, the quality of teaching staff, learning resources, a larger attention to performance data analysis and an increased focus on student-centred learning." Although many of the developments that drove quality management forward originated in the external environment of HEls, the implications for internal operations have been considerable. Institutional activities to design, assure, evaluate and improve the quality of teaching and learning (i.e. internal quality management practices, also refer to table I) gained a formal status and became viewed as a panacea to propel effectiveness, efficiency and transparency. ${ }^{12-14}$ 
The implementation of technical and rational approaches to evaluating and improving quality have produced various beneficial results. Among these are increased attention to the quality of teaching and diverse educational methods, ${ }^{6,15}$ a larger student involvement, ${ }^{16}$ clarified responsibilities, ${ }^{17}$ further professionalisation of work practices, ${ }^{18}$ and the introduction of key performance indicators that could help to break through prevailing educational traditions. ${ }^{19}$

Although the above narrative provides a positive account of quality management's proceedings in HEls, the formalisation of processes also set sail to a vast sea of more critical studies. Originating from attempts to reach 'zero defects' in industrial operations, the theory behind standardisation can, for instance, restrict the scope of innovation and experimentation. A certain freedom to experiment and innovate is however a necessary precondition for any organisation's ability to learn. ${ }^{20}$ Moreover, despite a steady increase in research on quality management implementation, agreement on whether quality management practices actually lead to improved educational quality is still inconclusive. ${ }^{5,21}$ A lack of effective quality management approaches might stem from the fact that standard management approaches in higher education do not sufficiently take into account institutional contexts and characteristics, such as the diversity in student intake, use of different education formats, and varying institutional strategies to safeguard financial sustainability and growth. ${ }^{22}$

Another significant and pertinent critical observation concerns the way in which quality management practices are experienced by academic staff members. The technocratic character of quality systems and procedures and their emphasis on control contrasts with staff values of professionalism, autonomy, and a focus on improving educational content rather than on what they might consider overly bureaucratic tasks. ${ }^{23-26}$ Quality management can be regarded as a mechanistic device that consists of imposed processes, manuals, guidelines and requirements. Although supposedly in place to reach improvement, this device is often not regarded as such by those who have to operate it. Quality management might be viewed by staff (and students) as something alien, something that demands compliance rather than engagement. Why is this the case? The answer lies, at least in part, in the fact that top-down management approaches fail to connect to the cultures and subcultures present in organisations and study programmes. ${ }^{27,28}$

\section{The significance of organisational culture and quality culture}

The organisational culture of a HEl encompasses a pattern of norms, values, practices, beliefs and assumptions that guide the behaviour of individuals and groups in the institution and that provide a frame of reference within which to interpret the meaning of events and actions. ${ }^{29}$ Research on the link between organisational cultures and effectiveness has revealed that the learnt assumptions that determine a group's coping strategies when confronted with problems of external adaptation and internal integration have an important impact on performance. ${ }^{30-32}$ Organisational culture theory holds that such underlying assumptions comprise values that are often unconscious and taken for granted. In addition to these assumptions, espoused values (strategies, goals or 
philosophies), and observable behaviour or artefacts form layers that reflect the organisational culture. $^{30,33,34}$ Where the theory about organisational culture implies shared beliefs and views and alignment between basic assumptions, espoused values and behaviour, the organisational reality is often more complex. Within organisations, multiple subcultures coexist, which can represent divergent and even contradictory or competing values. Subcultures in $\mathrm{HEls}$ relate not only to a shared involvement in research and / or teaching tasks, disciplinary backgrounds (e.g. in Medicine, Social Sciences or Economics), but also to institutional or departmental characteristics. ${ }^{35,36}$ The espoused values and behaviours concerning educational quality improvement might differ between members of these different subcultures, since they vary in underlying assumptions regarding educational quality. ${ }^{37,38}$ Moreover, while HEls' mission is to deliver high-quality research and education (and healthcare in the case of medical schools), staff incentives often merely concentrate on performance in research (or clinical tasks). There appears to be a mismatch between evaluation outcomes, educational policy and behaviours in practice. ${ }^{26,39}$

The notion of 'quality culture' embraces the idea that quality management systems and processes should be in line with the present organisational culture, so that they can reinforce each other. ${ }^{40}$ In 2002, the European University Association (EUA) launched a 4-year quality culture project that highlighted the topic's political and strategic relevance. By calling for a shift from control, accountability and regulation to autonomy, credibility and enhancement, this project also fuelled further research into the quality culture realm, as ways to reach the said objective required further exploration. ${ }^{33}$ The EUA described quality culture as an organisational culture intended to enhance quality permanently (see table I). A quality culture is characterised by two elements: a cultural/psychological element of shared values, beliefs, expectations and commitment concerning quality, and a structural/managerial element with defined processes that enhance quality and aim at coordinating individual efforts. ${ }^{41} \mathrm{~A}$ quality culture can be seen as a specific kind of organisational culture or subculture, that overlaps with the mosaic of other subcultures present in HEls. ${ }^{42}$ The first quality culture dimension comprehends 'soft' aspects such as a commitment to educational quality improvement and enhanced trust between stakeholders (i.e. accreditation bodies, policy makers, academics and students). In addition, 'hard' aspects such as monitoring processes, reporting systems and responsibility frames are subsumed under a second dimension. ${ }^{41} \mathrm{~A}$ quality culture is shaped by the organisational context and influenced by the phase of development and implementation quality management approaches in organisations are in. ${ }^{43}$

\section{Diverging interpretations of quality and quality culture}

It should be noted that the concepts of 'educational quality' and 'quality culture' are both elusive and difficult to define. Quality has been referred to as a slippery concept, because the word means different things to different people. ${ }^{2}$ The perhaps most often used conceptualisation of educational quality has been developed by Harvey and Green, who distinguished five interpretations of quality: 'fitness for purpose' (educating capable future professionals), 'value for money' (a return on 
investments), 'perfection' (focusing on zero defects), 'exceptional' (standing out as 'the best') and 'transformative' (focusing on the educational learning effect). ${ }^{44}$ The strategic choices that HEI make determine how the trade-off between these different quality conceptualisations works out in practice. The focus on one or more interpretations of educational quality also determines the way a quality culture is configured. In this respect, it is important to realise that a quality culture is not something that institutions have to develop from scratch. Each institution already possesses a kind of quality culture that -in line with organisational culture theory- determines how that institution reacts to external developments, and attempts to foster internal cohesion. For instance, external quality requirements aid to set the internal improvement agendas of institutions, while organisations might also focus internally on constant learning and therefore consciously embed quality improvement activities in their daily operations. ${ }^{45}$ Hence, the enhancement of a quality culture into a certain direction does not necessarily mean bringing new elements into institutions. Instead, it is primarily a process of changing existing quality improvement practices to better resonate with values of stakeholders and the context of the organisation.

Table I includes three definitions that recap the core concepts described earlier in this introduction. These definitions and the studies that we have conducted concentrate on an internal organisational perspective. However, as noted before, also externally set quality prerequisites will eventually impact the internal culture and management. This means that in our studies, external quality assurance processes (such as externally organised evaluations or reviews for programme accreditations) do receive attention, be it in a more indirect manner.

Table I Definitions of key concepts used throughout this dissertation

\section{Definition}

Quality

management

Organisational culture

Quality culture
All activities and processes deliberately organised by higher education institutions to design, assure, evaluate and improve the quality of teaching and learning. ${ }^{12(\text { (p. 104) }}$

The collective, mutually shaping pattern of norms, values, practices, beliefs and assumptions that guide the behaviour of individuals and groups in an institute for higher education and provide a frame of reference within which to interpret the meaning of events and actions on and off campus. ${ }^{29}($ p. 28$)$

An organisational culture that intends to enhance quality permanently and is characterised by two distinct elements: a cultural/psychological element of shared values, beliefs, expectations and commitment concerning quality and a structural/managerial element with defined processes that enhance quality and aim at coordinating individual efforts. ${ }^{4 !}$ (p. 10) 


\section{Research gaps and central research questions}

The quality culture concept appeals to a large field of quality managers, policymakers and academics concerned with quality in higher education. This is likely the case because the term has a positive connotation of collectiveness and attention to continuous improvement. The expanded attention to quality culture is rooted in studies that have explored the relation between organisational culture and performance, ${ }^{18,31,32}$ and in studies that have examined the question of why the implementation of quality management approaches in HEls can be a very challenging endeavour. ${ }^{12,25,26}$ Another reason for the rising popularity of the quality culture concept stems from its political relevance. ${ }^{28}$ The introduction and common use of the term 'quality culture' helps to shift the focus away from external quality control towards trust in the institutional capacities and commitment to improve. Although the literature has provided insight into components that are theoretically linked to quality culture, ${ }^{33,45}$ a comprehensive overview and sound conceptualisation of the construct is still missing. ${ }^{43} \mathrm{~A}$ quality culture can be interpreted in different ways, because of its multifarious constituents and complexity and the uniqueness of each institution's organisational culture. ${ }^{45}$ There is a need to identify key features of a quality culture that stimulate quality development in practice and to link these features to outcomes. However, such empirical research on quality cultures in the particular setting of higher education is lacking. ${ }^{33,46}$ To catalyse insights into quality culture(s), more systematic study approaches should be adopted that bring experiences and perspectives of stakeholders to the surface. With this destination in mind, we developed two central research questions for this dissertation that overarch the aims of our studies:

I. What are the most important features of a quality culture and how do these features interrelate?

A) Our first study aimed to identify hampering and promoting organisational context features impacting quality culture development based on a literature review; the goal was to explore the most important working mechanisms of a quality culture and to provide insights into outcomes associated with a quality culture.

B) In the second study, survey-based data were collected to investigate the relationships between organisational values, leadership, communication, staff work-related psychological attitudes, and quality enhancement practices.

2. How to promote a culture of continuous quality improvement?

A) The third study used focus groups to explore key features of quality cultures in medical schools and examined how these features contribute to continuous improvement of education according to members of the educational quality advisory committees.

B) Our fourth study was conducted to find out -through individual interviews- how a quality culture in health professions education can be enhanced according to educational leaders. 


\section{Dissertation outline}

The subsequent four chapters present the empirical studies that together provide an answer to our overarching research questions (see Table 2 for an overview of the studies). As this dissertation is based on journal articles, some repetition across chapters is inevitable. Chapter II maps previous research on the implementation of quality management approaches in $\mathrm{HEl}$ in relation to their organisational quality cultures. Relevant literature was identified by means of a systematic literature search. The realist review method applied served to develop an overall conceptual framework of quality culture(s) in HEls. Next, Chapter III further explores the interrelations between the key quality culture concepts that were identified in our first study. Informed by organisational psychological literature, a hypothetical path model was construed that we tested against survey data gathered from educational coordinators. Chapter IV presents the results of a qualitative study among students and staff members who occupy a representative role in educational quality advisory committees. By means of this interinstitutional study we gained further insights into the perspectives of students and staff members on quality culture and its relation to educational improvement. Chapter $V$ focuses on the way in which educational leaders can enhance the quality culture. This study used an appreciative inquiry approach to first identify positive experiences of staff members, which were consecutively used to project positive future developments. Chapter VI discusses the main research findings, lists implications for further research and practice and sets out the strengths and limitations of our work. Chapter VII, the appendices, include summaries of this dissertation in English and Dutch, an impact addendum, the author's acknowledgements and a brief biography. Lastly, an overview of recent dissertations completed at the School of Health Professions Education is presented.

\section{Research setting}

To set the stage for this $\mathrm{PhD}$ project, the first study provides a synthesis of previous research on quality management and quality culture in higher education based on a literature review. The second and fourth study were performed at Maastricht University's (UM) Faculty of Health, Medicine and Life Sciences (FHML). The UM is most known for its integral application of Problem-Based Learning in all its study programmes. The two studies took place in the FHML undergraduate programmes in Biomedical Sciences, European Public Health, Health Sciences, and Medicine. The respective curricula are typically structured around consecutive thematic courses spanning several weeks. Together with multidisciplinary planning group members, course coordinators bear responsibility for the implementation and systematic improvement of education at the executive level. These course coordinators were the subjects in the second and fourth study. For the fourth study, we also interviewed the undergraduate programme coordinators and domain directors (responsible for the quality of education of several undergraduate and graduate programmes in one educational domain). Our third study was 
conducted in an inter-institutional setting. Students and staff members represented in educational quality advisory committees of six Dutch study programmes in Medicine participated in focus-group meetings. These committees have formal rights of consent regarding educational regulations and quality management aspects. Moreover, the committees have as their central task to provide advice to the institutional management regarding all matters that impact on the quality of education.

Table 2 Overview of conducted empirical studies

\begin{tabular}{|c|c|c|c|c|}
\hline & \multicolumn{4}{|l|}{ Chapter } \\
\hline & II & III & IV & V \\
\hline Study & $\begin{array}{l}\text { Unravelling quality } \\
\text { culture in higher } \\
\text { education }\end{array}$ & $\begin{array}{l}\text { Reinforcing pillars for } \\
\text { quality culture } \\
\text { development }\end{array}$ & $\begin{array}{l}\text { Shaping a culture for } \\
\text { continuous quality } \\
\text { improvement }\end{array}$ & $\begin{array}{l}\text { Advancing quality } \\
\text { culture: leadership } \\
\text { perspectives }\end{array}$ \\
\hline Purpose & $\begin{array}{l}\text { To identify inhibiting } \\
\text { and promoting } \\
\text { context elements, } \\
\text { working } \\
\text { mechanisms and } \\
\text { associated } \\
\text { outcomes of quality } \\
\text { culture(s) in higher } \\
\text { education }\end{array}$ & $\begin{array}{l}\text { To examine } \\
\text { interrelations } \\
\text { between context } \\
\text { features, work- } \\
\text { related attitudes of } \\
\text { staff and quality } \\
\text { enhancement } \\
\text { practices }\end{array}$ & $\begin{array}{l}\text { To identify key } \\
\text { quality culture } \\
\text { features and explore } \\
\text { how these } \\
\text { contribute to } \\
\text { continuous quality } \\
\text { improvement of } \\
\text { medical education }\end{array}$ & $\begin{array}{l}\text { To explore how a } \\
\text { quality culture } \\
\text { can be enhanced } \\
\text { according to the } \\
\text { experiences and } \\
\text { perspectives of } \\
\text { educational } \\
\text { leaders }\end{array}$ \\
\hline \multirow[t]{2}{*}{ Method } & Realist review & Survey research & $\begin{array}{l}\text { Focus group } \\
\text { interviews }\end{array}$ & $\begin{array}{l}\text { Individual } \\
\text { interviews }\end{array}$ \\
\hline & $\begin{array}{l}\text { Systematic scientific } \\
\text { literature search } \\
\text { followed by a } \\
\text { theory-driven data } \\
\text { analysis }\end{array}$ & $\begin{array}{l}\text { Survey based data } \\
\text { gathering followed } \\
\text { by path analysis of a } \\
\text { predefined model. }\end{array}$ & $\begin{array}{l}\text { Semi-structured } \\
\text { focus groups } \\
\text { followed by a } \\
\text { thematic content } \\
\text { analysis }\end{array}$ & $\begin{array}{l}\text { Vignette- and } \\
\text { appreciative } \\
\text { inquiry based } \\
\text { interviews and } \\
\text { analysis }\end{array}$ \\
\hline $\begin{array}{l}\text { Context / } \\
\text { partici- } \\
\text { pants }\end{array}$ & $\begin{array}{l}\text { Comprehensive } \\
\text { search in } 7 \\
\text { databases on quality } \\
\text { management } \\
\text { implementation and } \\
\text { quality culture in } \\
\text { HEls }\end{array}$ & $\begin{array}{l}\text { Eighty-nine course } \\
\text { coordinators of four } \\
\text { undergraduate } \\
\text { programmes in } \\
\text { health professions } \\
\text { education }\end{array}$ & $\begin{array}{l}\text { Education } \\
\text { programme (quality } \\
\text { advisory) } \\
\text { committees of six } \\
\text { medical faculties in } \\
\text { the Netherlands }\end{array}$ & $\begin{array}{l}\text { Twenty-five } \\
\text { leaders of } \\
\text { courses, } \\
\text { undergraduate } \\
\text { programmes or } \\
\text { domains in health } \\
\text { professions } \\
\text { education }\end{array}$ \\
\hline
\end{tabular}




\section{Reflexivity}

'You look at where you are going and where you are and it never makes sense, but then you look

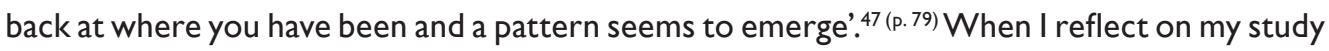
background, work as an educational policy advisor, and on my research project on quality culture, such a pattern indeed becomes visible. Some of the topics that I was, and still am, most interested in concern the quality of work and working conditions in organisations, ways in which employees in complex, knowledge-intensive institutions avail themselves of their discretionary space to cope with policies and rules, and the impacts such spheres in organisational life have on organisational performance. My research interests and the research questions I posed as well as the ones that I might have unconsciously discarded reveal something about where I identify with. The fact that three out of the four studies included in this dissertation were conducted in the setting of health professions education is obviously not a coincidence. Besides the practical advantages of having the opportunity to use the network that I have been able to build in my policy work, a commitment to the health professions education environment in which I performed this research was paramount and has always sparked my motivation. From a more critical perspective, it is inherent in the fluid task profile of a policy advisor (concerned with accreditation processes, curriculum reforms, project reporting and consultation, and supporting advisory committees) who also works as a part-time PhD candidate, that I have developed certain normative notions that resonate in the way discussions are framed throughout the following chapters. ${ }^{48}$ I was provided with the opportunity to cooperate with, and learn from, researchers that have backgrounds in the educational sciences health professions education. Some of these colleagues also hold senior management positions at the Institute for Education where I work. The close cooperation with these team members - who each approached the performed studies and their results from different angles - also coloured the way in which I interpreted the research findings. I would like to acknowledge and thank the students, academics and support staff members with whom I have closely cooperated over the past years and who have either directly or indirectly influenced the way I sketched the shores and horizons of my research. 


\section{References}

I. Sallis, E. (2002). Total quality management in education. London: Kogan Page.

2. Kolsaker, A. (2008). Academic professionalism in the managerialist era: a study of English universities. Studies in Higher Education; 3: 513--525.

3. Crosby, P. B. (1979). Quality is free: The art of making quality certain. New York: McGraw-Hill.

4. Ehlers, U.D. (2010). Moving from control to culture in higher education quality. In: Ehlers, U,D., Schneckenberg, D. (eds) Changing cultures in higher education. Berlin, Heidelberg: Springer,

5. Harvey, L. and Williams, J. (2010). Fifteen years of quality in higher education (Part Two). Quality in Higher Education; 16:81-113.

6. European University Association (2005). Developing an internal quality culture in European universities. Report on the Quality Culture project 2002-2003. Brussels: EUA.

7. Brennan, J., and Shah, T. (2000). Quality assessment and institutional change: Experiences from 14 countries. Higher Education; 40: 331-49.

8. Naidoo, R., Shankar, A. and Veer, E. (20II). The consumerist turn in higher education: policy aspirations and outcomes. Journal of Marketing Management; 27: II42-1162.

9. Boyle, P. and Bowden, J.A. (1997). Educational quality assurance in universities: an enhanced model. Assessment \& Evaluation in Higher Education; 22: III-I2I.

10. Bleiklie, I. (1998). Justifying the evaluative state: New public management ideals in higher education. Journal of Public Affairs Education; 4: 87-100.

II. European Association for Quality Assurance in Higher Education (2009). ENQA report on standards and guidelines for quality assurance in the European higher education area. Brussels: ENQA.

12. Kleijnen, J., D. Dolmans, J. Willems, and Van Hout, H. (20I4). Effective quality management requires a systematic approach and a flexible organisational culture: a qualitative study among academic staff. Quality in Higher Education; 20: 103-126.

13. Westerheijden, D.F., Hulpiau, V. and Waetens, K. (2007). From design and implementation to impact of quality assurance: An overview of studies into what impacts improvement. Tertiary Education and Management; 13: 295-312.

14. Harvey, L. (2006). Impact of quality assurance: Overview of a discussion between representatives of external quality assurance agencies. Quality in Higher Education; 12: 287-290.

15. Tavares, O., Sin, C., Videira, P. and Amaral, A. (2017). Academics' perceptions of the impact of internal quality assurance on teaching and learning, Assessment \& Evaluation in Higher Education; 42: 1293-1305.

16. Griffin, A. and Cook, V. (2009) Acting on evaluation: Twelve tips from a national conference on student evaluations. Medical Teacher; 31: 10I-104.

17. Huusko, M. and Ursin, J. (2010). Why (not) assess? Views from the academic departments of Finnish universities. Assessment \& Evaluation in Higher Education; 35: 859-869.

18. Kleijnen, J., Dolmans, D., Willems, J., and Van Hout, H. (2012). Does internal quality management contribute to more control or to improvement of higher education? A survey on faculty perceptions. Quality Assurance in Education; 19: 141-155.

19. Stensaker, B. (2006). Embedding quality culture in higher education: A selection of papers from the Ist European Forum for Quality Assurance, Munich 23-25 November, European University Association, Brussels, pp. 59-62.

20. Stensaker, B. and Norgard, J.D. (200I). Innovation and isomorphism: A case study of university identity struggle 1969-1999. Higher Education; 42: 473-492.

21. Williams, J. (2016) Quality assurance and quality enhancement: is there a relationship? Quality in Higher Education; 22: 97-102.

22. Lomas, L. (1999). The culture and quality of higher education institutions: Examining the links. Quality Assurance in Education; 7: 30-34.

23. Brookes, M. and Becket, N. (2007). Quality management in higher education: A review of international issues and practice. International Journal for Quality and Standards; I: I-37. 
24. Cruickshank, M. (2003). Total quality management in the higher education sector: A literature review from an international and Australian perspective. Total Quality Management and Business Excellence; 14: II59-1167.

25. Newton, J. (2000). Feeding the beast or improving quality? Academics' perceptions of quality assurance and quality monitoring. Quality in Higher Education; 6: 153-163.

26. Lomas, L. (2004). Embedding quality: The challenges for higher education. Quality Assurance in Education: An International Perspective; 12: 157-165.

27. Harvey, L. (2009). A critical analysis of quality culture. Paper presented at the International Network for Quality Assurance Agencies in Higher Education (INQAAHE) Conference. New Approaches to Quality Assurance in the Changing World of Higher Education, Abu Dhabi, United Arab Emirates, 30 March-2 April.

28. Yorke, M. (2000). Developing a quality culture in higher education. Tertiary Education and Management; 6: 19-36.

29. Kuh, G. D. and Whitt, E.J. (1988). The invisible tapestry: Culture in American colleges and universities. ASHE-ERIC Higher Education Report No. I. Washington, D.C.: Association for the Study of Higher Education.

30. Schein, E.H. (1992). Organizational culture and leadership, $2^{\text {nd }}$ ed. San Fransisco CA: Jossey-Bass.

3I. Cameron, K.S. and Quinn, R.E. (1999). Diagnosing and changing organisational culture based on the competing values framework. Reading MA: Addison-Wesley.

32. Smart, J. (2003). Organizational effectiveness of 2-year colleges: the centrality of cultural and leadership complexity. Research in Higher Education; 44: 673-703.

33. Ehlers, U.D. (2009). Understanding quality culture. Quality Assurance in Education, 17: 343-363.

34. Hildesheim, C. and Sonntag, K. (2020). The quality culture inventory: a comprehensive approach towards measuring quality culture in higher education. Studies in Higher Education; 45: 892-908.

35. Välimaa, J. (1998). Culture and identity in higher education research. Higher Education; 36: II9-138.

36. Chandler, N. (2010). Reasons and forms of organizational resistance to change in the higher education sector. Practice and Theory in Systems of Education; 5: 87-104.

37. Kleijnen, J., Dolmans, D. Willems, J. and van Hout, H. (2013). Teachers' conceptions of quality and organisational values in higher education: compliance or enhancement? Assessment \& Evaluation in Higher Education; 38: 152-166.

38. Berings, D. (2009). Reflection on quality culture as a substantial element of quality management in higher education. Paper presented at the fourth European Quality Assurance Forum (EQAF) of the European University Association (EUA), Copenhagen. Nov 19-21.

39. Engbers, R. (2017). Medical teaching: Policy implementation \& Teacher motivation in university hospital settings [PhD thesis]. Nijmegen: Ipskamp Printing.

40. Berings, D., Beerten, Z., Hulpiau, L.V. and Verhesschen, P. (2010). Quality culture in higher education: from theory to practice. Proceedings of the 5th European Quality Assurance Forum, Lyon, France. Brussels: EUA.

4I. European University Association (2006). Quality culture in European universities: A bottom-up approach. Report on the three rounds of the quality culture project 2002-2006. Brussels: EUA

42. Bendermacher, G.W.G., Dolmans, D.H.J.M., Wolfhagen, I.H.A.P. and oude Egbrink, M.G.A. (2013). Toward a multi-perspective model of quality culture in higher education institutions. Paper presented at the $8^{\text {th }}$ European Quality Assurance Forum. Gothenburg, Sweden.

43. Kottmann, A., J., Huisman, L., Brockerhoff, L. Cremonini, and Mampaey, J. (2016). How can one create a culture for quality enhancement? CHEPS, CHEGG.

44. Harvey, L. and Green, D. (1993). Defining quality. Assessment and Evaluation in Higher Education; 18: 8-35.

45. Harvey, L. and Stensaker, B. (2008). Quality culture: understandings, boundaries and linkages. European Journal of Education; 43: 427-42.

46. Lanarès, J. (2009). Tracking the development of a quality culture: Is the discourse translated into action? Paper presented at the Fourth European Quality Assurance Forum, Copenhagen, Denmark.

47. Pirsig, R. M. (2006). Zen and the art of motorcycle maintenance: an inquiry into values. New York, N.Y.: HarperTorch.

48. Seyfried, M. (2019). Undisclosed desires: quality managers' normative notions regarding the implementation of quality management. Assessment \& Evaluation in Higher Education; 44: II 06 - III9. 


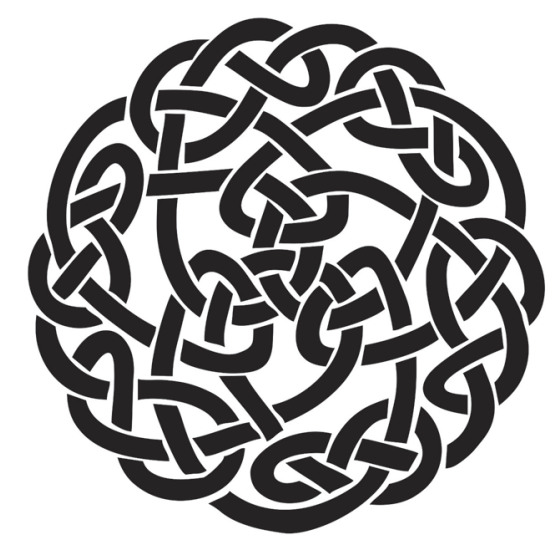

Guy Bendermacher

Mirjam oude Egbrink

Ineke Wolfhagen

Diana Dolmans

Published in:

Higher Education (2017); 73: 39-60 
Chapter II

\section{Unravelling quality culture in higher education institutions: a realist review}




\begin{abstract}
There is a growing belief that higher education institutions should nurture a 'quality culture' in which structural/managerial and cultural/psychological elements act in synergy to continuously improve education. Notwithstanding the positive connotation of the 'quality culture' concept, its exact configuration remains subject to debate. A realist review was conducted to identify inhibiting and promoting organisational context elements impacting quality culture, its working mechanisms and associated outcomes. Leadership and communication were identified as being of key importance in binding structural/managerial and cultural/psychological elements. Leaders are central 'drivers' of quality culture development through their ability to influence resource allocation, clarify roles and responsibilities, create partnerships and optimise people and process management. Adequate communication is considered a prerequisite to diffuse quality strategies and policies, evaluate results and identify staff values and beliefs. It is proposed that the working mechanisms of quality culture comprise increased staff commitment, shared ownership, empowerment and knowledge. Associated outcomes related to these mechanisms are positive effects on staff and student satisfaction, continuous improvement of the teachinglearning process and student and teacher learning and development. Institutions striving for the development of a quality culture should best operate from a contingency approach, i.e. make use of quality management intervention approaches which are tailored to the organisational context.
\end{abstract}

\title{
Keywords
}

Quality management, Quality culture, Educational improvement, Higher education, Realist review. 


\section{Introduction}

Whereas higher education institutions ( $\mathrm{HEI}$ ) nowadays find themselves confronted with a decrease in public funding, they simultaneously need to invest in organisational change processes in order to be able to gain position in an increasingly competitive market. In the past two decades, the intensified concern for the development of quality management in the field of higher education has been amplified by an increased public and political demand for 'accountability' as well as the strategic use of information on quality indicators for marketing purposes. ${ }^{1,2}$ Systematic and comprehensive quality management approaches have been widely adopted by $\mathrm{HEl}$ and now form an integral part of institutions' attempts to become more efficient, effective and client oriented. ${ }^{3}$

The formalisation and standardisation of quality management practices have contributed to expansion of quality monitoring and the potential to identify measures for improvement. However, it remains unclear whether these practices in themselves have contributed to the actual improvement of teaching and learning. ${ }^{4}$ For one reason, it can be questioned whether standard approaches to quality management are appropriate for institutions which often vary substantially in terms of their mission, objectives, size and nature of student intake. ${ }^{5}$ Moreover, increased attention to quality management yields opportunity costs and can meet reluctance of academics who feel these procedures are externally constructed, managed and imposed. ${ }^{6,7}$ Tools and instruments for quality management might not work as intended - or even have a negative impact on organisational processes - due to their implementation from a top down direction, neglect of individual staff members' autonomy and viewing of staff as passive receivers of policy instead of active contributors. ${ }^{8-10}$

Reported bottlenecks in HEl relating to the implementation of quality management are in line with findings of research conducted in a variety of disciplinary settings; in order to be successful, strategies, processes and tools for quality management should act in congruence with the present organisational culture. ${ }^{11-14}$ Higher education organisational culture has been defined as 'the collective, mutually shaping pattern of norms, values, practices, beliefs and assumptions that guide the behaviour of individuals and groups in an institute for higher education and provide a frame of reference within which to interpret the meaning of events and actions on and off campus.' ${ }^{5}$ (p. 28) The term 'quality culture' has been introduced more recently, to utter the idea that the culture of an organisation and educational quality should not be seen as independent entities, but rather that 'quality stems from a broader cultural perspective'. ${ }^{\text {(p. }}{ }^{\text {43l) }}$ The importance attributed to quality culture is rooted in its political applicability: it reflects a desired shift from quality control, emphasis on accountability and regulation, to increased autonomy, credibility and educational enhancement based on the experiences, expertise and values of HEl. ${ }^{16}$ The European University Association (EUA) has formulated a definition of quality culture which can be considered an important landmark in attempts to further operationalise the concept. Quality culture according to the EUA is: 
an organisational culture that intends to enhance quality permanently and is characterised by two distinct elements: on the one hand, a cultural/psychological element of shared values, beliefs, expectations and commitment towards quality and on the other hand, a structural/managerial element with defined processes that enhance quality and aim at coordinating individual efforts. ${ }^{16(p .10)}$

Quality culture can thus be regarded as a specific kind of organisational culture which encompasses shared values and commitment to quality. The definition holds that, in addition to 'hard' aspects (e.g. quality management, strategies and processes), 'soft' aspects (e.g. values, beliefs and commitment) influence quality culture. Moreover, a quality culture implies a collective responsibility: it is considered to coincide with management commitment to quality as well as a grass-roots involvement of academic and administrative staff and students. In order for a quality culture to develop, an appropriate balance between top-down and bottom-up approaches to enhance quality and coordinate individual efforts is required. ${ }^{16}$ In Fig. I, the EUA definition of quality culture is depicted. The figure illustrates that the organisational structural/managerial and organisational cultural/ psychological elements of quality culture are not to be considered separately: they must be linked through elements such as communication, participation and trust.

Although the positive connotation of quality culture implies that it is worth striving for, the exact meaning of the concept is also subject to debate. It has been noted for instance that it is too straightforward to speak about 'the quality culture' as such, since it constitutes a complex socialconstructivist phenomenon of which the contours are shaped by the organisational context, values, 9,17 and the development phase of dealing with quality management in which the organisation resides. ${ }^{18}$ The quality culture of an organisation is difficult to assess because it involves the taken-forgranted, shared assumptions of individuals in the organisation, which lie beneath the conscious level. ${ }^{19}$ This forms an explanation for the so far existing paucity of research on the emergence of quality culture and the grounding of its merit. ${ }^{20} \mathrm{~A}$ realist review, which encompasses a combination of in-depth analysis of previously conducted empirical research with the formulation of propositions contributing to further theory development on quality culture, was conducted with the aims to:

I. Identify hampering and promoting organisational context elements impacting quality culture development;

2. Explore the most important 'working mechanisms' of quality culture;

3. Provide insights in the outcomes associated with quality culture.

In line with its focus on quality management and the development of quality culture within $\mathrm{HEI}$, this study is directed to analysis of the internal context of organisations; it is targeted on the conditions, entities, events and factors within HEI that influence its activities and choices, particularly the behaviour of staff. Quality culture is envisaged throughout the paper as the conglomerate of its promoting organisational context elements, key working mechanisms and associated outcomes. 


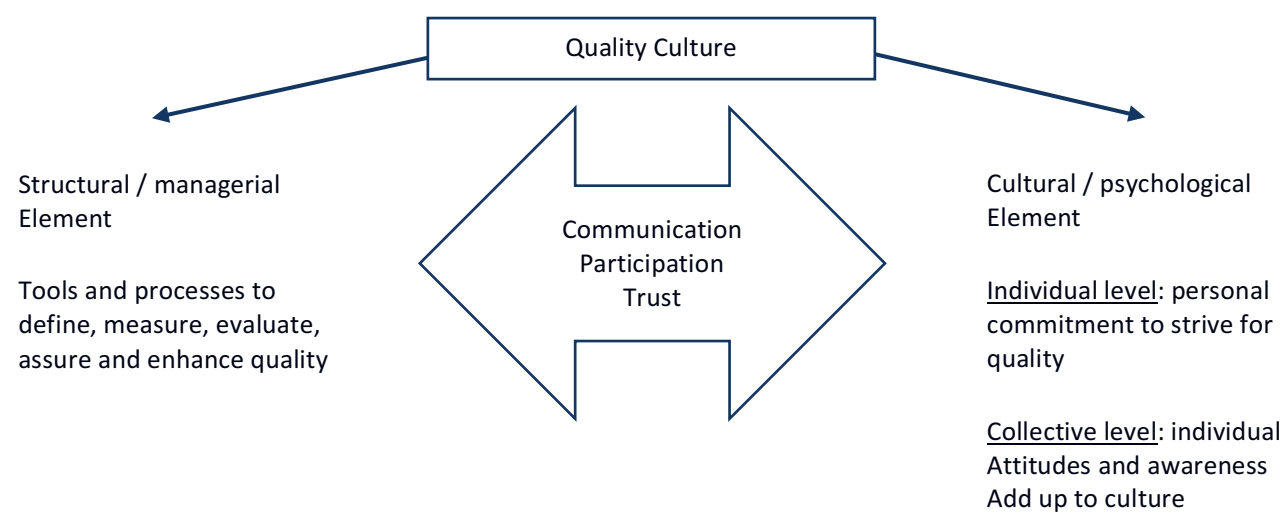

Figure I Elements of a quality culture. ${ }^{21}(p .17)$

\section{Methods}

\section{Realist review}

A realist review is a systematic and theory-driven approach aimed at searching and refining explanations of the relationship between contextual elements, mechanisms and outcome(s) of interventions. ${ }^{22}$ Realism holds that mechanisms matter because they generate outcomes and that contextual elements should be taken into account since they influence the processes by which an intervention produces outcomes. ${ }^{23}$ The term 'mechanism' refers to the reasoning or reaction of participants and stakeholders to an intervention. According to realists, it is not the intervention itself that produces outcomes. Rather, the intervention impacts on working mechanisms through addressing resources, opportunities and constraints which then lead to the decisions, choices and behaviour of stakeholders. Mechanisms are not directly observable, but can be identified by reconstructing the reasoning of stakeholders. ${ }^{24}$ The realist methodology allows for an interpretative, reflexive and iterative review process. ${ }^{25}$ As empirical research on quality culture is scarce, the conducted review included studies on quality management within $\mathrm{HEl}$, i.e. 'the institutional arrangements for assuring, supporting, developing and enhancing, and monitoring the quality of teaching and learning'. ${ }^{26(p .28)}$ Hence, quality management is seen as the intervention of concern. Quality management interventions are to be embedded in - and are influenced by - the organisational context and trigger mechanisms which lead to quality related outcomes. The study focuses on refining the understanding of quality culture by investigating differences between situations with effective and ineffective implementation of quality management. The organisational context elements, working mechanisms and realised outcomes, are considered attributes of the quality culture which provide explanations for differences in effectiveness of quality management interventions. 


\section{Systematic search strategy}

In June 2014 , a systematic literature search was performed to identify studies relating to the concepts of quality management and quality culture development in higher education. The search included seven databases, covering various disciplinary fields: Business Source Premier (BSP), Econlit, Education Resources Information Center (ERIC), Medline, Psycinfo, SocIndex and Web of Science. Databases were searched by using a combination of the key search terms 'quality culture', 'quality management', 'higher education' and 'improvement'. Synonyms and/or related concepts to the key search terms were used to gain an overview of relevant studies. A total number of 63 terms were applied in the search (the search terms are listed in Appendix I).

\section{In- and exclusion criteria and review process}

The initial search was limited to English peer-reviewed articles, published in academic journals between 1980 and June 2014. To be included, articles needed to adhere to various inclusion criteria. They had to concern (I) higher education, (2) internal quality management and (3) elements influencing quality management practices or educational enhancement (as opposed to studies merely assessing (service) quality). Moreover, articles had to (4) incorporate in-class education and (5) include a presentation of empirical data. Please refer to Appendix 2 for a detailed overview of inclusion and exclusion criteria). No further constraints for article selection were applied on methodological grounds. Titles and/ or abstracts of articles where initially reviewed by the first author. Whenever there were doubts as to whether or not articles fully met the inclusion criteria, their abstracts were independently reviewed and discussed by all authors and, if necessary, full texts were assessed. An overview of the articles was generated by summarising study objectives, study design, data collection instruments, setting/study population, main results, conclusion and information on quality culture elements. Thereafter, information from individual articles was extracted to construct a table which describes the context-mechanism-outcome configuration.

\section{Iterative search}

As the review process progressed, data suitability limitations occurred. The search strategy and application of in-and exclusion criteria led to an overrepresentation of studies involving implementation of total quality management (TQM) approaches in HEl. The applicability of TQM approaches in education has been questioned as they have a tendency towards structuralism/managerialism and focus on processes. ${ }^{4} \mathrm{It}$ was deemed necessary therefore, in line with the realist review approach, ${ }^{23}$ to iteratively search for articles with a more specific focus on cultural/psychological elements. The iterative search was conducted through 'snowballing' (cross-reference check of the articles with a main focus on culture, along with an author-based search). All articles identified in the iterative search fully met the before mentioned inclusion criteria. 


\section{Results}

Search results

The results of the systematic search and review process are presented in Fig. 2. The initial search yielded 1622 articles. Removal of non-English articles and duplicates led to a number of 1245 articles eligible for review. The five inclusion/exclusion criteria were addressed in three subsequent review rounds (Ist: title/abstract review by first author, 2 nd: title/abstract review by all authors, 3rd: full text review by first author) and resulted in 25 articles eligible for inclusion. An iterative search conducted by the first author resulted in an additional 6 articles to be included, leading to the final inclusion of 31 articles.

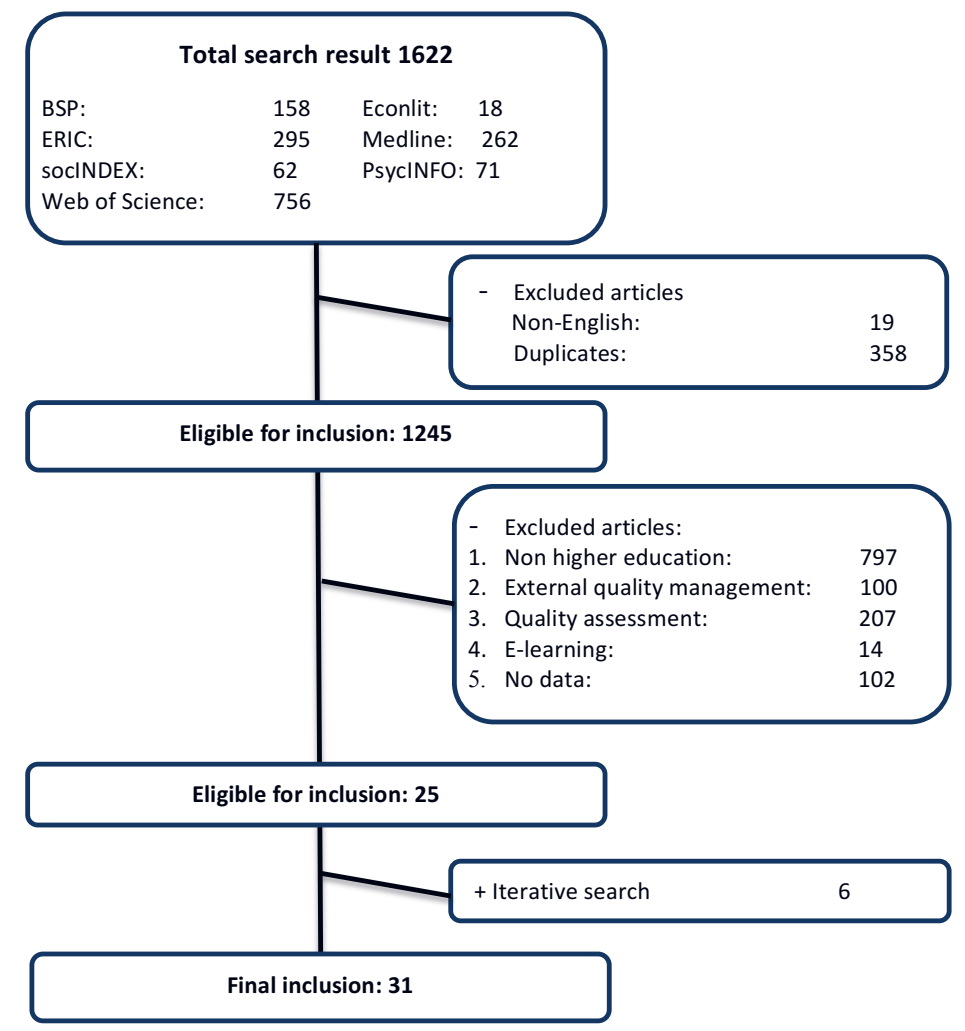

Figure 2 Article inclusion and exclusion. 
Table I Promoting and inhibiting organisational context factors impacting quality culture.

Promoting elements

Organisational structure/managerial elements

Strategy of continuous improvement

Quality management systems

Staff/student involvement in organisational decision making

Taking into account evolving student demands

Clear policies, procedures, systems, responsibilities
Inhibiting elements

Hierarchical structure/structural division

Lack of staff/student involvement in organisational decision making

Neglect of evolving student demands

Lack of policies, procedures, systems, responsibilities

Lack of resources

Top-down (managerial) approaches to quality management implementation

Research focus

Rigid, control oriented cultures

Presence of strong disciplinary cultures

Research culture/undervaluing education

Lack of leadership commitment and skills

Focus on inspection and control

Acting as communication gatekeepers

Lacking communication/information for quality Lack of sharing best practices across the organisatio Lack of appropriate communication channels

\section{Organisational context: promoting and inhibiting elements shaping quality culture} Promoting and inhibiting elements shaping quality culture which are related to the organisational context were derived by exploring patterns in studies performed on implementation of quality management and quality culture development in $\mathrm{HEI}$. 'The structural/managerial' dimension and a 'cultural/psychological' dimension as formulated in the EUA definition of quality culture served to frame the promoting and inhibiting elements. 'Leadership' and 'communication' elements are considered to have both 'structural/managerial' and 'cultural/psychological' attributes and act as binding elements between the two. A summary of promoting and inhibiting elements relating to the organisational context is presented in Table I (a summary including literature references is included as Appendix 3). 


\section{Structural and managerial elements of a quality culture}

In order to provide quality culture a permanent place high on organisational agendas, its development is ideally a main focal point of the institutional mission. ${ }^{3,27,28}$ Taking into account and acting upon evolving demands of students, form part of structural attempts to create a culture of continuous educational improvement. ${ }^{29-32}$ Moreover, involvement of students through participation in education and institutional decision making is deemed important for quality culture development. It should be noted though that, while involvement of a small part of the student population is safeguarded through representation in advising or decision making bodies, increasing involvement of the mass of students remains a challenge. ${ }^{30}$ The active involvement of HEl staff in decisionmaking and setting of educational policies, procedures and responsibilities has been shown to help overcome staff reluctance stemming from top-down approaches to quality management and nurture quality culture through grass-roots involvement. ${ }^{2,33-36} \mathrm{~A}$ basic requirement for quality culture development is for $\mathrm{HEl}$ to have the evaluation systems in place to provide information on (evolving) student demands and identify opportunities for enhancement. 2,27,37

Various inhibiting structural/managerial elements of quality culture comprise the counterparts of the promoting elements described above, e.g. lack of staff and student involvement, ${ }^{36}$ lack of clear policies, procedures, ${ }^{2,38}$ and responsibilities. ${ }^{39}$ Inhibiting elements can be inherent to the typical hierarchical structure of $\mathrm{HEI}$. Centrally determined quality management policies and procedures might overlook that requirements and responsibilities of specific roles are either not clear to, or assumed by, staff. 2,39,40 Another premise on the 'structural/managerial side' of the organisational context spectrum is availability of resources. Allocation of scarce means to quality culture development requires a strategic prioritisation of education. Various studies report that staff experience high workloads and lack time to spend on responsibilities in quality management and quality culture development. ${ }^{27,33,34,38}$ The issue of resource availability relates to the existing dichotomy between demands on staff to, on the one hand, excel by attaining the highest possible research assessment scores and, on the other hand, demands to enhance the quality of educational programmes and teachings skills. ${ }^{6,38,41}$ Finding the right balance between teaching and research has been found to be a major challenge for HEl staff). ${ }^{28}$

The impact of subcultures and psychological elements on quality culture development $\mathrm{HEl}$ possess several organisational culture types. ${ }^{19}$ These 'subcultures' within the organisation emerge as a consequence of staff being active in a variety of disciplines and departments. Quality culture coincides and overlaps with other organisational subcultures. An important implication of research on the relationship between culture types and various $\mathrm{HEl}$ effectiveness criteria (i.e. student satisfaction, staff satisfaction, ability to acquire resources) is that culture types have a diverse influence on effectiveness criteria. Explanations for the existing differences in organisational subcultures' effectiveness lie in the attributed reasons for 'bonding' and the 'strategic emphases' of each culture type. The typical 'hierarchy' subculture type is characterised by bonding based on rules, policies, procedures, clear expectations and assignments and a strategic emphasis on 
stability, predictability and smooth operations. This contrasts with 'adhocracies', which emphasise bonding through a shared commitment to entrepreneurship, flexibility and risk and a strategic emphasis on innovation, growing and acquiring new resources. 'Market' subculture types are characterised by bonding through goal orientation, production and strategic emphasis on competition and market superiority. The 'clan' subculture type resembles loyalty, tradition and interpersonal cohesion and strategies directed to human resource development and maintaining commitment and morale. ${ }^{19}$ In general, flexible, people-oriented cultures ('clan' and 'adhocracy') have been found to be related to most effectiveness criteria, followed by competitive, goaloriented ('market') cultures and more rigid, control-oriented ('hierarchy') subcultures. 19,34,42,43

Subcultures potentially encompass alternative value orientations towards educational quality and influence the way quality management is perceived and effectuated.44,45 For instance, strong, convergent, and disciplinary subcultures have been reported to be able to maintain their relative independence from institutional pressures of $\mathrm{HEl}$ management. ${ }^{33}$ The sense of belonging to a subculture with its own educational values, working ethos and commitment, can hamper the development of an overall quality culture if the quality culture values are experienced by staff as not being in line with the values of their subculture. ${ }^{41}$ The emphasis of quality management on 'control' rather than 'improvement' is generally reported by (academic) $\mathrm{HEl}$ staff as a factor inhibiting the development of a quality culture, since it conflicts with their autonomy and professional values. ${ }^{8,27,35,43}$ Moreover, the significance of research tasks also impacts the potential for development of quality culture since the status of education can also be undervalued from a normative point of view. ${ }^{33}$ Significant other common denominators of institutions focusing on quality culture development are shared goal orientation, responsibility and valuing of educational quality. ${ }^{6,31,41}$

\section{Leadership and communication as binding internal context elements}

The crucial role of leadership commitment to quality culture development has been underlined by various empirical studies..$^{28,29,35,38,40,45,46}$ Studies conducted by Flumerfelt and Banachowski, ${ }^{40}$ and Calvo-Mora et al. ${ }^{46}$ indicate that leaders are able to address impeding elements relating to the structural/managerial organisational context dimension: they influence the allocation of resources, clarify roles and responsibilities, create partnerships and influence people and process management. Moreover, especially leaders at the department level influence the development of quality culture through creating a climate of trust and shared understanding. ${ }^{45}$ Leadership styles focusing on creating a culture of collegiality and consultation are preferred over styles addressing quality issues through inspection and control. ${ }^{8,38}$ Effective leaders are considered to be those able to fulfil multiple roles, i.e. motivator, vision setter, task masters and analyser. ${ }^{28,47}$ In order to be able to disseminate initiatives which nurture a quality culture, $\mathrm{HEI}$ require appropriate communication channels. ${ }^{6}$ Osseo-Asare and Pieris identified a lack of sharing best practices, failing ICT structure and deficient reporting systems as important bottlenecks. ${ }^{28} \mathrm{~A}$ well-functioning communication infrastructure enables $\mathrm{HEl}$ management to consult, interact with and inform 
students and staff about policies and strategic directions. ${ }^{2,28,38,48}$ Leaders play an important role in the communication climate within the organisation, as they are able to spread messages as well as specific expectations and instructions concerning responsibilities and tasks both vertically and horizontally. ${ }^{3,40,49}$ Their central role in the hierarchy, however, also entails the risk that leaders act as information gatekeepers who consciously or unconsciously withhold (strategic) information to staff. ${ }^{38}$ In addition to providing staff with the basic information needed for core processes (timely data, information on policies, intelligence), communication within and across departments is essential to identify and proactively deal with feelings of misunderstanding which can evolve when organisational change processes are set in motion which impact the present (sub)culture..$^{35,36}$

\section{The working mechanisms of a quality culture}

Based on an analysis of various quality management interventions described in the reviewed articles, propositions are made here on the working mechanisms which influence HEI staff behaviour favourable for development of a quality culture. Specific focus lies on 'agency', that is the beliefs and reasons that staff draw on to justify action or inaction and 'relations', referring to human interaction and distribution of rights and powers. ${ }^{50}$

\section{Staff agency through fostering commitment and shared ownership}

Commitment to education can be seen as a quintessential working mechanism of quality culture. Ardi et al. found that the commitment of Faculty's top management influences commitment at the department level. ${ }^{29}$ This suggests that commitment passes down hierarchical lines in the organisation and that commitment in lower levels (partly) stems from commitment at the top. It seems plausible to argue, however, that leadership and management commitment are in the first place a requirement relating to the organisational context. ${ }^{35}$ Teaching and learning processes as well as the practical organisation of education are essentially results of first-line (inter)actions of academic staff, supportive staff and students. Although commitment of management is a necessary condition for top-down facilitation of quality culture development, in its own, it does not suffice. To be able to speak of an overall quality culture, there should be a commitment to educational quality and its continuous improvement throughout the organisation. ${ }^{6,51}$ Quality culture encompasses the agency of staff directly involved in (the organisation of) education. Commitment can be considered to be a determinant of agency through its enacting upon choice and behavioural actions. From an intrinsic motivation point of view, commitment is expected to increase if staff assumptions and values are in line with those effectuated by institutional management. ${ }^{6,43} \mathrm{~A}$ lack of employee commitment might be a consequence of a lack of involvement of staff in organisational decision making. In addition, quality culture development is more likely to be successful in case its appeals to staff members' professionalism and motivation to improve. ${ }^{8}$ Staff commitment can also be stimulated through extrinsic triggers, e.g. through recognition and providing incentives, allocating grants to educational projects, awarding teacher prizes and offering opportunities for career tracks based on teaching performance..$^{41,46}$ 
The presence of subcultures in $\mathrm{HEl}$ become an impeding factor for quality culture development in case subculture members have a strong inbound view and make use of their belonging to a strong group to frustrate policies. If staff do not feel they 'own' educational programmes, their attitude towards quality management is more likely to be negative and unfruitful. ${ }^{36}$ By emphasising shared ownership based on collegiality and consultation of staff across various disciplines and departments, chances of best practices remaining localised can be reduced. The mechanism of shared ownership as contributor to quality culture development is illustrated by initiatives such as learning communities, which create opportunities for staff to create an optimal social and academic learning environment. ${ }^{52}$ Moreover, shared ownership and decision making by staff members of different departments allows for provision of mutual support and reinforcement of the teacher identity. ${ }^{8}$ Cross-functional collaboration and breakdown of barriers between academic and supportive staff through partnering and teamwork can be seen as quality management interventions influencing quality culture development by addressing the mechanism of shared ownership. ${ }^{3}$

\section{Optimising human relations: increasing staff knowledge and empowerment}

Staff knowledge of $\mathrm{HEl}$ educational plans, strategies and objectives, is essential for the nurturing of a quality culture. ${ }^{2,41}$ In terms of structure and processes, the roles, responsibilities and instructions regarding job tasks of staff members need to be clear. Sharing of knowledge allows for creating an increased awareness among staff on both the investments needed as well as the benefits which can be derived from a quality culture. HEl staff members are usually active in several activity systems, with the academic department or subunit being the main activity system. ${ }^{44}$ The structural divide between staff in departments and the existence of subcultures can hamper opportunities to increase staff knowledge on both good practices as well as problems in teaching and learning. ${ }^{45}$ The value of knowledge sharing across departments in $\mathrm{HEI}$ lies not only in the exchange of information on practices which have a more or less direct impact on educational processes. Discussion of the philosophy and methods for developing a quality culture are also needed to be able to spread interest and enthusiasm. ${ }^{34}$ Working on quality culture through optimising the exchange of present expertise can be considered one way to invest in learning processes. ${ }^{33}$ In addition, engaging quality experts for the delivering of training can prove worthwhile in fostering increased staff knowledge. ${ }^{27}$

A final working mechanism of quality culture entails academic and administrative staff empowerment. Empowerment is viewed as distinctive from involvement as the latter is regarded as a component of the organisational context and refers to representation of $\mathrm{HEI}$ staff in decision making or advisory bodies. Sahney et al. state that 'employee participation and involvement is the process of empowering the members of the organisation to make decisions and to solve problems appropriate to their levels in the organisation'. ${ }^{3(p .67)}$ Whereas participation and involvement can be seen as important elements in the organisation of processes, it is through empowerment as a mechanism that changes can be achieved. Empowerment holds the devolving of control mechanisms to staff members. ${ }^{36}$ Osseo-Asare and Pieris found that suggestions to improve academic quality 
were not used, as staff was not granted sufficient autonomy over determining teaching methods. ${ }^{28}$ This indicates the existence of a misalignment between staff responsibility, authority and chances for development of a quality culture. The empowerment of employees fits with the generally accepted view that quality culture development requires a bottom-up approach. ${ }^{28}$

\section{Quality culture and its associated outcomes}

Various studies on interrelationships between structural/managerial, leadership, communication and cultural/psychological quality culture elements conclude that an integrative and simultaneous addressing of these elements contribute to achieving results of enhanced educational processes and outcomes. ${ }^{37,38,53} \mathrm{Ali}$ and Musah explicitly investigated the relationship between the notion of 'quality culture' and organisational performance. ${ }^{53}$ They concluded that 'when universities establish a quality culture-oriented workplace, academic staff are more likely to be satisfied with the nature of their professional academic life and therefore work constructively for the cause of organisational success'. ${ }^{33}$ (p. 305) The finding that job satisfaction of academic and supporting staff is both a result of a quality culture as well as a determinant of staff performance is supported by other studies as well. ${ }^{3,43}$ In addition to staff satisfaction, satisfaction of students is an important outcome of quality culture. Ardi et al. found that student satisfaction is positively influenced by commitment of faculty management and the ability of students to provide feedback for quality improvement. ${ }^{29}$ Research by Cameron and Freeman, ${ }^{19}$ and Smart and St. John, ${ }^{42}$ revealed that 'clan' organisational subculture types, which are characterised by loyalty, strategic emphasis on human resources, cohesion and leaders in the role of facilitator/mentor are most strongly associated with both staff (administrative and academic) and student satisfaction.

Structural/managerial processes aimed at continuous improvement of teaching and learning have been reported earlier in this study to contribute to quality culture development. The continuous improvement of teaching-learning processes can be seen as an 'intermediate' outcome of the embedding of a quality culture in $\mathrm{HEI}$ (as the actual improvement of teaching and learning is difficult to reveal). Various studies provide insights in the interrelationships between quality culture elements and (perceived) quality of process management as an outcome measure. ${ }^{37,43,44,46}$ Leadership is found to be an overall driving factor for quality culture development, while policy and strategy, people management and partnerships and resources influence the perceived effectiveness of process management directly. ${ }^{37,46}$ Systematic approaches to quality management, such as adoption of TQM models, have been reported to contribute to increased student performance, better services and reduced costs. ${ }^{27}$ However, these structural/managerial approaches can trigger adverse effects in case they are not aligned to the present culture. ${ }^{32,41}$ A third domain of quality culture outcomes is manifested in student, academic staff and administrative staff learning and development. The cooperation and shared commitment to educational quality of a mix of academic and support staff as well as involved students contributes to the establishment of an organisational learning environment. ${ }^{33}$ Ali and Musah point to the centrality of learning and development as an (intermediate) outcome of quality culture by 
stressing that 'achieving quality in staff performance requires advanced and dynamic staff training programmes [...] to respond quickly and appropriately to rapid changes in the field of education and staff needs'.53 (p. 29l) An 'adhocracy' organisational subculture type, which is consistent with core values of scholarship and values of academic staff (i.e. flexibility, freedom and individual discretion, creativity and growth), was found to impact most on student academic and professional development and quality of staff in a study conducted among $334 \mathrm{HEl}$ in the U.S. ${ }^{19}$ In addition, the interaction between staff and students is important for learning and development. Kinzie and Kuh revealed that $\mathrm{HEI}$ with high completion rates are characterised by staff and students closely working together to maintain study success. ${ }^{31}$

Figure 3 outlines the context-mechanism-outcome configuration of quality culture in $\mathrm{HEI}$. It sketches the main classification of promoting and inhibiting elements relating to the organisational context (structural/managerial, communication, leadership, cultural/psychological), working mechanisms (knowledge, empowerment, shared ownership and commitment) and quality culture outcomes (student/staff satisfaction, continuous improvement of the teaching-learning process and student/staff learning and development). In addition, examples of quality management interventions are included which illustrate the potential to affect the organisational context elements through addressing mechanisms of human relations and agency.

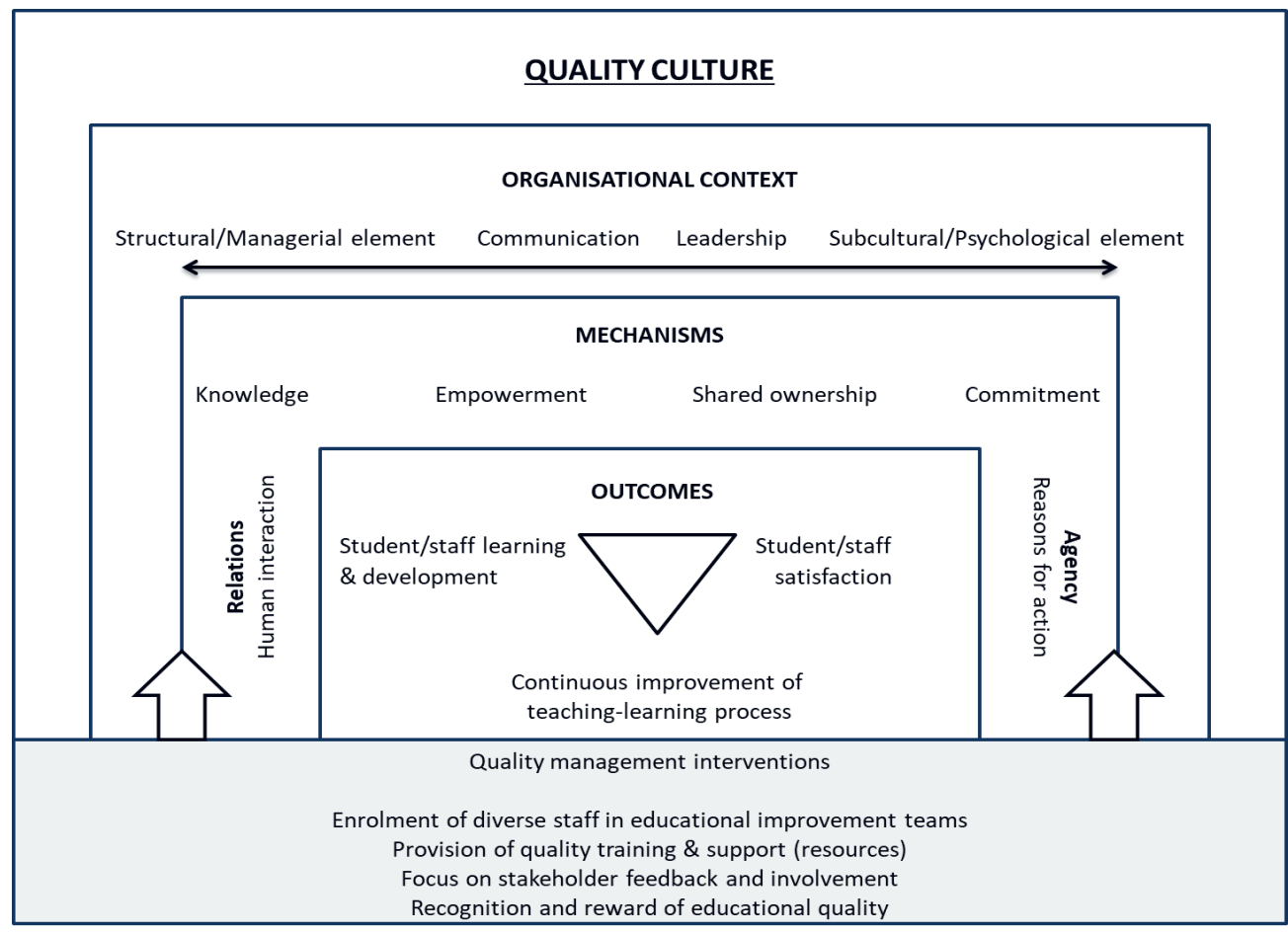

Figure 3 Context-mechanism-outcome configuration of quality culture in $\mathrm{HEl}$ 


\section{Conclusion}

Quality culture in HEI results from an interplay between contributing organisational context elements, working mechanisms and quality related outcomes. $\mathrm{HEl}$ attempts to address the structural/managerial dimension of quality culture are reflected in their attention to improvement strategies, evaluation systems, staff and student involvement, student centeredness and attention to policies, procedures and responsibilities. Along with the counterparts of these basic facilitators for quality culture development, the hierarchy in $\mathrm{HEl}$, their structural division in departments and need to balance research and education tasks, form impeding elements. While the necessity to invest in structural/managerial elements is apparent, efforts to nurture a quality culture have proven to fail in case they neglect its subculture/psychological dimension. A quality culture is a specific kind of organisational subculture which overlaps with other subcultures based on shared educational values of its members, a people-oriented focus and valuing of autonomy and professionalism. The subcultures in HEI form a potential asset as different culture types are related to various effectiveness criteria. Strong disciplinary and research-oriented subcultures, however, can hamper quality culture development as they encompass an inbound view, whereas quality culture entails transcending structural and subcultural boundaries.

Leadership is an organisational context element which 'binds' the structural/managerial and cultural/psychological elements through creating trust and shared understanding. Leaders within $\mathrm{HEl}$ act as central drivers to quality culture development by affecting the allocation of resources, clarification of roles and responsibilities, creation of partnerships and influencing people and process management. Effective leaders are considered to be those who are able to take on multiple roles, i.e. motivator, vision setter, task masters and analyser. Communication serves as a second binding organisational context element. First, since communication enables the distribution of strategies, policies and responsibilities. Second, since it is through communication that staff acquires information on best practices, is able to evaluate core processes and signal points of improvement. Third, because communication is vital to identify and deal with diverging value orientations among staff.

The most important working mechanisms of a quality culture in $\mathrm{HEl}$ involve relations (human interaction) and agency (reasons for action). Commitment as a mechanism implies a willingness to put extra effort into ones work and a tendency to be concerned with its quality. Commitment emerges from providing incentives to staff, involving them in organisational decision making, alignment of staff and management values and an appeal to staff expertise. Shared ownership reflects the mutual responsibility for quality culture development in $\mathrm{HEI}$. It contributes to quality culture development by facilitating peer support and reinforcement of the teacher identity. Staff knowledge, a third mechanism, is essential for identifying and resolving bottlenecks in teaching and learning. Staff empowerment, a fourth identified mechanism, holds that staff have the opportunity to initiate educational improvements. It impacts staff leeway to bring their experience and expertise into practice. 
The multifaceted and integrative nature of a quality culture encompasses that it is difficult to provide one-on-one claims on outcomes associated with its embedding in $\mathrm{HEl}$. Most empirical research concentrates on 'hard', directly observable, quality culture elements. The (perceived) improvement of quality of teaching and learning processes is reported as main beneficial outcome of devoting to the structural/managerial quality culture elements. Student and staff satisfaction as quality culture outcomes stem to a more considerable degree from the cultural/ psychological (value) dimension of quality culture. Especially commitment of staff, student involvement and ability of students to provide feedback for improvement determine student satisfaction. Academic and supportive staff satisfaction can be considered a vital quality culture outcome, since satisfied staff is more likely to constructively contribute to achieving organisational goals. The ingrained climate of close staff and student interaction and cooperation is exemplary for a quality culture and contributes to organisational learning, staff and student personal development and study success.

\section{Discussion}

The present study nuances the picture of quality culture as a monolithic entity characterised by shared values, beliefs and expectations towards quality. ${ }^{21}$ The results are in line with the view that a quality culture is a complex, socially constructed phenomenon which cannot be seen in isolation from the specific context in which it is embedded and cannot be simply transferred from one organisation to the other. ${ }^{9}$ The positive relationship between quality culture development and presence of various subcultures in $\mathrm{HEl}$ is further underpinned in the work of Berings. ${ }^{54} \mathrm{His}$ research indicates that multiple organisational culture profiles have a predictive value for effective quality management implementation and the degree of student and staff satisfaction.

It is therefore worthwhile to raise awareness of the present basic beliefs and subculture values of different $\mathrm{HEl}$ staff groups, as staff being part of various subcultures might lack the natural bonds to work together on quality culture development. ${ }^{33}$ Instead of challenging potentially conflicting beliefs and values, the focus should lie on attempts to bundle expertise and work on a state of shared commitment to educational quality. ${ }^{55}$ The complex structure and culture of $\mathrm{HEl}$ indicates an urge for leaders who are able to balance differences in management, staff and student interest. The most appropriate leadership style would be one which is sensitised to the procedures and practices, values and specific requirements of staff. ${ }^{44,56}$ The relevance of leadership for the development of quality culture is indisputable, yet it is perhaps best captured by the statement that 'a quality culture cannot be implemented from above although strong leadership may be necessary to start and promote the process in the first place'. ${ }^{57 \text { (p. } 1073)}$ The proposed 'working mechanisms' of a quality culture in this study are in congruence with the essential effectiveness dependence of $\mathrm{HEI}$ on human capital. ${ }^{43}$ The proposed mechanisms provide insight in underlying reasons for staff behaviour in $\mathrm{HEl}$ in a broad sense. It should be 
taken into account that individual needs can differ (e.g. since differences can exist in experience and ambition). Therefore, interventions aimed at triggering the proposed working mechanisms should be sensitive to both the expectations of $\mathrm{HEl}$ management as well as staff. Agreeing on a 'psychological contract', based on a process of enquiry and negotiation in which HEl management, students and staff make their expectation's explicit and come to a workable agreement on how to nurture a quality culture, might prove a valuable exercise. ${ }^{58}$

\section{Theoretical and practical implications}

Whereas review studies are considered appropriate for addressing the question 'what intervention practices work for whom in what circumstances', the present study contributes to the further untangling and theory development on quality culture by addressing the 'why' question of social intervention programmes. ${ }^{25}$ Based on both qualitative and quantitative research results, the study provides empirical support for the thesis that quality culture can assume various shapes. In a practical sense, the study implies that a diagnosis of the specific context and subcultures present across departments and disciplines is needed. Once the subcultures, their assets, pitfalls and potentially contradicting meanings attached to 'quality' have been brought to surface, quality practices can be developed which optimise the conditions for continuous educational quality improvement. ${ }^{59}$ The study calls to draw attention to leadership and communication, as these organisational context elements might prove more straightforward to alter, in comparison to structural/managerial and cultural/psychological elements.

\section{Study limitations}

The research reported in this study has some limitations which should be taken into account. Due to publication bias, studies with overly positivistic or negativistic results might be overrepresented in the articles included for review. ${ }^{60}$ In addition, despite the involvement of various authors in the selection process for final inclusion of articles, the review process remained to some degree subjective and interpretive. As the article aimed to improve the understanding of quality culture and the grounding of its merit based on empirical research findings, it refrained from in-depth analysis of (valuable) theoretical studies on quality culture. The study focused on quality culture within $\mathrm{HEl}$ and moved past processes that influence $\mathrm{HEl}$ or take place between the academic world and society at large. ${ }^{61}$ The role of external quality assessment and national legislation, for instance, has an ample influence on organisational functioning, by impacting on organisational policies, financing and perhaps even organisational cultures. $^{62}$

The 'internal' focus was chosen to reflect $\mathrm{HEI}$ abilities to influence the internal organisational context elements (unlike external context elements) and quality management in order to develop a quality culture. External quality management was also excluded since it has a stronger tendency to serve accountability purposes. 


\section{Suggestions for further research}

Provided that there is relative shortage of research into the synergy between 'hard' (structural, managerial), 'soft' (cultural, psychological) quality culture elements and associated outcomes (e.g. quality of the teaching-learning process), the added value of conducting empirical research in this field is apparent. More specifically, research into the daily experiences of staff and students in quality management as well as exploring their practical suggestions to nurture a quality culture deserves further stimulation. 


\section{References}

*Reviewed articles

I. Boyle, P. and Bowden, J.A. (1997). Educational quality assurance in universities: An enhanced model. Assessment \& Evaluation in Higher Education; 22: III-I2I.

2. Sutic, I. and Jurcevic, M. (2012).Strategic management process and enhancement of quality in higher education. Poslovna Izvrsnost/Business Excellence: 6: 147-161.**

3. Sahney, S., Banwet, D.K., and Karunes, S. (2010). Quality framework in education through application of interpretive structural modelling: An administrative staff perspective in the Indian context. TQM Journal; 22: 56-7I.*

4. Harvey, L. and Williams, J. (2010). Fifteen years of quality in higher education. Quality in Higher Education; 16: 3-36.

5. Lomas, L. (1999). The culture and quality of higher education institutions: Examining the links. Quality Assurance in Education; 7: 30-34.

6. Lomas, L. (2004). Embedding quality: The challenges for higher education. Quality Assurance in Education: An International Perspective; 12: 157-165.*

7. Newton, J. (2000). Feeding the beast or improving quality? Academics' perceptions of quality assurance and quality monitoring. Quality in Higher Education; 6: 153-163.

8. Davies, J., Douglas, A., and Douglas, J. (2007). The effect of academic culture on the implementation of the EFQM excellence model in UK universities. Quality Assurance in Education; 15: 382-40I.*

9. Harvey, L. and Stensaker, B. (2008). Quality culture: Understandings, boundaries and linkages. European Journal of Education; 43: 427-442.

10. European University Association (20I2). Examining quality culture part III: From self-reflection to enhancement. Brussels: EUA.

II. Irani, Z., Beskese, A., and Love, P.E.D. (2004). Total quality management and corporate culture: Constructs of organisational excellence. Technovation; 24: 643-650.

12. Maull, R., Brown, P., and Cliffe, R. (200I). Organisational culture and quality improvement. International Journal of Operations \& Production Management; 21: 302-326.

13. Powell, T.C. (1995). Total quality management as competitive advantage: A review and empirical study. Strategic Management Journal; 16: 15-37.

14. Prajogo, D.I. and McDermott, C.M. (2005). The relationship between total quality management practices and organizational culture. International Journal of Operations \& Production Management; 25: II0I-II 22.

I5. Kuh, G.D. andWhitt, E.J. (1988). The invisible tapestry: Culture in American colleges and universities.ASHE-ERIC Higher Education Report No. I.Washington, D.C.:Association for the Study of Higher Education.

16. European University Association (2006). Quality culture in European universities: A bottom-up approach. Report on the three rounds of the quality culture project 2002-2006. Brussels: EUA.

17. Berings, D. and Grieten, S. (20I2). Dialectical reasoning around quality culture. Paper presented at the seventh European Quality Assurance Forum (EQAF) of the European University Association (EUA), Tallinn. Nov 22-24.

18. Bollaert, L. (2014). A manual for internal quality assurance in higher education with special focus on professional higher education. Brussels: European Association of Institutions in Higher Education.

19. Cameron, K.S. and Freeman, S.J. (1991). Cultural congruence, strength, and type: Relationships to effectiveness. Research in organizational change and development; 5: 23-58.*

20. Ehlers, U.D. (2009). Understanding quality culture. Quality Assurance in Education: An International Perspective; 17: 343-363.

2I. European University Association (2010). Examining quality culture part I: Quality assurance processes in higher education institutions. Brussels: EUA.

22. Pawson, R., Greenhalgh, T., Harvey, G., and Walshe, K. (2005). Realist review: A new method of systematic review designed for complex policy interventions. Journal of Health Services Research Policy; 10: 2I-34.

23. Wong, G., Greenhalgh, T., Westhorp, G., Buckingham, J., and Pawson, R. (2013). RAMESES publication standards: Realist syntheses. BMC Medicine; II: 2 I. 
24. Wong, G., Westhorp, G., Pawson, R., \& Greenhalgh, T. (2013). Realist synthesis. RAMESES training materials. Derived from: www.ramesesproject.org/media/Realist_reviews_training_materials.pdf.

25. Pawson, R. and Manzano-Santaella, A. (2012). A realist diagnostic workshop. Evaluation; 18: 176-191.

26. Council on Higher Education, Higher Education Quality Committee (2004). Criteria for institutional audits. Pretoria: Council on Higher Education.

27. Kanji, G.K. and Tambi, A.M.B. (1999). Total quality management in UK higher education institutions. Total Quality Management; 10: 129-153**

28. Osseo-Asare, D.L. and Pieris, C. (2007). Managerial leadership for total quality improvement in UK higher education. TQM Magazine; 19:54I-560**

29. Ardi, R., Hidayatno, A., and Zagloel, T.Y.M. (2012). Investigating relationships among quality dimensions in higher education. Quality Assurance in Education: An International Perspective; 20: 408-428.*

30. Doval, E. and Bondrea, E. (20II). Building quality culture within European and national framework: Filling the gaps. Economics, Management \& Financial Markets; 6: 868-878.*

3I. Kinzie, J., \& Kuh, G.D. (2004). Going DEEP: Learning from campuses that share responsibility for student success. About Campus; 9: 2-8**

32. Sulaiman, N.F., Manochehri, N.N., and Al-Esmail, R.A. (2013). Level of total quality management adoption in Qatari educational Institutions: Private and semi-government sector. Journal of Education for Business; 88: 76-87.*

33. Haapakorpi, A. (20II). Quality assurance processes in Finnish universities: Direct and indirect outcomes and organisational conditions. Quality in Higher Education; 17: 69-81.*

34. Horine, J.E. and Hailey, W.A. (1995). Challenges to successful quality management implementation in higher education institutions. Innovative Higher Education; 20: 7-17.*

35. Newton, J. (2002). Barriers to effective quality management and leadership: Case study of two academic departments. Higher Education; 44: 185-212.*

36. Spencer-Matthews, S. (200I). Enforced cultural change in academe. A practical case study: Implementing management systems in higher education.Assessment \& Evaluation in Higher Education; 26:51-59.*

37. Burli, S., Bagodi, V., \& Kotturshettar, B. (2012). TQM dimensions and their interrelationships in ISO certified engineering institutes of India. Benchmarking: An International Journal; 19: 177-192.*

38. Osseo-Asare, D.L., Longbottom, D., and Murphy, W.D. (2005). Leadership best practices for sustaining quality in UK higher education from the perspective of the EFQM excellence model. Quality Assurance in Education: An International Perspective; 13: 148-170.*

39. Valiuskeviciute, A. and Ziogeviciute, A. (2006). Responsibility of university and college staff for higher education quality management. Quality of Higher Education; 3: 44-67.*

40. Flumerfelt, S. and Banachowski, M. (20II). Understanding leadership paradigms for improvement in higher education. Quality Assurance in Education: An International Perspective; 19: 224-247.*

4I. Skelton, A. (20I2). Colonised by quality? Teacher identities in a research-led institution. British Journal of Sociology of Education; 33: 793-811.*

42. Smart, J.C., \& St. John, E.P.S. (1996). Organizational culture and effectiveness in higher education: A test of the "culture type" and "strong culture" hypotheses. Educational Evaluation and Policy Analysis; 18: 219-24I.*

43. Trivellas, P. and Dargenidou, D. (2009). Organisational culture, job satisfaction and higher education service quality. The case of technological educational institute of Larissa. TQM Journal; 21: 382-399.*

44. Kleijnen, J., Dolmans, D., Willems, J., \& van Hout, H. (20II). Does internal quality management contribute to more control or to improvement of higher education? A survey on faculty's perceptions. Quality Assurance in Education: An International Perspective; 19: 141-155.*

45. Knight, P.T. and Trowler, P.R. (2000). Department-level cultures and the improvement of learning and teaching. Studies in Higher Education; 25: 69-83.*

46. Calvo-Mora, A., Leal, A., and Roldan, J.L. (2006). Using enablers of the EFQM model to manage institutions of higher education. Quality Assurance in Education: An International Perspective; 14: 99-122**

47. Smart, J. (2003). Organizational effectiveness of 2-year colleges: The centrality of cultural and leadership complexity. Research in Higher Education; 44: 673-703.* 
48. Sahu, A.R., Shrivastava, R.R. and Shrivastava, R.L. (2013). Critical success factors for sustainable improvement in technical education excellence: A literature review. TQM Journal; 25: 62-74.*

49. Sakthivel, P.B., \& Raju, R. (2006). Conceptualizing total quality management in engineering education and developing a TQM educational excellence model. Total Quality Management \& Business Excellence; 17: 913-934.*

50. Souza, D.E., de. (2014). Culture, context and society: The underexplored potential of critical realism as a philosophical framework for theory and practice. Asian Journal of Social Psychology; 17: 141-151.

5I. Manochehri, N.N., Sulaiman, N.F., and AI-Esmail, R. (2012). Total quality culture in educational institutions: A Gulf Corporation Council region study. Academy of Educational Leadership Journal; 16: I-14.*

52. Smith, B.L. and MacGregor, J. (2009). Learning communities and the quest for quality. Quality Assurance in Education: An International Perspective; 17: 118-139.*

53. Ali, H.M. and Musah, M.B. (2012). Investigation of Malaysian higher education quality culture and workforce performance. Quality Assurance in Education: An International Perspective; 20: 289-309.*

54. Berings, D. (2009). Reflection on quality culture as a substantial element of quality management in higher education. Paper presented at the fourth European Quality Assurance Forum (EQAF) of the European University Association (EUA), Copenhagen. Nov 19-21, 2009.

55. Lomas, L., \& Nicholls, G. (2005). Enhancing teaching quality through peer review of teaching. Quality in Higher Education; II: 137-149.

56. Kekale, J. (2000). Quality assessment in diverse disciplinary settings. Higher Education; 40: 465-488.

57. Katiliute, E. and Neverauskas, B. (2009). Development of quality culture in the universities. Economics \& Management; 25: 1069-1076.

58. Rowley, J. (1996). Motivation and academic staff in higher education. Quality Assurance in Education; 4 : II-16.

59. Tam, M. (200I). Measuring quality and performance in higher education. Quality in Higher Education; 7 : 47-54.

60. Davies, P. (2000). The relevance of systematic reviews to educational policy and practice. Oxford Review of Education; 26: 365-378.

6I. Valimaa, J. (1998). Culture and identity in higher education research. Higher Education; 36: I19-138.

62. Brennan, J. and Shah, T. (2000). Quality assessment and institutional change: Experiences from I4 countries. Higher Education; 40: 331-349. 
Appendix I: Key systematic search terms

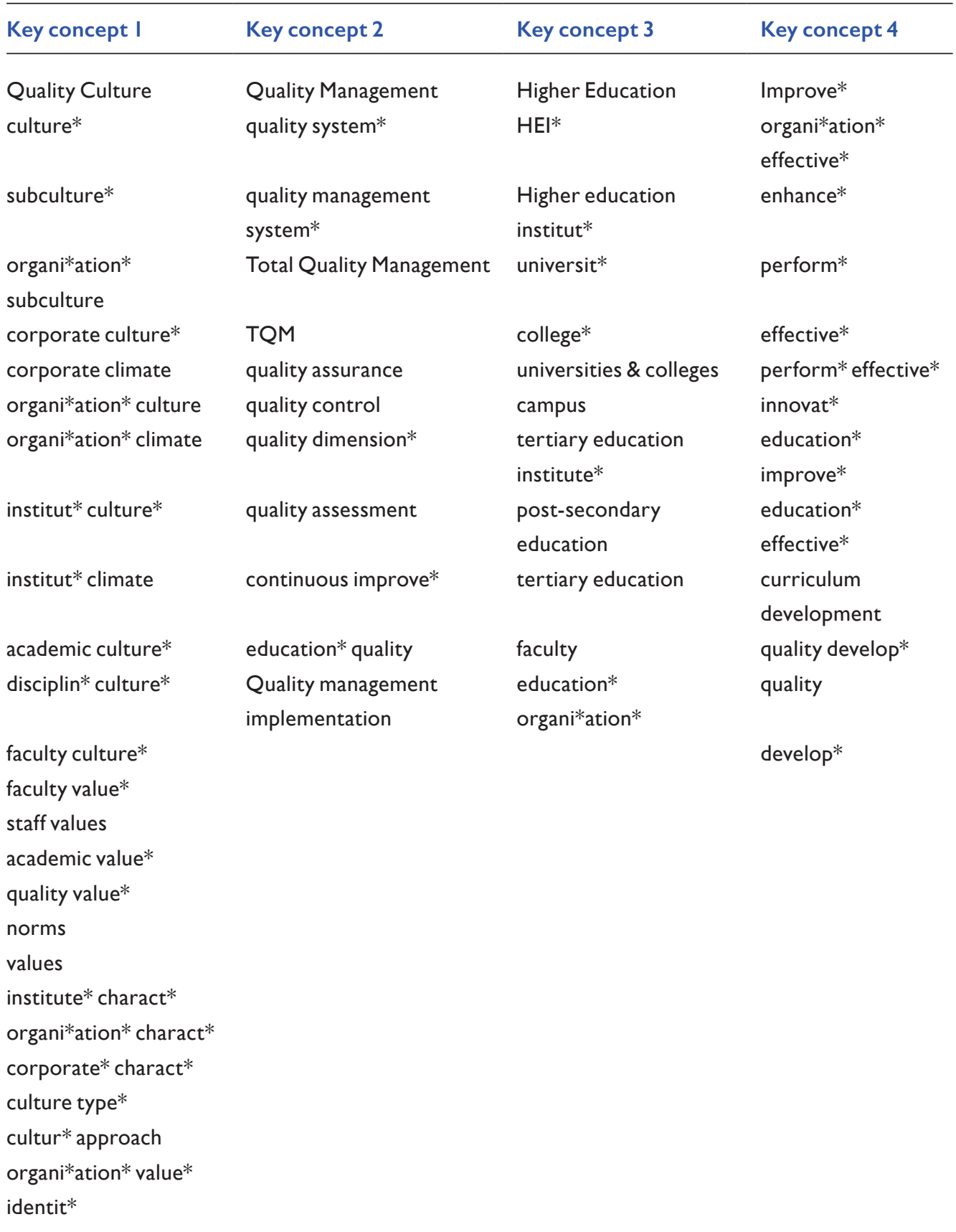


Appendix 2: Inclusion and exclusion criteria

Inclusion

\section{General study characteristics}

Peer-reviewed journal article

Language full article in English

Publication date 1980-current

Full access to article via internet

\section{Study content (main focus)}

Higher Education

Internal (institutional)quality Management

Elements influencing quality management practices or educational improvement

In-class education

\section{Study Methodology}

Incorporate qualitative or quantitative empirical data (interviews, questionnaires, document analysis, structured literature reviews)

\section{Book chapters}

Conference proceedings

Language full article only Non-English

Publication prior to 1980

No full access via internet

Non higher education

Research in Higher Education

Industry an business institutions

Primary and secondary education,

PhD education

External quality management

(accreditation/benchmarking/rankings)

Supra-organisational level

Quality assessment/evaluation instruments

Quality assessment/evaluation outcomes

Measuring service quality

E-learning

Conceptual/theoretical papers

Descriptive case studies (narrative, without data) 
Appendix 3: Promoting and inhibiting organisational context factors impacting quality culture

\section{Organisational structure/managerial elements}

\section{Promoting elements}

Strategy of continuous improvement

Quality management systems

Staff/student involvement in organisational decision making/consider evolving student demands

Clear policies, procedures, systems, responsibilities

\section{Inhibiting elements}

Hierarchical structure /structural division

Lack of staff/student involvement in organisational decision making/ neglect of evolving student demands

Lack of policies, procedures, systems, responsibilities

Lack of resources

Top-down (managerial) approaches to quality management implementation
Kanji and Tambi (1999), Osseo-Asare and Pieris (2007), Sahney et al. (2010)

Doval and Bondrea (20II), Kanji and Tambi (1999), Sahney et al. (2010)

Ardi et al. (20I2), Doval and Bondrea (20II),

Kinzie and Kuh (2004), Sulaiman et al. (2012)

Burli et al. (20I2), Sahney et al. (20I0)

Horine and Hailey (1995), Kleijnen et al. 20II

Doval and Bondrea (20II), Newton (2002),

Spencer-Matthews (200I)

Flumerfelt and Banachowski (20II), OsseoAsare et al. (2005), Sutic and Jurcevic (2012), Valiuskeviciute and Ziogeviciute (2006)

Haapakorpi (201I), Horine and Hailey (1995), Kanji and Tambi (1999), Osseo-Asare et al. (2005) Haapakorpi (2011), Horine and Hailey (1995), Flumerfelt and Banachowski (20II), Newton (2002), Spencer-Matthews (200I), Sutic and Jurcevic (20I2), Valiuskeviciute and Ziogeviciute (2006)

Research focus Lomas (2004), Osseo-Asare et al. (2005), Skelton, (2012) 


\section{Organisational (sub)culture/psychological elements}

\section{Promoting elements}

Flexible, people oriented cultures

Cameron and Freeman (1991), Horine and Hailey (1995), Smart and St. John (1996), Trivellas and

Dargenidou (2009)

Presence of various cultures

Cameron and Freeman (1991), Smart (2003)

Shared (educational) quality values

Kinzie and Kuh (2004), Lomas (2004), Skelton (2012)

\section{Inhibiting elements}

Rigid, control oriented cultures

Cameron and Freeman (1991), Smart and St. John (1996), Trivellas and Dargenidou (2009)

Presence of strong disciplinary cultures Haapakorpi (20II), Skelton (20I2)

Research culture/undervaluing education

Haapakorpi (20II), Lomas (2004), Newton (2002),

Skelton 2012

\section{Promoting elements}

Leadership commitment and skills

\section{Allocate resources}

Create partnerships, influence people and process management

Create climate of trust and shared understanding

Ability to perform multiple roles

Setting and communicating policies

\section{Inhibiting elements}

Lack of leadership commitment and skills

Focus on inspection and control

Acting as communication gatekeepers
Ardi et al. (20I2), Burli et al. (20I2), Calvo-Mora et al. (2006), Flumerfelt and Banachowski (20II), Knight and Trowler (2000), Newton (2002); Osseo-Asare et al. (2005), Sahney et al. (2010), Sakthivel and Raju (2006)

Davies et al. (2007), Horine and Hailey (1995), Kanji and Tambi (1999), Newton (2002), OsseoAsare et al. (2005) 


\section{Communication elements}

\section{Promoting elements}

Communication/information for quality

Provide information on strategies and policies

Clear task requirements and responsibilities
Calvo-Mora et al. (2006), Lomas (2004), Manochreni et al. (20I2), Newton (2002),

Osseo-Asare et al. (2005), Sahney et al. (2010), Sakthivel and Raju (2006), Sutic and Jurecevic (2012)

\section{Inhibiting elements}

Lacking communication/information for quality

Lack of sharing best practices across the organisation

Lack pf appropriate communication channels
Newton (2002), Osseo-Asare and Pieris (2007), Spencer-Matthews (200I), Sulaiman et al. (20I3), Sutic and Jurcevic (20I2) 



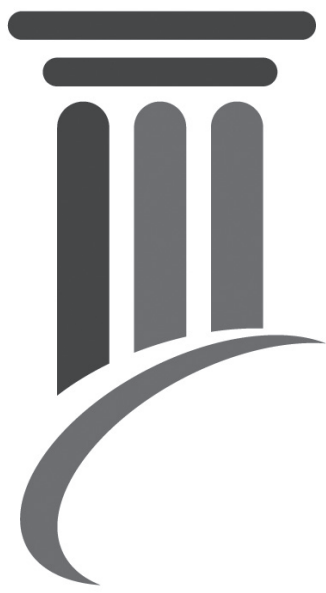

Guy Bendermacher

Mirjam oude Egbrink

Ineke Wolfhagen

Jimmie Leppink

Diana Dolmans

Published in:

Studies in Higher Education (2019); 44: 643-662. 
Chapter III

Reinforcing pillars for quality

culture development:

a path analytic model 


\begin{abstract}
To this date, research on the interplay between organisational structure/managerial and organisational value/psychological elements which impact on educational quality is scarce and fragmented. As a consequence of a lack of knowledge in this area, institutions often address these elements in isolation, moving past integral approaches, which reinforce the organisations' quality culture. In order to examine interrelationships between context characteristics, workrelated psychological attitudes of staff and enhancement practices, a path analysis was performed on data collected from academics with teaching coordination roles. The findings highlight the paramount importance of a 'human relation' value orientation; this orientation influences empowerment, commitment and communication satisfaction. Rational goal values and ownership are positively related to quality enhancement practices. It is advocated that institutional policies and strategies directed at educational quality enhancement should leave discretionary space for the availing of academics' expertise. Nurturing collaborative teaching/learning communities with explicit concern for morale, involvement and development, deserves further cultivation.
\end{abstract}

\title{
Keywords
}

Higher education; quality management; quality culture; quality enhancement; path analysis 


\section{Introduction}

Higher education finds itself in a turbulent era, facing challenges of massification, diversification, increased competition and the introduction of consumerist levers to enhance student choice and control over education processes. ${ }^{1,2}$ These developments, along with attempts to increase effectiveness and efficiency in times when resources are under pressure, have fostered the implementation of systematic quality management approaches in Higher Education Institutes (HEI). ${ }^{3,4}$ As government policies, particularly in a number of western countries, are redirected towards deregulation and to an emphasis on $\mathrm{HEl}$ autonomy, the significance of internal quality management - 'all activities and processes deliberately organised by $\mathrm{HEl}$ to design, assure, evaluate and improve the quality of teaching and learning' 5 (p.104) is further amplified..$^{6,7}$

Notwithstanding its indelible place on institutional agendas, the added value of quality management in higher education is contested. Whereas various authors report on its merits, such as increased transparency on performance indicators, improvement of teaching processes, readiness for change and staff/student involvement, ${ }^{5,8,9}$ others express concerns that managerial approaches mainly serve 'control' and 'accountability' purposes. ${ }^{10,11}$ Quality management has been reported to generate staff resistance if it exaggerates bureaucracy, relies too heavily on a top-down implementation and strains individual autonomy. ${ }^{8,12}$ As academics closely identify with their own (teaching) discipline, the evaluation and assessment of educational quality can touch upon their sense of professionalism. ${ }^{13}$ The evaluation and assessment of education are potentially sensitive matters which have an impact on staff morale. ${ }^{14}$

Against this backcloth, the concept of 'quality culture' has captured an increased interest of researchers and policy makers in the field of higher education. The concept implies that, in addition to structural/managerial elements, organisational values/psychological elements should be addressed in order to enhance educational quality. ${ }^{15} \mathrm{~A}$ quality culture can be regarded as a specific kind of organisational culture which encompasses a shared commitment to - and responsibility for - quality, grass-roots involvement of staff and students and an adequate balance between top-down and bottom-up improvement initiatives. ${ }^{15}$

The importance of aligning quality management with the values and the identity of employees has been well-underpinned by research in business and industry settings. ${ }^{16-19}$ In higher education, empirical studies have been conducted on the relationship between organisational values and their effectiveness (e.g. Cameron and Freeman; Smart), ${ }^{20,21}$ on organisational culture types and quality management (e.g. Berings; Kleijnen et al.; Trivellas and Dargenidou) ${ }^{5,22,23}$ and on barriers to the implementation of quality management (e.g. Horine and Hailey; Lomas; Newton). ${ }^{24-26}$ However, there is a paucity of comprehensive studies in higher education on the way in which cultural and managerial characteristics of the institutional context trigger work-related psychological attitudes of academic staff, the way these attitudes interrelate, and their impact 
on staff's involvement in practices aimed at educational quality enhancement. Note that the term 'quality enhancement practices' is deliberately used in the remainder of this article in preference over 'quality management', to more specifically refer to the institutional activities and processes serving educational improvement purposes. The notion of 'quality management' is more often associated with control and accountability purposes. ${ }^{27}$

Attitudes towards - and behaviours of front line academics in - teaching are quintessential for educational quality and its continuous development, through staff's involvement in quality enhancement of the existing education offered, but also (perhaps even more important) through staff's direct engagement in the initial design of education and the execution of teaching roles. ${ }^{28}$ In order to nurture a quality culture, an integral approach which enacts on both organisational values/psychological elements and structural/managerial elements is required. ${ }^{29}$ ${ }^{31}$ Up to now, limited insight exists in the way these two dimensions interrelate, which causes them to be most often addressed in isolation.

This study aims to investigate the interrelationships between the most important organisational value/psychological and structural/managerial elements for quality culture development. These are represented as a configuration of internal-organisational context characteristics (value orientation, leadership and communication), work-related psychological attitudes of staff (empowerment, commitment and ownership) and quality enhancement practices. ${ }^{15,32,33}$ The research variables are operationalised in a 'quality culture survey'. Data collected from academics with teaching coordination roles (affiliated to four different bachelor study programmes) were analysed in order to construct a path analytic model. 


\section{Conceptual framework}

Throughout this conceptual framework, definitions of the researched variables are provided. Figure I depicts the theory-driven hypotheses (referred to in the conceptual framework between brackets/in italics; (HI-HIO)).

\section{Organisational culture: a competing values approach}

'Organisational culture' in the setting of HEl can be defined as; The collective, mutually shaping pattern of norms, values, practices, beliefs and assumptions that guide the behaviour of individuals and groups within an $\mathrm{HEl}$ and provide a frame of reference within which to interpret the meaning of events and actions on and off campus. ${ }^{34(\mathrm{p} .28)}$ As research in the field of organisational culture progressed, the shared norms and values approach, as implied by this definition, appeared to have its flaws: employees are part of - and are influenced by - multiple, coinciding subcultures, which can encompass different, possibly competing values. These subcultures emerge through a shared belonging to an academic profession (research, teaching), discipline, type of institution or specific department within the institution. ${ }^{35-38}$ The competing values model, as developed by Quinn and Rohrbaugh, ${ }^{39}$ provides a framework for assessing organisational value orientation. The model consists of two dimensions: external versus internal value orientation and focus on control versus flexibility. ${ }^{5}$ Organisations can identify with and strive for different values at the same time: to be structured and stable ('internal process'; internal/control orientation), to be a collaborative community ('human relation'; internal/flexible orientation), to be proactive and innovative ('open system'; external/flexible orientation) and to be goal-oriented and efficient ('rational goal'; external/control orientation). ${ }^{40,41}$

\section{Linking organisational value orientation, leadership and communication}

The value orientation within HEl forms a frame of reference for its 'leaders' and inspires their behaviour. Bland et al. ${ }^{42(\text { (.1228) }}$ note that 'How leaders perceive the organisation greatly affects what they believe are the best ways to influence it'. In other words, whereas leaders themselves are likely to be influenced by the organisational value orientation, they are at the same time in a position to reinforce or alter specific orientations. ${ }^{43}$ This implies the existence of a bidirectional relation (a correlation) between leadership behaviour on the one hand, and organisational value orientation on the other. According to Bass, ${ }^{44}$ positive organisational leadership can be conceptualised as a complementary construct(ion) of 'transactional' and 'transformational' styles. Transactional leadership entails an exchange relationship between leaders (or managers) and employees. ${ }^{45}$ It denotes that employees receive valued outcomes (such as wages, promotion and prestige) when they act in accordance with the wishes of higher management. Transactional leadership styles motivate employee behaviour by making clear what is expected and by providing information on the way in which performance is reimbursed. This style fits in well with stable cultures, risk avoidance, efficiency and attention for constraints in resources. ${ }^{46}$ 


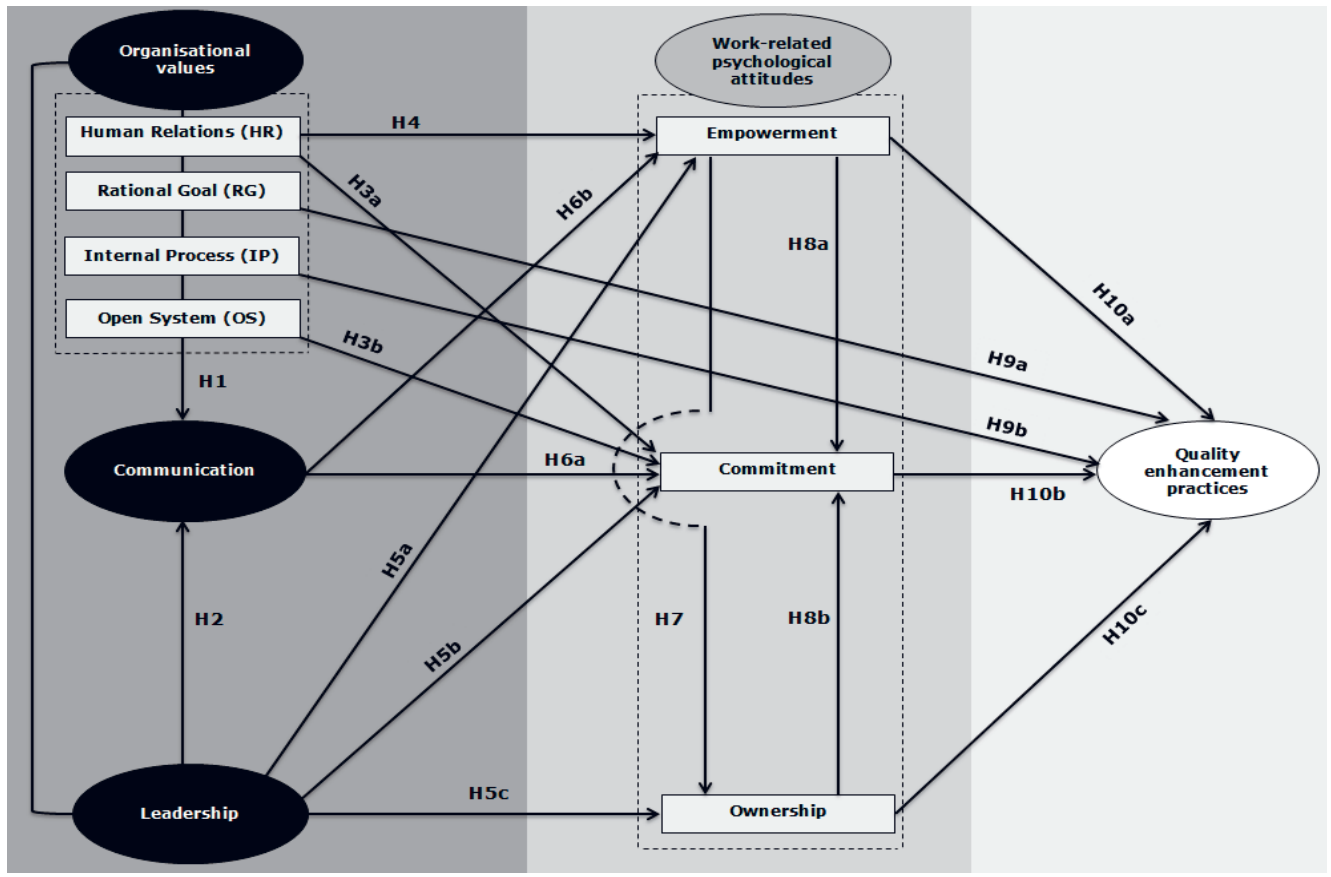

Figure I: Hypothesised path relationships between quality culture variables.

Note: the line connecting the 'leadership' and 'organisational values' variables reflects that a relation between these variables is expected, but that the direction of causality is unknown

Transformational leadership styles are focused on broadening employee interests, generating awareness and acceptance of the purpose of the organisation and on motivating employees to go beyond their self-interest for the good of the organisation. ${ }^{45}$ This style is aimed at finding new ways of working, seeking opportunities and valuing of effectiveness over efficiency. Transformational leaders envision an attractive future and inspire staff to be committed to achieve that future. They provide meaning to staff's work by enhancing their levels of self-efficacy, confidence, meaning and self-determination. ${ }^{47}$ Communication satisfaction in this study refers to the content of organisational messages (what is being communicated) and the 'communication climate' (how information is communicated). The organisational value orientation is posited to influence communication satisfaction $(\mathrm{HI})$, since their experienced and preferred value orientation affects staff attitudes pertaining to the management of information and communication practices within the organisation. ${ }^{48}$ Moreover, the value orientation promoted by the organisation's management and support departments is inherently linked to their communication strategy. ${ }^{49}$ As their position in the organisational hierarchy allows leaders to acquire information needed to develop strategies and policies and act as 'information distributors', a positive leadership style (defined in this study as a combination of transactional and transformational leadership behaviours) is hypothesised to contribute to communication satisfaction as well $(\mathrm{H} 2) .{ }^{50}$ 


\section{Work-related psychological attitudes: empowerment, commitment and ownership}

The presence of a supportive organisational context forms a basic requirement for human resources to achieve sustainable growth and performance. ${ }^{51}$ The organisations' value orientation, leadership and communication can constitute such supportive contextual characteristics and are hypothesised to be positively associated with work-related psychological attitudes: 'empowerment', 'affective commitment' and 'ownership'.

Empowerment reflects a cognitive state characterised by a sense of perceived control, competence and goal internalisation. ${ }^{52}$ Affective commitment resembles an emotional attachment to, identification with and involvement in the organisation. ${ }^{53}$ Ownership refers to 'the psychological state in which individuals feel as though the target of ownership or a piece of that target is theirs. ${ }^{54(p .86)}$ Ownership conceptually differs from empowerment as the former asks 'how much do I feel this entity is mine', while the latter asks 'do I feel capable and intrinsically motivated in my work role. ${ }^{55}$

Employees have been shown to feel more affectively committed to organisations with which they share values. ${ }^{56,57}$ Previous research in higher education settings indicates that the more policies and practices reflect concern for staff morale and development (a human relation value orientation) and encourage innovation and growth (open systems values orientation), the higher the level of affective commitment experienced by employees. ${ }^{57,58}$ The present study tests the hypothesis that human relation value orientation and open systems value orientation are positively related to teaching coordination staff's affective commitment $(\mathrm{H} 3$ a, b). In addition, since a human relation value orientation aims to promote participation, involvement and staff development, it is expected to have a positive effect on staff empowerment $(\mathrm{H} 4)$.

Leaders can provide incentives to staff, create a sense of involvement, set a vision which is in line with staff's norms and values and offer room for staff development and autonomy. ${ }^{53,59}$ These positive attributes of transformational and transactional leadership styles are hypothesised to trigger employee empowerment, affective commitment and ownership ( $\mathrm{H} 5 \mathrm{a}$, b, c).

Another important internal context element relevant for organisational performance is access to information (facilitated by and optimal usage of communication channels), as this offers staff the opportunity to learn and develop themselves. ${ }^{60}$ Adequate internal communication can help reduce uncertainty and equivocality by providing staff with a thorough understanding of their work environment. ${ }^{61}$ The way in which staff experience the communication climate is hypothesised to contribute to their affective commitment to the organisation and the degree in which they feel empowered in their work ( $\mathrm{H} 6 \mathrm{a}, \mathrm{b})$. Hence, 
adequate communication can be considered a prerequisite for staff to be able to identify with the organisations' mission, aims and value orientation, and it is through adequate communication and information provision that staff can acquire the knowledge needed to develop a sense of empowerment.

The three work-related psychological attitudes of staff are deemed to interrelate. Since empowered staff members are entrusted with more responsibilities and have considerable opportunities to make decisions, it is expected that staff experiencing higher degrees of empowerment also experience higher degrees of ownership $(\mathrm{H7})$. In addition, staff members who feel empowered and who have a sense of ownership are hypothesised to develop a stronger sense of affective commitment to the organisation ( $\mathrm{H} 8 \mathrm{a}, \mathrm{b})$.

\section{Implications for quality enhancement practices}

Quality enhancement practices are associated with devoting effort to information management, communication, planning and goal setting. ${ }^{62}$ This systematic, structured side of quality enhancement is hypothesised to fit in best with control-oriented value orientations: internal process value orientation (reflecting attempts to improve from an internal-organisational perspective) and rational goal value orientation (reflecting the aim to develop processes and practices in order to respond to evolving external demands) $(\mathrm{H} 9 \mathrm{a}, \mathrm{b})$.

By definition, empowered staff members view themselves as being able to influence their job and work environment in meaningful ways and are likely to proactively execute their responsibilities by, for instance, anticipating problems and acting independently. ${ }^{63}$ Empowered employees possess a certain amount of responsibility, autonomy and decisiveness. These traits of empowered staff members are considered to have a positive effect on quality enhancement practices $(\mathrm{HIO} \mathrm{a})$.

Staff members who want to belong to the organisation (referring to their sense of affective commitment) are expected to exert more effort on behalf of the organisation, compared to those who experience a need to belong to the organisation because there are high costs associated with leaving (i.e. continuance commitment) or those who feel they ought to stay, for example because the organisation has invested in them (i.e. normative commitment). ${ }^{53}$ The affective commitment of employees has been reported to be positively correlated with outcomes relevant for the organisation, such as attendance, job satisfaction, performance and organisational citizenship behaviour. ${ }^{64-66}$ Highly affectively committed employees are willing to put extra effort into their work and have a tendency to be more concerned with its quality. ${ }^{53}$ Therefore, it is postulated that affective commitment contributes to quality enhancement practices $(\mathrm{HIO}$ b). The term 'commitment' as further used in this article refers specifically to the affective dimension of commitment.

Conventional wisdom suggests that people will take better care of, and strive to maintain and nurture what they perceive to be their own. Research by Vandewalle, Van Dyne, and Kostova 
revealed that experienced ownership is associated with a sense of responsibility, pride and the performance of extra role behaviour; constructive work efforts that go beyond the basic required work activities. ${ }^{67}$ Teaching coordination staff members who consider educational courses to be 'their own' are expected to report higher degrees of quality enhancement practices being realised ( $\mathrm{HIO} \mathrm{c})$.

\section{Theoretical model and hypotheses}

Figure I depicts the theoretical framework and direction of hypothesised causal relationships by the unidirectional arrows linking two variables. The line connecting the 'leadership' and 'organisational values' variables reflects that a relation between these variables is expected, but that the direction of causality is unknown. Leadership and organisational values are independent variables (they are not hypothesised to be influenced by the other included variables; they do not have 'incoming' arrows). Communication, empowerment, commitment and ownership are dependent and mediator variables (the variables have both incoming as well as outgoing arrows), while the dependence of quality enhancement practices on other variables is reflected by it only having incoming arrows. Note that for the hypothesised relation between organisational values and communication, no specific hypotheses are formulated for the four individual archetypical orientations. $\mathrm{HI}$ therefore has a more general, explorative character.

HI The organisational value orientation affects communication satisfaction.

H2 Leadership is positively related to communication satisfaction.

H3 The higher the degree of 'human relation' ( $a$ ) and 'open systems'( $b$ ) values experienced, the higher the degree of experienced commitment of staff.

H4 A human relation value orientation has a positive effect on staff empowerment.

H5 Leadership positively affects empowerment (a) commitment (b) and ownership (c).

H6 Communication satisfaction contributes to staff commitment (a) and empowerment (b).

H7 Empowered staff members experience higher degrees of ownership.

H8 Empowerment (a) and ownership (b) are positively related to commitment.

H9 The more staff experiences a presence of rational goal (a) and internal process values (b), the higher their report of quality enhancement practices being realised.

HIO Empowerment (a) commitment (b) and ownership (c) are positively related to quality enhancement practices 


\section{Research design and methods}

\section{Setting and participants}

The hypotheses were tested against data collected from the course coordinators of four bachelor's programmes: Bachelor in Health Sciences, Bachelor in Biomedical Sciences, Bachelor in Medicine and Bachelor in European Public Health, at Maastricht University (NL). All programmes apply Problem-Based-Learning as core methodology, with curricula being structured in a sequence of thematic courses of several weeks. Course coordinators, together with a number of planning group members, are responsible for the quality enhancement of their respective course; they are expected to systematically work on the improvement of education, taking into account both their own experiences as well as other sources of information, e.g. quantitative and qualitative results of student evaluations and input of involved teaching staff (tutors and lecturers). Coordinators report to the study programme's management team and are accountable for translating strategic decisions of the management team into educational practices. After explaining the background and purpose of the study, the voluntary nature of participation, and the confidentiality of responses, informed consent was obtained from all participants by means of a 'tick-box' statement at the start of the digital survey. The study has been approved by the ethical review board of the Dutch Association for Medical Education (NERB dossier number 530).

In total, 123 coordinators were invited to fill out the online survey, which requested staff to reflect on experiences regarding the previous run of their course. Eighty nine responses were collected (including three partly completed surveys), representing a response rate of $72 \%$. Fifty six percent of the respondents are male. Survey respondents were active in the role of course coordinator in the specific programme for respectively <3 years (17\%), 3-6 years (40\%), 6-9 years (24\%), 9-12 years (6\%) or > 12 years $(14 \%)$.

\section{Survey development}

The 'quality culture' survey was constructed by means of combining subscales of existing, wellvalidated questionnaires, incorporating items of original questionnaires into new scales, and item/scale development by the authors. The final version of the survey consisted of 62 items in total. The survey is included as Appendix I. Organisational value orientation (24 items) was measured with the 'Organisational Culture Assessment Index', ${ }^{39}$ which includes questions to explore the experienced presence of human relation values (6 items), open systems values (6 items), rational goal values (6 items) and internal process values (6 items). Leadership was measured with six items of the 'Charismatic Leadership In Organisations' questionnaire. ${ }^{68}$ This questionnaire includes both items on transformational leadership originating from the Multifactor Leadership questionnaire as developed by Bass (1985) and items on transactional leadership. Communication satisfaction (six items) was measured with items of standardised communication audits. ${ }^{69,70}$ Focus was placed on communication flow 'down the organisation', i.e. the way course coordinators experience the communication initiated by others in the organisation (support departments and higher management). ${ }^{61}$ 
Empowerment (six items) was measured with the subscales 'self-determination' (reflecting autonomy over the initiation and continuation of work behaviour and processes) and 'impact' (the degree to which a person can influence strategic, administrative or operating outcomes at work), derived from the 'Psychological Empowerment Scale'. ${ }^{63}$ Commitment (seven items) was operationalised with the 'Affective Commitment Scale' as included in the 'Organisational Commitment Questionnaire'.' One additional item, measuring willingness to exert 'extra effort' on behalf of the organisation, was derived from the 'Organisational Commitment Questionnaire'.72 Ownership (five items) was measured with the subscales 'self-efficacy' (one's belief in the personal ability to accomplish a given task) and 'accountability' (the tendency to feel a sense of responsibility for the object of ownership) of the Psychological Ownership Questionnaire. ${ }^{73}$

Quality enhancement practices (eight items) were measured with items derived from 'Quality Management Activities Scale', as developed by Kleijnen et al. ${ }^{74}$ in combination with self-developed items by the authors.

Items of original questionnaires were modified in order to fit in with the specific organisational context. A pilot test was conducted among six former course coordinators to check the survey's content validity and correct terminology. Since the original subscales and items were adapted, a principal component analysis (with oblique rotation to allow for correlations between components) was conducted to identify whether subscale items sufficiently loaded on one dimension and thus could be interpreted as one concept. Items with insufficient loadings on the variable subscale were removed. Decisions on the final (sub)scale construction were based on the consideration of multiple criteria: extracted communalities, scree plots, total variance explained and the structure matrix (item loading). Computation of Cronbach's alpha $(\alpha)$ for the subscales led to acceptable results: all scales met the rule of thumb of $\alpha>.7 .^{75}$ Scale reliability estimates $(\alpha)$ are included in Table I. Results from the principal component analysis are available from the first author upon request.

\section{Statistical analysis}

Descriptive statistics and bivariate correlations were calculated to describe the population sample. Responses to all items were provided on a 5-point scale; strongly disagree (I); disagree (2); neither agree nor disagree (neutral, 3); agree (4) and strongly agree (5). Subsequently, a path analysis was carried out to test the formulated hypotheses $(\mathrm{HI}-\mathrm{HIO})$. The standardised path coefficients $(\beta)$ and their significance provide information on the relative strength of the hypothesised relationship between variables. Standardised coefficients can vary between -1.00 and +1.00 and indicate how many standard deviations a dependent variable will change, per standard deviation increase in its predictor variable. $\beta$-weights around $.10, .25$ and .40 respectively represent small, medium and large effects. ${ }^{76}$ Coherence between several goodness-of-fit indices was used to determine whether the theoretical model fitted the empirical data, i.e. relative chisquare statistic, normed fit index (NFI), comparative fit index and the root mean square error of approximation (RMSEA). A further elaboration on these measures and their interpretation is provided in the result section under the heading 'model fit'. 


\section{Results}

\section{Descriptive statistics}

Table I presents the descriptive statistics, correlations $(r)$ between variables and scale reliabilities $(\alpha)$ in parenthesis on the diagonal. With regard to the organisational value orientation, coordinators indicated to be 'neutral' to experienced control-oriented values (internal process; $M=3.16, S D=0.54$, rational goal values; $M=3.18, S D=0.52$ ). Flexibility oriented values; both with an internal focus (human relations; $M=2.87, S D=0.62$ ) and an external focus (open systems, $M=2.90, S D=0.56$ ) also reached a near neutral score, with mean scores being almost equivalent. When drawing to the other 'context' related variables, staff indicated to be neutral with regard to communication satisfaction $(M=3.05, S D=0.73)$ and also tend to neither agree nor disagree with regard to the presence of (positive) leadership. ( $M=$ $3.19, S D=0.60)$. The mean scores on work-related psychological attitude variables reveal that, overall, staff members who agree that they feel empowered in their role as coordinator $(M=$ $3.99, \mathrm{SD}=0.65$ ), score 'moderate' (between neutral and agreement) with regard to questions concerning their commitment to the study programmes $(M=3.66, S D=0.54)$, and agree that they experience a sense of ownership of their course $(M=4.14, S D=0.45)$. Moreover, staff members tend to agree with quality enhancement practices being enacted within their respective courses $(M=3.85, S D=0.51)$.

The correlation coefficients for variables being hypothesised to interrelate $(\mathrm{HI}-\mathrm{HIO})$ are presented in Table I in bold. These coefficients provided preliminary support for most of the expected interrelations between variables included in the path model. Exemptions (nonsignificant correlations) are the hypothesised relations between leadership and empowerment $(r=-.05)$, communication and empowerment $(r=.06)$, the relation between leadership and ownership $(r=.06)$ and the positive association of both internal process value orientation $(r=.06)$ and commitment $(r=.19)$ with quality enhancement practices. Rational goal value orientation appeared to have no correlation with leadership and communication, whereas, in line with the hypotheses, the other three value orientations were found to be correlated to leadership and communication satisfaction. Both correlations between organisational value orientation and leadership and organisational value orientation and communication satisfaction turned out to be the highest for the human relation value orientation archetype. 
Table I Descriptive statistics, correlations and Alpha Reliability Estimates (on the diagonal) of quality culture variables

\begin{tabular}{|c|c|c|c|c|c|c|c|c|c|c|c|c|c|}
\hline & $\mathbf{M}^{\curvearrowright}$ & SD & $\mathbf{N}$ & I & 2 & 3 & 4 & 5 & 6 & 7 & 8 & 9 & 10 \\
\hline I. Human Relations & 2.87 & .62 & 86 & (.79) & & & & & & & & & \\
\hline 2. Internal Process & 3.16 & .54 & 86 & .17 & $(.73)$ & & & & & & & & \\
\hline 3. Rational Goal & 3.18 & .52 & 86 & .09 & $.4 I^{* *}$ & $(.72)$ & & & & & & & \\
\hline 4. Open Systems & 2.90 & .56 & 86 & $.63 * *$ & .04 & $.21^{*}$ & $(.74)$ & & & & & & \\
\hline 5. Leadership & 3.19 & .60 & 87 & $.56 * *$ & $.32 * *$ & .02 & $.38 * *$ & $(.83)$ & & & & & \\
\hline 6. Communication & 3.05 & .73 & 89 & $.59 * *$ & $.26 *$ & .05 & $.43 * *$ & $.65^{* *}$ & $(.84)$ & & & & \\
\hline 7. Empowerment & 3.99 & .65 & 89 & $.24^{*}$ & -.2 & -.07 & .18 & -.05 & .06 & $(.87)$ & & & \\
\hline 8. Commitment & 3.66 & .65 & 87 & $.5 I^{* *}$ & .19 & -.05 & $.25 *$ & $.34 * *$ & $.44^{* *}$ & $.22 *$ & $(.87)$ & & \\
\hline 9. Ownership & 4.14 & .45 & 89 & .01 & .05 & .03 & .03 & .06 & .07 & $.32 * *$ & $.22 *$ & $(.76)$ & \\
\hline 10. Qual. enhancement & 3.85 & .51 & 89 & .15 & .06 & $.26 *$ & .16 & -.07 & .12 & $.23 *$ & .19 & $.39 * *$ & $(.76)$ \\
\hline
\end{tabular}

Notes: M: Mean; SD: Standard Deviation; N: Number of observations. $\$ Scale I-5, I: strongly disagree, 5: strongly agree. *Correlation is significant at thethe $<.05$ level (2-tailed), ${ }^{* *}$ Correlation is significant at the $<.01$ level (2-tailed); correlations between variables hypothesised to causally relate are presented in bold.

\section{Interrelationships between researched variables}

Figure 2 presents the path model including tests of the hypothesised relationships between variables as outlined in the conceptual framework; only significant paths are included. Note that the correlation coefficients between organisational value orientations and leadership are presented in Table I. For a complete overview of path coefficients, standard errors and p-values, please refer to Appendix 2.

With regard to $\mathrm{HI}$ (the effect of value orientation on communication satisfaction) the analysis revealed that this hypothesis solely holds ground for the predicted effect of human relation value orientation on communication satisfaction $(\beta=.28, p<.05)$. Hence, no relation was found between the three other organisational value orientations and communication satisfaction. The analysis also provides support for $\mathrm{H} 2$ (a positive relationship between leadership and communication satisfaction $(\beta=.44, \mathrm{p}<.001)$.

Both higher degrees of experienced human relation value orientation and open system value orientation were hypothesised to lead to higher degrees of commitment $(\mathrm{H} 3 \mathrm{a}, \mathrm{b})$.

Whereas the analyses support this thesis for the association between human relation value orientation and commitment $(\beta=.46, \mathrm{P}<.001)$, no significant relation was identified between open systems value orientation and commitment. 
Human relation value orientation was confirmed to have a positive effect on empowerment $(H$ $4 ; \beta=.38, \mathrm{p}=$ empowerment, commitment and ownership ( $\mathrm{H} 5 \mathrm{a}, \mathrm{b}, \mathrm{c})$, nor for the contribution of communication satisfaction to experienced staff commitment and empowerment $(\mathrm{H} 6 \mathrm{a}, \mathrm{b})$.

When turning to the interrelations between the three work-related psychological attitudes, the analyses indicate that more empowered employees experience higher degrees of ownership $(\mathrm{H} 7 ; \beta=.33, \mathrm{p}=<.05$ level $(\mathrm{H} 8 \mathrm{~b})$. These results imply that an indirect path runs from empowerment to commitment via ownership.

Rational goal and internal process value orientation were predicted antecedents of quality enhancement practices (H9). This hypothesis too was only partly confirmed: a direct mediumsized effect exists for rational goal orientations' impact on quality enhancement practices $(\mathrm{H} 9$ $\mathrm{a} ; \beta=.29, \mathrm{p}<.0 \mathrm{I})$. No relation exists, however, between internal process value orientation and quality enhancement practices $(\mathrm{H} 9 \mathrm{~b})$. Finally, of the predicted association of work-related psychological attitudes with quality enhancement practices ( $\mathrm{HIO} a, b, c)$ only the impact of ownership was found to be significant $(\beta=.32, p=<.001)$.

The relative amount of variance of the dependent variables (communication, empowerment, commitment, ownership and quality enhancement practices) explained or accounted for by their predicator variables is represented by the squared multiple correlation (R2). R2 communication $=.50, \mathrm{R} 2$ empowerment $=.10, \mathrm{R} 2$ ownership $=.1 \mathrm{I}, \mathrm{R} 2$ commitment $=.36, \mathrm{R} 2$ quality enhancement practices $=.26$. 


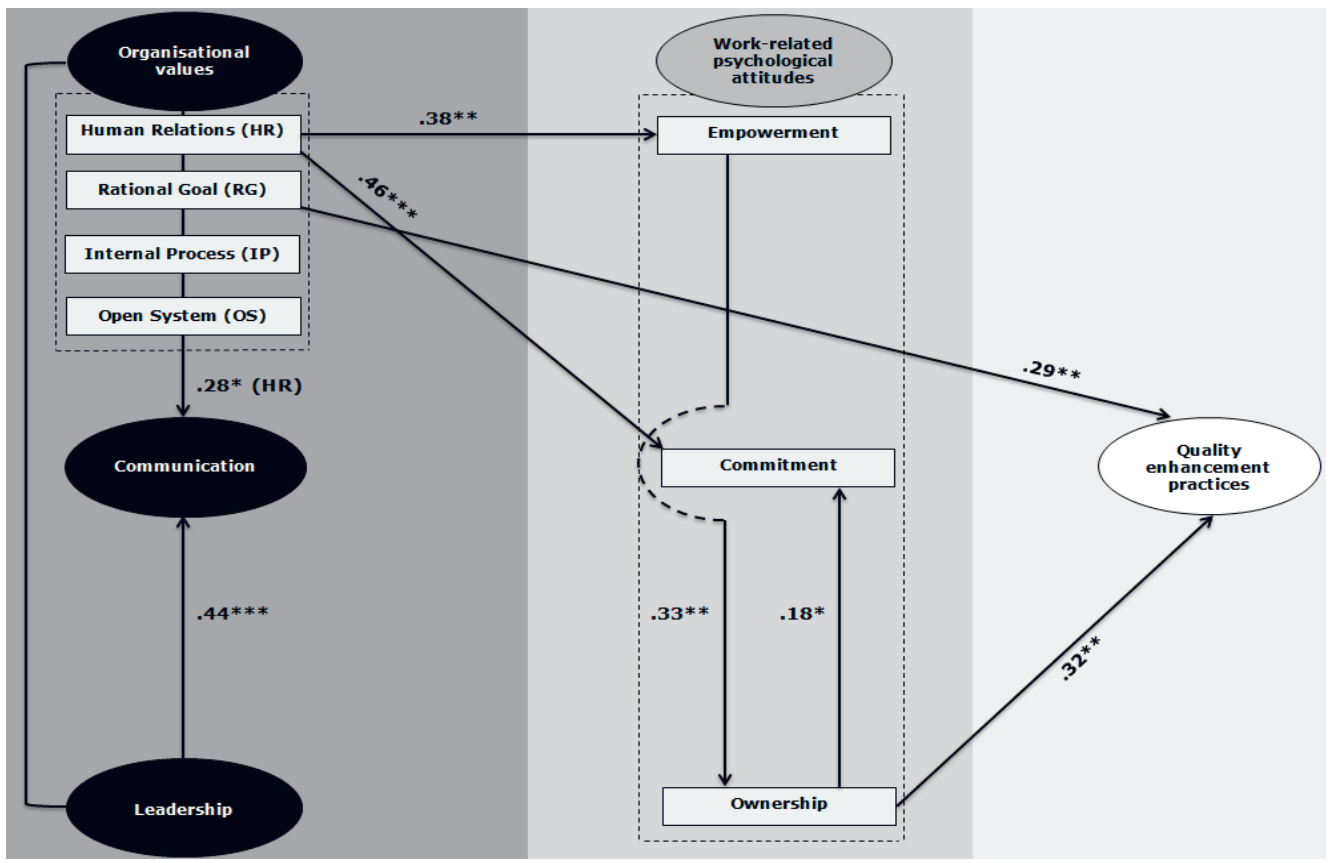

Figure 2: Path model standardised coefficients of the relations between quality culture variables; ${ }^{*} p<.05 ; * * p<.01, * * * p<.001$.

Note: the relationships between variables depicted in figure 2 resemble the hypothesised relationships as presented in figure I which were found to be statistically significant; the line connecting the 'leadership' and 'organisational values' variables reflects that a relation between these variables is expected, but that the direction of causality is unknown

\section{Model fit}

The coherence between several statistics was used to determine whether the theoretical model fitted the empirical data. The chi-square statistic tests the null hypothesis that the model adequately represents the population data. The nonsignificant Chi-square $(p=.365)$ indicates that the null hypothesis should not be rejected (meaning that the overall fit of the model is satisfactory). It is argued that the chi-square statistic divided by the degrees of freedom is a more reliable fit index, since it compensates for sample size. A relative chi-square of 2 or less indicates a good fit. ${ }^{77}$ For the tested model Chi-square/df $=1.085$. Alternative measures for fit are the NFI, the CFI and the RMSEA. A good fit is indicated by values greater than 0.90 for NFI and 0.95 and greater for $\mathrm{CFI} .{ }^{78} \mathrm{NFI}$ of the tested model $=0.943, \mathrm{CFI}=0.994$. For RMSEA, a value of 0 is interpreted as an exact fit and an RMSEA of 0.05 or less indicates a close fit. ${ }^{79}$ RMSEA of the tested model $=0.03 \mathrm{I}$, further reflecting an adequate fit of the model. 


\section{Discussion}

In this study, hypothesised interrelationships between organisational context characteristics (value orientation, leadership and communication), work-related psychological attitudes of academics with teaching coordination roles (empowerment, commitment and ownership) and educational quality enhancement practices were tested in a path analytic model. The findings highlight the paramount importance of a 'human relation' value orientation within $\mathrm{HEI}$, as this orientation contributes to staff empowerment and commitment, indirectly impacts on ownership (through empowerment) and has a positive effect on communication satisfaction. Moreover, out of the four archetypical organisational value orientations, the human value orientation was found to have the strongest correlation with positive leadership. Successfully shaping work-related psychological attitudes of academics is crucial, since these attitudes do not only influence 'in role' behaviour (acting in accordance with requirements set by the organisation), but also affect 'extra role' behaviour (going beyond formal requirements of a role) which is an important determinant of productivity, creativity, innovation and overall organisational performance. ${ }^{55}$

The fact that 'rational goal' values which emphasise planning, goal attainment, and efficiency were found to impact on the execution of quality enhancement practices, resembles the significance of the organisational structure/managerial pillar for quality culture development: organisational policies, strategies and guidelines determine to a certain degree whether evaluation and enhancement practices are being executed by staff. This study reveals, however, that in order to reinforce this structural/managerial pillar, as well as the organisational value/ psychological pillar for quality culture development, the nurturing of an academic teaching/ learning community characterised by collaboration, explicit concern for staff morale and involvement (i.e. reflecting a human relation value orientation) as well as the promotion of ownership, need further cultivation. Especially the implementation of longitudinal faculty development initiatives, which incorporate attention to staff's motivations for teaching, values and professional identities, can contribute to favourable outcomes in this respect. That is, the intentional community building which coincides with comprehensive faculty development programmes has shown to impact on increased staff self-awareness, acquisition of new skills and expertise, and a higher degree of perceived institutional support for taking on responsibilities which impact on continuous educational quality enhancement. ${ }^{80}$ The finding that especially the degree of ownership experienced by teaching coordinators impacts positively on the execution of quality enhancement activities implies that it will be worthwhile to increase their involvement in the design of quality evaluation and improvement measures: staff is more likely to act on quality evaluation data which they feel exemplify the key criteria of educational quality in 'their' domain. 
Counter to the theoretical predictions, no direct relation was identified in this study between leadership and staff's experienced empowerment, commitment and ownership. One reason for the finding that leadership and work-related psychological attitudes were not related can stem from staff's self-views as being autonomous and competent professionals. Hence, staff's professionalism, internal motivation and preference for an independent way of working mitigate their need for strong/directive leadership. ${ }^{81}$ Academics might need a more covert form of leadership entailing protection, support and the management of autonomy. ${ }^{59} \mathrm{~A}$ second reason for the absent relation between leadership and psychological work-related attitudes can be derived from the performed path analysis: leadership correlates to a variety of value orientations, which suggests that instead of a direct path from leadership to work-related psychological attitudes, an indirect path runs from leadership to these attitudes via the value orientation reinforced by leaders. This is in line with findings of a literature review performed by Bland et al. ${ }^{82}$ on factors influencing successful curriculum development and organisational change in medical schools: leaders' assertive, participative and cultural/value-influencing behaviours were found to substantially contribute to positive change outcomes, since leaders promoted collaboration, shared values in the light of the envisioned change, built trust and facilitated involvement and open communication.

It is imperative that sufficient resources (time, expertise and adequate evaluation instruments) are available in order to collect data on educational quality and to identify potential areas of improvement. ${ }^{83,84}$ While it is acknowledged that resource availability inevitably plays a role in quality enhancement practices, the present study refrained from focusing on material aspects in favour of providing insight in ways to successfully shape work related psychological attitudes of academics. The study paves the way for developing organisational strategies for quality culture development based on empirical research on the interrelationship between organisational values/psychological elements and organisational structure/managerial elements. To our knowledge, this empirical approach to quality culture development is unique in its kind. It is advocated that institutional policies and strategies directed at educational quality enhancement should leave sufficient discretionary space for the availing of academic professionals' expertise and the promotion of ownership, while leadership in higher education should especially be directed to the promotion of a human relation value orientation.

\section{Limitations}

It should be noted that, while the path model included many variables important for the development of a quality culture, it was only able to account for a modest proportion of variance in some variables. Hence, characteristics of the organisational context, work-related psychological attitudes and quality enhancement practices are likely to also be affected by factors outside the model (for instance resource availability). Although the path analysis technique allows for testing plausible, prespecified relations between variables, in itself it cannot distinguish whether a correlation between $A$ and $B$ represents a causal effect of $A$ on $B$, a causal 
effect of B on A, mutual dependence on other variables C, D or a mixture of these. ${ }^{85}$ However, in this study, the adequate application of the path analysis technique and the interpretation of relationships between the researched variables were supported by a sound theoretical framework. ${ }^{86}$ Caution is warranted on the generalisability of the findings as the data collected is context specific. In countries characterised by collectivistic values, higher education staff's behaviour is more likely to be influenced by shared norms, group interdependence and experienced obligations toward the organisation, instead of individualism, independence and the primacy of personal needs and rights, which is more typical for western cultures. ${ }^{87}$

\section{Suggestions for further research}

The empirical insight in ways to promote quality culture development in $\mathrm{HEI}$ can be augmented by conducting cross-institutional studies on this theme. Moreover, qualitative research on quality culture will prove to be valuable in terms of its potential to enlarge the understanding of academic staff's perceptions and behavioural determinants which have not been incorporated in the present study.

\section{Disclosure statement}

No potential conflict of interest was reported by the authors. 


\section{References}

I. Brennan, J., and Shah, T. (2000). Quality assessment and institutional change: Experiences from 14 countries. Higher Education; 40: 331-49.

2. Naidoo, R., Shankar, A., and Veer, E. (20II). The consumerist turn in higher education: Policy aspirations and outcomes. Journal of Marketing Management; 27: II42-II62.

3. Harvey, L.E.E. and Stensaker, B. (2008). Quality culture: understandings, boundaries and linkages. European Journal of Education; 43: 427-442.

4. Schwarz, S. and Westerheijden, D.F. (2004). Accreditation and evaluation in the European higher education area. Higher Education Dynamics Vol. 5. Dordrecht: Kluwer.

5. Kleijnen, J., Dolmans, D., Willems, J., and Van Hout, H. (20I4). Effective quality management requires a systematic approach and a flexible organisational culture: A qualitative study among academic staff. Quality in Higher Education; 20: 103-126.

6. Harvey, L.E.E. and Newton, J. (2007). Transforming quality evaluation: Moving on. In Quality Assurance in Higher Education. Trends in Regulation, Translation and Transformation, edited by D. F. Westerheijden, B. Stensaker, and M. J. Rosa. Dordrecht: Springer.

7. Jarvis, D.S.L. (2014). Regulating higher education: Quality assurance and neo-liberal managerialism in higher education. Policy \& Society: An Interdisciplinary Journal of Policy Research; 33: I55-166.

8. Cruickshank, M. (2003). Total quality management in the higher education sector: A Literature review from an international and Australian perspective. Total Quality Management and Business Excellence; 14: II59-II67.

9. Lillis, D. (2012). Systematically evaluating the effectiveness of quality assurance programmes in leading to improvement in institutional Performance. Quality in Higher Education; 18: 59-73.

10. Brookes, M., and Becket, N. (2007). Quality management in higher education: A review of international issues and practice. International Journal for Quality and Standards; I: I-37.

II. Newton, J. (2000). Feeding the beast or improving quality? Academics' perceptions of quality assurance and quality monitoring. Quality in higher education; 6: 153-163.

12. Baker, G.R., Gelmon, S., Headrick, L., Knapp, M., Norman, L., Quinn, D., and Neuhauser, D. (1998). Collaborating for improvement in health professions education. Quality Management in Health Care; 6: I-II.

13. Lueddeke, G.R. (2003). Professionalising teaching practice in higher education: a study of disciplinary variation and 'teaching-scholarship. Studies in Higher Education; 28: 213-228.

14. Gordon, G. (2002). The roles of leadership and ownership in building an effective quality culture. Quality in Higher Education; 8: 97-106.

15. European University Association (2006). Quality culture in European universities: A bottom-up approach. Report on the three rounds of the quality culture project 2002-2006. Brussels: EUA.

16. Irani, Z. Beskese, A., and Love, P.E.D. (2004). Total quality management and corporate culture: constructs of organisational excellence. Technovation; 24: 643-50.

17. Maull, R., Brown, P., and Cliffe, R. (200I). Organisational culture and quality improvement. International Journal of Operations \& Production Management; 21: 302-326.

18. Powell, T.C. (1995). Total quality management as competitive advantage: A review and empirical study. Strategic Management Journal; 16: 15-37.

19. Prajogo, D.I. and McDermott, C.M. (2005). The relationship between total quality management practices and organizational culture. International Journal of Operations \& Production Management; 25: II0I-II 22.

20. Cameron, K.S. and Freeman, S.J. (1991). Cultural congruence, strength, and type: Relationships to effectiveness. Research in Organizational Change and Development; 5: 23-58.

2I. Smart, J. (2003). Organizational effectiveness of 2-year colleges: the centrality of cultural and leadership complexity. Research in Higher Education; 44: 673-703.

22. Berings, D. (2009). Reflection on quality culture as a substantial element of quality management in higher education." Paper presented at the fourth European quality assurance forum (EQAF) of the European university association (EUA), Copenhagen, November 19-21. 
23. Trivellas, P. and Dargenidou, D. 2009. Organisational culture, job satisfaction and higher education service quality. The case of technological educational institute of Larissa. The TQM Journal; 21: 382-399.

24. Horine, J.E. and Hailey, W.A. (1995). Challenges to successful quality management implementation in higher education institutions. Innovative Higher Education; 20: 7- 17.

25. Lomas, L. (2004). Embedding quality: the challenges for higher education. Quality Assurance in Education: An International Perspective; 12: 157-165.

26. Newton, J. (2002). Barriers to effective quality management and leadership: Case study of two academic departments. Higher Education; 44: 185-2I2.

27. Williams, J. (2016). Quality assurance and quality enhancement: Is there a relationship? Quality in Higher Education; 22: 97-102.

28. Westerheijden, D.F., Hulpiau, V., and Waetens, K. (2007). From design and implementation to impact of quality assurance: An overview of some studies into what impacts improvement. Tertiary Education and Management; 13: 295-312.

29. Ali, H.M. and Musah, M.B. (2012). Investigation of Malaysian higher education quality culture and workforce performance. Quality Assurance in Education; 20: 289-309.

30. Burli, S., Bagodi, V., and Kotturshettar, B. (2012). TQM dimensions and their interrelationships in ISO certified engineering institutes of India. Benchmarking: An International Journal; 19: 177-92.

31. Osseo-Asare, D.L., Longbottom, D., and Murphy, W.D. (2005). Leadership best practices for sustaining quality in UK higher education from the perspective of the EFQM excellence model. Quality Assurance in Education: An International Perspective; I3: 148-170.

32. Bendermacher, G.W.G., Oude Egbrink, M.G.A., Wolfhagen, I.H.A.P., and Dolmans, D.H.J.M. (2016). Unravelling quality culture in higher education: A realist review. Higher Education; 73: I-22.

33. European University Association (2010). Examining quality culture part I: Quality assurance processes in higher education institutions. Brussels: EUA.

34. Kuh, G.D. and Whitt, E.J. (1988). The invisible tapestry: Culture in American colleges and universities. Washington, DC: Association for the Study of Higher Education. ASHE-ERIC Higher Education Report No. I.

35. Austin, A.E. (1990). Faculty cultures, faculty values. New Directions for Institutional Research; 68: 61-74.

36. Chandler, N. (20II). Understanding complexity: A multi-perspective model of organizational culture in higher education institutions. Practice and Theory in Systems of Education; 6: I-I0.

37. Lomas, L. (1999). The culture and quality of higher education institutions: Examining the links. Quality Assurance in Education; 7: 30-34.

38. Välimaa, J. (1998). Culture and identity in higher education research. Higher Education; 36: I19-138.

39. Quinn, R.E. and Rohrbaugh, J. (1983). A spatial model of effectiveness criteria: towards a competing values approach to organizational analysis. Management Science; 29: 363-77.

40. Berings, D. (200I). Dealing with competing values as a condition for the development of integral quality management in higher vocational education in Flanders. [Omgaan met concurrerende waarden als voorwaarde tot de ontwikkeling van integrale kwaliteitszorg in het hogescholenonderwijs in Vlaanderen.] (PhD Thesis), K.U. Leuven, EHSAL, Brussel.

4I. Cameron, K.S. and Quinn R.E. (1999). Diagnosing and changing organizational culture based on the competing values framework. Reading, MA: Addison-Wesley.

42. Bland, C.J., Starnaman, S., Wersal, L., Moorhead-Rosenberg, L., Zonia, S., and Henry, R. (2000). Curricular change in medical schools: How to succeed. Academic Medicine; 75: 575-94.

43. Dannefer, E.F., Johnston, M.A., and Krackov, S.K. (1998). Communication and the process of educational change. Academic Medicine; 73: S16-23.

44. Bass, B.M. (1985). Leadership and performance beyond Expectations. New York: Free Press.

45. Den Hartog, D.N., Van Muijen, J.J., and Koopman, P.L. (1997). Transactional versus transformational leadership: An analysis of the MLQ. Journal of Occupational and Organizational Psychology; 70: 19-34.

46. Lowe, K. B., Kroeck, K.G., and Sivasubramaniam, N. (1996). Effectiveness correlates of transformational and transactional leadership: A meta-analytic review of the MLQ literature. The Leadership Quarterly; 7: 385-425.

47. Avolio, B.J., Zhu, W., Koh, W., and Bhatia, P. (2004). Transformational leadership and organizational 
commitment: Mediating role of psychological empowerment and moderating role of structural distance. Journal of Organizational Behavior; 25: 95I-68.

48. Brown, A.D. and Starkey, K. (1994). The effect of organizational culture on communication and information. Journal of Management Studies; 31: 807-28.

49. Quinn, R., Hildebrandt, H., Rogers, P., and Thompson, M. (1991). A competing values framework for analyzing presentational communication in management contexts. Journal of Business Communication; 28 : 213-232.

50. Flumerfelt, S. and Banachowski, M. (20II). Understanding leadership paradigms for improvement in higher education. Quality Assurance in Education; 19: 224-247.

5I. Luthans, F. and Avolio, B.J. (2003). Authentic leadership: A positive developmental approach. In Positive Organizational Scholarship, edited by K. S. Cameron, J. E. Dutton, and R. E. Quinn. San Francisco: Barrett-Koehler.

52. Menon, S.T. (1999). Psychological empowerment: Definition, measurement, and validation. Canadian Journal of Behavioural Science / Revue Canadienne des Sciences du Comportement; 31: 16I-164.

53. Meyer, J.P. and Allen, N.J. (1991). A three-component conceptualization of organizational commitment. Human Resource Management Review; I: 6I-89.

54. Pierce, J.L., Kostova, T., and Dirks, K.T. (2003). The state of psychological ownership: Integrating and extending a century of research. Review of General Psychology; 7: 84-107.

55. Van Dyne, L. and Pierce, J.L. (2004). Psychological ownership and feelings of posession: Three field studies predicting employee attitudes and organizational citizenship behavior. Journal of organizational behavior; 25: 439-459.

56. Lok, P. and Crawford, J. (1999). The relationship between commitment and organizational culture, subculture, leadership style and job satisfaction in organizational change and development. Leadership \& Organization Development Journal; 20: 365-374.

57. Meyer, J. P., Gagné, M., and Parfyonova, N.M. (2010). Toward an evidence-based model of engagement: What we can learn from motivation and commitment research. In The Handbook of Employee Engagement: Perspectives, Issues, Research and Practice, edited by S. Albrecht. Cheltenham: Edwin Elgar.

58. Ovseiko, P.V. and Buchan, A.M. (2012). Organizational culture in an academic health center: an exploratory study using a competing values framework. Academic Medicine; 87: 709-18.

59. Bryman, A. (2007). Effective leadership in higher education: A literature review. Studies in higher education; 32: 693-710.

60. Ghani, N.A.A., Hussin, T.A.B., and Jusoff, K. (2009). Antecedents of psychological empowerment in the Malaysian private higher education institutions. International Education Studies; 2: 161-165.

6I. Thornhill, A., Lewis, P., and Saunders, M.N.K. (1996). The role of employee communication in achieving commitment and quality in higher education. Quality assurance in education; 4: 12-20.

62. Reitsma, A. (2003). Kritische succesfactoren bij visitatie en kwaliteitsverbetering van P\&A opleidingen. Case study onderzoek [Critical Success Factors in Visitation and Quality Improvement of Personnel Management Programmes, A CaseBased Approach]. PhD thesis, Open Universiteit, Heerlen.

63. Spreitzer, G.M. (1995) Psychological empowerment in the workplace: Dimensions, measurement and validation." Academy of Management Journal; 38: I442-1465.

64. Meyer, J.P., Stanley, D.J., Herscovitch, L., and Topolnytsky, M. (2002). Affective, continuance, and normative commitment to the organization: A meta-analysis of antecedents, correlates, and consequences. Journal of Vocational Behaviour; 61: 20-52.

65. Marchiori, D.M. and Henkin, A.B. (2004). Organizational commitment of a health profession faculty: dimensions, correlates and conditions. Medical Teacher; 26: 353-358.

66. Cooper-Hakim, A. and Viswesvaran, C. (2005). The construct of work commitment: Testing an integrative framework. Psychological Bulletin; I31: 241-59.

67. Vandewalle, D., Van Dyne, L., and Kostova, T. (1995). Psychological ownership: An empirical examination of its consequences. Group \& Organization Management; 20: 210-226.

68. De Hoogh, A.H.B., Koopman, P.L., and Den Hartog, D.N. (2004). The development of the CLIO, a questionnaire for charismatic leadership in organisations. [De ontwikkeling van de CLIO, een vragenlijst voor charismatisch leiderschap in organisaties.] Gedrag \& Maatschappij; 17: 354-38I. 
69. Downs, C., and Adrian, A. (1997). Communication audits. Lawrence, KS: Communication Management.

70. Postmes, T., Tanis, M., and De Wit, B. (200I). Communication and commitment in organizations: A social identity approach. Group Processes \& Intergroup Relations; 4: 227-246.

7I. Meyer, J.P., Allen, N.J., and Smith, C.A. (1993). Commitment to organizations and occupations: Extension and test of a three-component conceptualization. Journal of Applied Psychology; 78: 538-55I.

72. Mowday, R.T., Steers, R.M., and Porter, L.W. (1979). The Measurement of organizational commitment. Journal of Vocational Behavior; 14: 224-247.

73. Avey, J.B., Avolio, B.J., Crossley, C.D., and Luthans, F. (2009). Psychological ownership: Theoretical extensions, measurement and relation to work Outcomes. Journal of Organizational Behavior; 30: 173-91.

74. Kleijnen, J., Dolmans, D., Willems, J., and Van Hout, J. (2013). Teachers' conceptions of quality and organisational values in higher education: Compliance or enhancement? Assessment and Evaluation in Higher Education; 38: 152-166.

75. Nunnally, J.C. and Bernstein, I.H. (1994). Psychometric theory. 3rd ed. New York: McGraw-Hill.

76. Lipsey, M.W. and Wilson, D.B. (200I). Practical meta-analysis. London: Sage.

77. Ullman, J.B. (200I). Structural Equation Modeling. In Using Multivariate Statistics. 4th ed., edited by B. G. Tabachnick and L. S. Fidell. Needham Heights, MA: Allyn \& Bacon.

78. Hu, L. and Bentler, P.M. (1999). Cut off criteria for fit indexes in covariance structure analysis: Conventional criteria versus new alternatives. Structural Equation Modeling: A Multidisciplinary Journal; 6: I-55.

79. Browne, M.W. and Cudeck, R. (1993). Alternative Ways of Assessing Model Fit. In Testing Structural Equation Models, edited by K. A. Bollen, and J. S. Long, 136-62. Newbury Park, CA: Sage.

80. Steinert, Y., Mann, K., Anderson, B., Barnett, B.M., Centeno, A., Naismith, L., Prideaux, D. et al. (2016). A systematic review of faculty development initiatives designed to enhance teaching effectiveness: $A$ 10-year update. Medical Teacher; BEME guide No. 40: I-18.

8I. Hall, P. and L. Weaver, L. (200I). Interdisciplinary education and teamwork: A long and winding road. Medical Education; 35: 867-875.

82. Bland, C.J., Starnaman, S., Hembroff, L., Perlstadt, H., Henry, R., and Richards. R. (1999). Leadership behaviors for succesful university-community collaborations to change curricula. Academic Medicine; 74: 1227-37.

83. Gerrity, M.S. and Mahaffay, J. (1998). Evaluating change in medical school curricula; how did we know where we were going. Academic Medicine; 73: S55-S59.

84. Kottmann, A., Huisman, J., Brockerhoff, L., Cremonini, L., and Mampaey, J. (2016). How can one create a culture for quality enhancement? CHEPS, CHEGG.

85. Stage, F. K., Hasani, C.C., and Amaury, N. (2004). Path Analysis: an introduction and analysis of a decade of research. The Journal of Educational Research; 98: 5-13.

86. Leppink, J. (2015). On causality and mechanisms in medical education research: An example of path analysis. Perspectives on Medical Education; 4: 66-72.

87. Wasti, S.A. (2003). Organizational commitment, turnover intentions and the influence of cultural values. Journal of Occupational and Organizational Psychology; 76: 303-321. 
Appendix I: Quality culture questionnaire

\begin{tabular}{|c|c|c|c|c|c|}
\hline Statements & $\mathrm{N}$ & Mean & Min & Max & SD \\
\hline \multicolumn{6}{|l|}{ Human Relations Model } \\
\hline $\begin{array}{l}\text { I. The study programme has a very personal character. It is like an } \\
\text { extended family. People seem to share a lot of themselves. }\end{array}$ & 86 & 2.67 & I & 5 & 0.94 \\
\hline $\begin{array}{l}\text { 2. The leadership in the study programme is generally considered to } \\
\text { exemplify mentoring, facilitating or nurturing }\end{array}$ & 86 & 2.76 & I & 4 & 0.91 \\
\hline $\begin{array}{l}\text { 3. The management style in the study programme is characterised } \\
\text { by teamwork, consensus and participation. }\end{array}$ & 86 & 3.01 & I & 5 & 0.91 \\
\hline $\begin{array}{l}\text { 4. The glue that holds the study programme together is loyalty } \\
\text { and mutual trust. Commitment to the study programme runs } \\
\text { high. }\end{array}$ & 86 & 3.40 & 2 & 5 & 0.84 \\
\hline $\begin{array}{l}\text { 5. The study programme emphasizes human development. High } \\
\text { trust, openness and participation persist. }\end{array}$ & 86 & 2.93 & I & 4 & 0.88 \\
\hline $\begin{array}{l}\text { 6. The success of the study programme is defined on the basis of } \\
\text { the development of human resources, teamwork, commitment, } \\
\text { and concern for staff }\end{array}$ & 86 & 2.47 & I & 5 & 0.82 \\
\hline
\end{tabular}

Open Systems Model

I. The study programme is very dynamic and entrepreneurial.

\begin{tabular}{|c|c|c|c|c|}
\hline $\mathbf{N}$ & Mean & Min & Max & SD \\
\hline 86 & 2.67 & I & 5 & 0.94 \\
\hline 86 & 2.76 & I & 4 & 0.91 \\
\hline 86 & 3.01 & I & 5 & 0.91 \\
\hline 86 & 3.40 & 2 & 5 & 0.84 \\
\hline 86 & 2.93 & I & 4 & 0.88 \\
\hline 86 & 2.47 & I & 5 & 0.82 \\
\hline 86 & 2.71 & I & 5 & 0.87 \\
\hline 86 & 2.81 & I & 5 & 0.89 \\
\hline 86 & 2.93 & I & 5 & 0.82 \\
\hline 86 & 2.99 & I & 4 & 0.74 \\
\hline 86 & 2.97 & I & 4 & 0.80 \\
\hline
\end{tabular}

4. The glue that holds the study programme together is commitment to innovation and development. There is an emphasis on being on the cutting edge.

5. The study programme emphasizes acquiring new resources and creating new challenges. Trying new things and prospecting for opportunities are valued.

6. The success of the study programme is defined on the basis of having the most unique or newest teaching methods. The programme is leading in innovation of education.

2. The leadership in the study programme is generally considered to exemplify entrepreneurship, innovation or risk taking.

3. The management style in the study programme is characterised by innovation, freedom and uniqueness. 
Appendix I: Quality culture questionnaire [continued]

Statements

Rational Goal Model

I. The study programme is very result-oriented. A major concern is to get the teaching job done. Teachers are achievement oriented (value high evaluation scores).

2. The leadership in the study programme is generally considered to exemplify a no-nonsense, result-oriented focus.

3. The management style in the study programme is characterised by competitiveness with other programmes, high demands and achievement.

4. The glue that holds the study programme together is the emphasis on achievement and goal accomplishment.

5. The study programme emphasizes competitive actions and achievement.

6. The success of the study programme is defined on the basis of outpacing the competition. Competitive educational leadership is key.
N Mean Min Max SD

$\begin{array}{lllll}86 & 3.56 & \text { I } & 5 & 0.76\end{array}$

$\begin{array}{lllll}86 & 3.10 & \text { I } & 5 & 0.84\end{array}$

$\begin{array}{lllll}86 & 3.12 & \text { I } & 5 & 0.89\end{array}$

$\begin{array}{lllll}86 & 3.4 I & \text { I } & 5 & 0.71\end{array}$

$\begin{array}{lllll}86 & 2.98 & \text { I } & 5 & 0.78\end{array}$

$\begin{array}{lllll}86 & 2.91 & \text { I } & 5 & 0.85\end{array}$

\section{Internal Process Model}

I. The study programme is very controlled and structured. Formal processes generally govern what people do.

2. The leadership in the study programme is generally considered to exemplify coordinating, organising, or smooth-running efficiency.

3. The management style in the study programme is characterised by conformity, predictability, and stability in relationships.

4. The glue that holds the study programme together is formal rules and policies. Maintaining a smooth-running organisation is important.

5. The study programme emphasizes permanence and stability. Efficiency, control and smooth operations are important

$\begin{array}{lllll}86 & 3.00 & \text { I } & 5 & 0.84\end{array}$

$\begin{array}{lllll}86 & 2.73 & \text { I } & 5 & 0.85\end{array}$

6. The success of the study programme is defined on the basis of efficiency. Smooth scheduling and efficient organisation of education are critical

86

$$
86
$$

86

86 $\begin{array}{lllll}86 & 3.24 & \text { I } & 5 & .853\end{array}$

$\begin{array}{lllll}8 & 3.37 \quad & 5 & .921\end{array}$ 
Appendix I: Quality culture questionnaire [continued]

\begin{tabular}{|c|c|c|c|c|c|}
\hline Statements & $\mathbf{N}$ & Mean & Min & Max & SD \\
\hline \multicolumn{6}{|l|}{ Leadership: charismatic/transactional } \\
\hline I. Can be believed and relied upon to keep its word. & 87 & 3.40 & I & 5 & 0.77 \\
\hline 2. Can be relied upon to meet its obligations. & 87 & 3.49 & 2 & 5 & 0.65 \\
\hline 3. Keeps control and takes charge when problems arise. & 87 & 3.07 & I & 5 & 0.86 \\
\hline $\begin{array}{l}\text { 4. Has a vision and imagination on the future of the study } \\
\text { programme. }\end{array}$ & 87 & 3.16 & I & 5 & 0.93 \\
\hline $\begin{array}{l}\text { 5. Is able to get the study programme's staff enthusiastic about its } \\
\text { ideas. }\end{array}$ & 87 & 2.76 & I & 5 & 0.86 \\
\hline 6. Highly values clear agreements. & 87 & 2.62 & 1 & 5 & 0.96 \\
\hline
\end{tabular}

Communication: vertical/strategic

I. I was adequately informed about changes within the study programme

2. The study programme management regularly took the initiative to discuss educational issues with me.

3. I received sufficient feedback from the study programme management about the work I did as a (vice) coordinator

4. I received sufficient information on the study programme's policies and goals.

5. The communication within the study programme motivated and stimulated an enthusiasm for meeting the study programme's goals.

6. I received adequate information, which was needed to do my job as a (vice) coordinator

$\begin{array}{lllll}89 & 3.13 & \mid & 5 & 1.04\end{array}$

$\begin{array}{lllll}89 & 2.85 & \text { I } & 5 & 1.12\end{array}$

$\begin{array}{lllll}89 & 2.87 & \text { I } & 5 & 0.91\end{array}$

$\begin{array}{lllll}89 & 3.12 & \text { I } & 5 & 0.92\end{array}$

$\begin{array}{lllll}89 & 2.83 & \text { I } & 5 & 0.97\end{array}$

$\begin{array}{lllll}89 & 3.47 & \text { I } & 5 & 0.88\end{array}$ 
Appendix I: Quality culture questionnaire [continued]

\begin{tabular}{llllll}
\hline Statements & $\mathrm{N}$ & Mean & Min & Max & SD \\
\hline $\begin{array}{l}\text { Commitment } \\
\text { I. I would be very happy to keep on being active in this study }\end{array}$ & 87 & 3.66 & । & 5 & 0.93 \\
$\quad$ programme for the rest of my career. & & & & & \\
2. I really feel as if the study programme's problems are my own. & 87 & 3.39 & I & 5 & 0.93 \\
3. I feel a strong sense of belonging to this study programme. & 87 & 3.82 & I & 5 & 0.87 \\
4. I feel emotionally attached to this study programme. & 87 & 3.77 & 2 & 5 & 0.82 \\
5. I feel like part of the family in this study programme. & 87 & 3.14 & I & 5 & 1.03 \\
6. This study programme has a great deal of personal meaning for me. & 87 & 3.75 & 2 & 5 & 0.70 \\
7. I am willing to put in a great deal of effort beyond that normally & 87 & 4.10 & I & 5 & 0.76 \\
$\quad$ expected in order to make the study programme successful. & & & & &
\end{tabular}

\section{Ownership'}

I. I set high quality goals for the course/cluster I held a (shared) responsibility for.

2. I felt my course/cluster made a positive contribution to the quality of the study programme.

3. I did not hesitate to tell colleagues in the course/cluster if I saw something that was done wrong.

89

89

$\begin{array}{llll}4.22 & 3 & 5 & 0.62\end{array}$

89

3.93

4.3

4.22

3

3

0.69

\section{Quality enhancement practices}

I. There was sufficient communication with students about evaluation results and potential improvements.

2. There was sufficient communication with teachers about evaluation results and potential improvements

3. Educational quality management (quality monitoring and improvement) was considered an important task of course/ cluster planning group members.

4. Student evaluations were used to take concrete measures for improvement before the next running phase of the course/cluster.

5. Ad-hoc measures for resolving issues with regard to the organisation of education were taken whenever needed

$$
89
$$

$\begin{array}{lllll}89 & 3.67 & 2 & 5 & 0.82\end{array}$

$\begin{array}{lllll}89 & 3.92 & 2 & 5 & 0.79\end{array}$

6. Specific attention was spent to safeguard an optimal organisation of education.

7. The feedback of teachers (tutors, trainers) was used to further develop the education.

8. The results of evaluations were systematically compared with predetermined educational quality criteria or standards

$\begin{array}{lllll}89 & 4.13 \quad & 5 & 0.76\end{array}$

$\begin{array}{lllll}89 & 4.19 & \text { I } & 5 & 0.71\end{array}$

$\begin{array}{lllll}89 & 4.01 & \text { I } & 5 & 0.87\end{array}$

$\begin{array}{lllll}89 & 4.07 & 2 & 5 & 0.72\end{array}$

$\begin{array}{lllll}89 & 3.07 & \text { I } & 5 & 1.09\end{array}$ 
Appendix 2: Path coefficients, standard errors and p-values

\begin{tabular}{llcccc}
\hline & & b & S.E. & $\beta$ & P \\
\hline Communication & <--- Leadership & .534 & .120 & .435 & $* * *$ \\
Communication & <--- Human_Relations & .326 & .131 & .275 & .013 \\
Communication & <--- Open_Systems & .118 & .136 & .089 & .386 \\
Communication & <--- Rational_Goal & -.047 & .125 & -.033 & .707 \\
Communication & $<---$ Internal_Process & .109 & .125 & .080 & .385 \\
Empowerment & $<---$ Communication & .008 & .126 & .009 & .951 \\
Empowerment & $<---$ Leadership & -.290 & .152 & -.267 & .057 \\
Empowerment & $<---$ Human_Relations & .396 & .139 & .376 & .004 \\
Ownership & $<---$ Empowerment & .226 & .069 & .328 & .001 \\
Ownership & $<---$ Leadership & .054 & .076 & .072 & .477 \\
Commitment & $<---$ Ownership & .271 & .135 & .184 & .045 \\
Commitment & $<---$ Communication & .200 & .109 & .222 & .067 \\
Commitment & $<---$ Leadership & -.023 & .134 & -.021 & .865 \\
Commitment & $<---$ Empowerment & .070 & .097 & .069 & .473 \\
Commitment & $<---$ Human_Relations & .494 & .142 & .464 & $* * *$ \\
Commitment & $<---$ Open_Systems & -.181 & .133 & -.153 & .171 \\
Enhancement & $<---$ Commitment & .107 & .077 & .137 & .163 \\
Enhancement & $<---$ Rational_Goal & .289 & .101 & .293 & .004 \\
Enhancement & $<---$ Internal_Process & -.080 & .099 & -.084 & .420 \\
Enhancement & $<---$ Ownership & .367 & .115 & .319 & .001 \\
Enhancement & $<---$ Empowerment & .074 & .079 & .093 & .349 \\
\hline
\end{tabular}

$\mathrm{b}=$ unstandardised path coefficients

S.E. = standard error

$\beta=$ standardised path coefficients

$\mathrm{P} \quad=$ probability/strength of evidence to reject the null hypothesis

$* * *=\mathrm{p}<.001$

\section{Endnote}

I Three sample items are presented for this scale (total subscale included in the survey consisted of 5 items). Copyright 2007 Psychological Ownership Questionnaire (POQ) by James B. Avey \& Bruce J. Avolio. All rights reserved in all medium. Published by Mind Garden, Inc. www.mindgarden.com. This instrument was modified --by GB -- from the original. 

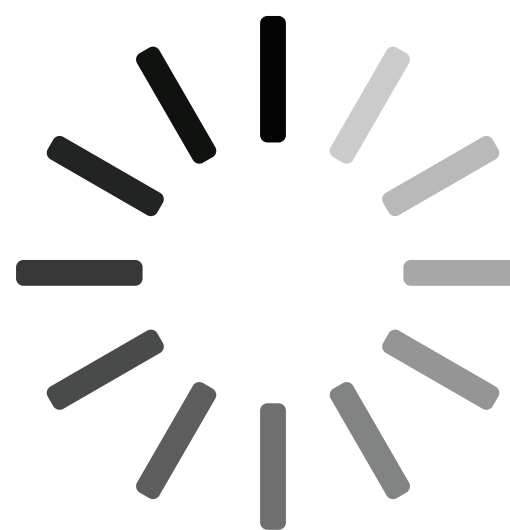

Guy Bendermacher

Willem de Grave

Ineke Wolfhagen

Diana Dolmans

Mirjam oude Egbrink

Published in:

Academic Medicine (2020); 95: 1913-1920 
Chapter IV

Shaping a culture for continuous quality improvement in undergraduate medical education 


\section{Abstract}

\section{Purpose}

This study sought to identify key features of an organisational quality culture and explore how these features contribute to continuous quality improvement of undergraduate medical education.

\section{Method}

Between July and December 2018, researchers from Maastricht University in the Netherlands conducted a multi centre focus group study among 6 education quality advisory committees. Participants were 22 staff and 18 student representatives affiliated with 6 medical schools in the Netherlands. The group interviews focused on quality culture characteristics in relation to optimising educational development, implementation, evaluation, and (further) improvement. Template analysis, a stepwise type of thematic analysis, was applied to analyse the data.

\section{Results}

Five main themes resembling quality culture constituents to continuous educational improvement were identified: (I) fostering an open systems perspective, (2) involving stakeholders in educational (re)design, (3) valuing teaching and learning, (4) navigating between ownership and accountability, and (5) building on integrative leadership to overcome tensions inherent in the first 4 themes. A supportive communication climate (which can be fuelled by the organisation's leaders) contributes to and is integrated within the first 4 themes.

\section{Conclusions}

The results call for a shift away from static quality management approaches with an emphasis on control and accountability toward more flexible, development-oriented approaches focusing on the 5 themes of a culture for continuous quality improvement. The study provides new insights in the link between theory and practice of continuous quality improvement. Specifically, in addition to quality management systems and structures, staff's professional autonomy, collaboration with peers and students, and the valuing of teaching and learning need to be amplified. 
Continuous quality improvement (CQI) strategies are of key importance to medical schools, given the need for curricula to keep pace with advancing public demands, evidence-based medicine, and an increased attention to effectiveness and efficiency. ${ }^{1,2}$ Since the early 1990s, medical schools have invested considerably in quality management approaches, resulting in better insights in staff performance, further opportunities to signal topics for improvement, and more clearly defined responsibilities. ${ }^{3,4} \mathrm{CQI}$ resembles a state in which schools take on the challenge to address different notions of educational quality in a methodical manner. Depending on the perspective of a stakeholder, educational quality can be understood as fitness for purpose (educating capable future physicians), value for money (a return on investment in education), perfection (focusing on zero defects), exceptional (standing out as the best programme), or transformative (focusing on the educational learning effect). ${ }^{5}$ Implementation frameworks such as the plan-do-check-act (PDCA) cycle illustrate that CQI is a repetitive and incremental process. The PDCA cycle holds that educational outcomes are compared to predetermined goals and that based on evaluations, action can be taken to address disparities. ${ }^{6}$

Notwithstanding the positive effects of current quality management approaches, there is a growing consensus that educational improvement is not a straightforward process. ${ }^{7}$ Three main arguments underpin this conception. First, the success of quality systems and processes depends on the way they are implemented and received by staff members, support staff, and students. ${ }^{8}$ Traditions of academic freedom, for instance, can stand at odds with the judgemental character of programme evaluations. ${ }^{9}$ Second, medical schools are complex, hierarchical organisations, which include different subcultures. ${ }^{10}$ These characteristics hamper a collective engagement in improvement efforts." Third, CQI is bounded by available information, time, and incentives. ${ }^{12}$ The lack of rewards for extra efforts to improve education can explain why evaluations are not followed up with concrete actions. ${ }^{13}$ The idea that structures and processes for CQI should be complemented by an organisational (sub)culture with care for educational quality at its core forms the foundation of the quality culture concept. ${ }^{14,15}$ This concept is linked to the perspective that organisational cultures reflect "a way to cope with problems of external adaptation and internal integration," 16 and builds on previous research on organisational (sub)culture(s) and performance. ${ }^{17}$ A quality culture promotes trust and involvement, while leadership and communication can reinforce the link between its hard (system or process oriented) and soft (psychological or value-related oriented) dimensions. . $^{8,19}$

Several studies have contributed to a better definition of the quality culture concept, ${ }^{20,21}$ and have identified subcultures within higher education. ${ }^{22,23}$ Moreover, previous research has contributed to the insight that the success of quality management can be explained by its alignment with cultural factors and staff preferences. ${ }^{24,25}$ Yet most studies on quality culture are of a theoretical, descriptive nature. ${ }^{19}$ There is a lack of empirical research on the way 
students and staff members involved in quality policies and procedures conceptualise a quality culture. Specifically, an enhanced insight across institutions is needed in how work-related psychological attitudes counterbalance quality control and accountability procedures. Increased knowledge in this area will support the merit of nurturing a quality culture.

Our study addresses the questions what are the key features of an organisational quality culture and how do these features contribute to continuous improvement of undergraduate medical education? As systems and processes for CQI in medical schools are increasingly becoming alike, we mainly focus on how work-related psychological attitudes and organisational value orientations make a difference in CQI.

\section{Method}

\section{Study design}

We conducted a multi centre focus group study, operating from a social constructivist stance. The study design is characterised by combining a deductive (from theory to practice) and inductive (from practice to theory) approach. ${ }^{26}$ Focus group discussions served to capture the broad array of participants' experiences, perspectives, and attitudes. ${ }^{27}$ Data collection, analysis, and interpretation were conducted sequentially, allowing for iterative adaptations and refinement of the analysis procedure.

\section{Setting}

Education quality advisory committees (ECs) of the 8 medical schools in the Netherlands were purposively selected to participate in this research. EC members are formally elected staff and student representatives. The central task of ECs is to provide the programme management with recommendations on all matters influencing quality of education. ECs have formal rights of consent and advice on the manner in which programme evaluations are organised. The committees consist of an equal number of students and staff members (each $\mathrm{EC}$ has 8 to 12 members). Four reasons underpin the choice to conduct focus groups among ECs. First, EC staff members generally are academics with ample experience in the development, implementation, evaluation, and improvement of education. Staff with clinical, nonclinical, or preclinical, research, and education backgrounds are represented in the participating ECs. Second, EC members are familiar with the quality systems and procedures in place; EC members have derived additional knowledge on these systems and procedures through training and cooperation with evaluation and policy departments. Third, ECs include student representatives. This representation allows for the incorporation of a different perspective on quality and quality improvement (besides that of staff). Fourth, the acquaintance of staff and students through their shared EC membership facilitates open discussion in a heterogeneous group setting. 
Each medical school in the Netherlands has a somewhat distinct organisational culture based on its history, record in research and education, and diversity of student intake. Moreover, educational approaches applied within the schools vary to some extent. The educational organisation structures and quality management approaches applied across schools are comparable, however. All programmes are offered by, or in close cooperation with, academic medical centers. In all participating schools, the PDCA cycle serves as guiding structure for CQI, and all programmes adhere to the Dutch Framework for Undergraduate Medical Education. ${ }^{28}$

\section{Data collection}

We developed an initial focus group guide, with questions structured according to the PDCA cycle. The choice to follow this structure was based on the presupposition that optimising each step of this cycle will lead to CQI. The guide (Appendix I) was tested in a pilot focus group session with former EC members from the researchers' home institution and thereafter adjusted; the order of questions was revised, and the use of theoretical concepts was limited. In May 2018, we approached the ECs of all 8 medical schools in the Netherlands. Six of the 8 committees agreed to participate. Reasons given for not participating were the required time investment and difficulty in planning a meeting and changes in the composition of the ECs. In total, 40 EC members (18 students and 22 staff) participated in the 6 focus groups (see Table I). The meetings were conducted between July and December 2018. All meetings (average duration, 79 minutes) were transcribed verbatim, and anonymised and coded transcripts were sent to participants for approval. At the start of each focus group, we asked participants to write down what they considered the most important elements of a quality culture. This exercise activated prior knowledge and was used as a form of data triangulation. At the end of the focus group meeting, we asked participants if their written comments were covered in the discussion.

Table I Number of participants per focus group. Study of continuous quality improvement in undergraduate medical education, Maastricht University, the Netherlands, 2018.

\begin{tabular}{lccccccc}
\hline & \multicolumn{7}{c}{ Focus group } \\
Participant & 1 & 2 & 3 & 4 & 5 & 6 & Total \\
\hline Staff, no & 5 & 3 & 2 & 4 & 2 & 6 & 22 \\
Students, no. & 4 & 2 & 2 & 2 & 4 & 4 & 18 \\
Total & 9 & 5 & 4 & 6 & 6 & 10 & 40 \\
\hline
\end{tabular}




\section{Data analysis}

We used template analysis, a stepwise type of thematic analysis, to analyse the data. In template analysis, a succession of coding templates consisting of hierarchically structured themes is developed and iteratively applied to the data. Themes are modified continuously as the analysis progresses. ${ }^{29}$ As a first step, G.W.G.B. and W.S.d.G. open coded 2 transcripts independently, searching for codes that recurred within and between transcripts. Topics described in a recent literature review on quality culture served as sensitising concepts. ${ }^{19}$ Subsequently, these 2 authors met to compare and merge codes and identify themes. The initial coding template comprised 24 themes and 183 codes. Iterative changes to the template were then made by G.W.G.B. based on the analysis of remaining transcripts. These changes concerned further detailing, merging, and linking codes. Hereafter, G.W.G.B. and W.S.d.G. met again to establish the final version of the coding template (including 25 themes and 199 codes). As a last step, G.W.G.B. recoded all transcripts using the final version of the template. The analysis process was supported by application of Atlas-ti 8.3 software (ATLAS.ti, GmbH, Berlin, Germany). The coding of the written exercise performed at the start of focus groups, analysis of transcripts, and discussion of transcripts with the full research team contributed to the identification of 5 overarching themes.

\section{Reflexivity}

To reflect on diverse interpretations in the data gathering and analysis stages, the full research team held several meetings. In these meetings, we discussed the anonymised and coded transcripts, field notes, and our individual understandings of CQI. All research team members are affiliated with the Faculty of Health, Medicine and Life Sciences at the School of Health Professions Education at Maastricht University in the Netherlands. The focus group moderator (W.S.d.G.) is an educational scientist with extensive experience in interviewing individuals and groups. Another team member, who is a doctoral candidate in quality culture development, acted as observer and note taker (G.W.G.B.). The research team further included an educational scientist with experience in quality assurance (I.H.A.P.W.), a medical physiologist who is a medical education innovator (M.G.A.o.E.), and an educational scientist focusing on innovative learning arrangements (D.H.J.M.D.). Our diverse expertise (in quality management, policy making, and medical education) enabled inclusion of multiple perspectives. From team discussions, we reached a negotiated consensus on the study's results.

\section{Ethical considerations}

The study was approved by the Dutch Association for Medical Education Ethical Review Board (NVMO ERB-1046). 


\section{Results}

We identified 5 main themes that reflect quality culture constituents to CQI: (I) fostering an open systems perspective, (2) involving stakeholders in educational (re) design, (3) valuing teaching and learning, (4) navigating between ownership and accountability, and (5) building on integrative leadership. A supportive communication climate (which can be fuelled by the organisation's leaders) contributes to, and is integrated within, the first 4 themes. In the following sections, we discuss the themes and their characterising elements (see Figure I) and illustrate them with student $(\mathrm{Sn})$ and faculty members $(\mathrm{Fn})$ quotes derived in the focus group meetings (FGn).

Our findings reveal a consistent picture on what participants considered the most important aspects of a quality culture. The results are therefore presented in an integrated manner (alternating student and staff quotes). Participants' responses were in line with prompts structured under the PDCA model, which implies that staff and students have internalised a systematic way of working on improvement. This finding is supported by results from the written exercise performed at the start of the focus groups in which respondents frequently referred to the importance of systematic approaches or the PDCA cycle (Appendix 2).

\section{Fostering an open systems perspective}

Participants identify a general atmosphere of openness, combined with an external orientation and freedom to experiment, and innovate as essential for CQI. They express a constant need for internal alignment (between courses) and external alignment (with developments in, and requirements of, the field). As the following staff member illustrates, taking an open systems perspective is relevant on different levels:

[Course coordinators] need to look a bit further than just their assignment in the strict sense. I always call that the micro level, where the translation to education is being made. But then, there's also the meso level. Within the programme, you should consider what precedes and what comes after. How the horizontal and vertical connections are made, and at the macro level, from the program to the societal context and the demand for specialisms, the alignment with postgraduate training.... That you have to develop education in such a complicated situation. That is the challenge (FGI, F5).

Participants refer to openness and an external orientation as important contributors to the organisation's adaptivity. New insights obtained from within or outside the program environment are seen as drivers of change for CQI. Examples are new insights derived through recommendations by accreditation panels; benchmarking with other programmes in Medicine; inputs from the labour market; and advice from educationalists, peers, and students. To 
translate these insights into practice, flexibility, creativity, and room to experiment and innovate are needed:

The related culture is that it is all right to make mistakes and that you can be open about it. If we demand from each other that everything goes perfect, then you suppress that....Also ... that the educational material is not completely set in stone, but has a bit of a flexible format, so that everyone can find their way in it. That way, people thrive and you can collect information on how different approaches work (FGI, F2).

It is important that staff dares to change educational approaches. For instance, it has often been said that lectures are not per se effective. However, we are still in a situation in which lectures are common practice (FG3, SI).

Students and staff members point out that communication within teaching teams and between teaching coordinators requires attention, especially to safeguard alignment of the curriculum content.

Involving stakeholders in educational (re)design

The EC members elaborate that involvement and a shared goal orientation of staff and students in the (re)design of education require attention. This involvement contributes to considering various scenarios, opportunities, and challenges:

Everyone has a different view on it [development of education], and everyone sees different possibilities or implementations. Also, for example, where things can go wrong. Something can look great on paper but can be experienced totally different by students and staff. That is why I think we need everyone on board (FG5, S2).

Respondents further note that involvement of staff members and students is important to clarify expectations, take away uncertainty, and therewith create support for educational change activities. However, in practice, the objective to involve - and communicate with - the larger community can be difficult to meet:

During the whole period of plan development, we insufficiently involved the people who eventually needed to implement it. We did not inform them sufficiently and what happens all of a sudden, the pressure was on. It needed to happen. Without people being fully aware of why we were doing this. What the reason was (FG6, F6). 


\begin{tabular}{|c|c|c|c|}
\hline $\begin{array}{l}\text { Open systems } \\
\text { perspective }\end{array}$ & $\begin{array}{l}\text { Stakeholder } \\
\text { involvement }\end{array}$ & $\begin{array}{c}\text { Valuing teaching and } \\
\text { learning }\end{array}$ & $\begin{array}{l}\text { Ownership and } \\
\text { accountability }\end{array}$ \\
\hline $\begin{array}{l}\text { - Openness and external } \\
\text { orientation }\end{array}$ & $\begin{array}{l}\text { - Shared goal } \\
\text { orientation }\end{array}$ & $\begin{array}{l}\text { - Commitment to } \\
\text { student development }\end{array}$ & $\begin{array}{l}\text { - Professional autonomy } \\
\text { and peer support }\end{array}$ \\
\hline $\begin{array}{l}\text { - Freedom to } \\
\text { experiment and } \\
\text { innovate }\end{array}$ & $\begin{array}{l}\text { - Creation of support } \\
\text { for educational } \\
\text { change initiatives }\end{array}$ & $\begin{array}{l}\text { - Self-reflective attitude } \\
\text { of faculty }\end{array}$ & - Constructive feedback \\
\hline $\begin{array}{l}\text { - Internal and external } \\
\text { alignment }\end{array}$ & $\begin{array}{l}\text { Balancing top-down } \\
\text { and bottom-up } \\
\text { approaches }\end{array}$ & $\begin{array}{l}\text { - Attention to and } \\
\text { appreciation of } \\
\text { education }\end{array}$ & $\begin{array}{l}\text { - Systematic evaluation } \\
\text { and improvement } \\
\text { approaches }\end{array}$ \\
\hline $\begin{array}{l}\text { - Adaptivity, } \\
\text { creativeness, and } \\
\text { flexibility }\end{array}$ & - Sharing best practices & $\begin{array}{l}\text { - Staff-student } \\
\text { community building }\end{array}$ & $\begin{array}{l}\text { - Clear responsibility } \\
\text { structure }\end{array}$ \\
\hline
\end{tabular}

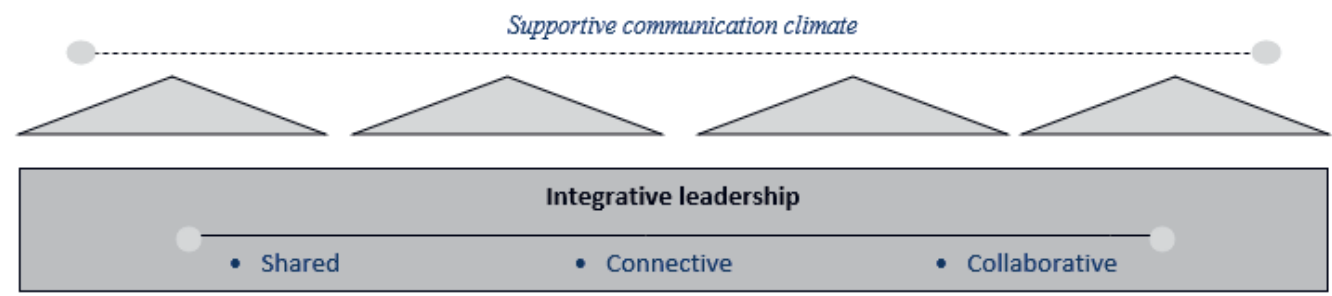

Figure I Study themes and their main characteristics, reflecting quality culture constituents to continuous quality improvement in undergraduate medical education. ${ }^{a}$

${ }^{a}$ The multicentre focus group study was conducted by researcher from Maastricht University, the Netherlands, in 2018; 22 staff members and 18 students from 6 medical schools in the Netherlands participated in the 6 focus groups. The theme of integrative leadership influences the other 4 themes (partly via creating a supportive communication climate). The supportive communication climate contributes to and is integrated within the 4 themes depicted at the top of the figure.

The balance between bottom-up and top-down improvement approaches is often referred to. On the one hand, approaches initiated at a high level in the organisation are needed to provide a basic framework and (re)development structure, while on the other hand, the ability of staff and students to contribute to plans is important:

That it is neither a top-down nor a bottom-up implementation, but that we identify issues in consultation with all parties involved, and that a consensus can be reached that way. At least, that is the philosophy. Instead of a coordinator or professor designing a curriculum and implementing it like "here you go" (FG5, S3). 
Specific value is attributed to representative bodies. These bodies contribute to improvement by identifying new ideas and providing advice based on insights in -and sharing of - best practices:

I believe that students are very well equipped to map the strong aspects and best practices within education.... In my opinion, part of the challenge for us as students [representatives] is to be aware of what those quality aspects actually are ... to consider "this was the idea, this is how it is implemented, and these are the points of attention to improve quality" (FG3, SI).

The respondents indicate that to safeguard stakeholder involvement, change leaders require project management and communication skills. A lack of attention for such skills in the medical education setting is expressed as reason for experiencing a shortfall of involvement.

\section{Valuing teaching and learning}

The motivation of staff to improve education stems, to an important degree, from commitment to the (academic and professional) development of students. Staff members, for example, point to the motivating effect of meeting with students after teaching activities, during which time students express appreciation for the learning effect of certain activities. According to students, staff's commitment manifests in several ways (e.g., through visibility and approachability, responsiveness to student questions, enthusiasm in lecturing). Committed staff members are more inclined to attain a self-reflective attitude and are more responsive to feedback, stemming from an internal drive to improve:

Yes, I believe for one thing, it involves the willingness of the teacher to improve. This is also what you get from many very different improvement plans: one teacher is far more open to criticism than the other. (FG2, S2).

Both teachers and students report that their participation in decision-making processes and shared goal formulation contribute to commitment. In general, attention to and appreciation of education fuel staff's motivation to teach. The following quote from a staff member illustrates that valuing research over education can hamper efforts to invest in education:

\footnotetext{
A head of department is far more interested in staff members' research and you producing manuscripts. That is something which pays off ... if you implement blended learning or create a new study programme blueprint ... that's also output, but it's not the kind of output that makes the department head happier (FG5, F2).
}

Respondents from all 6 institutions report that excessive workload hinders the commitment to education. As a counterbalance, attention to - and appreciation of - education from upper management stimulates commitment: 
The quality of education is made or broken by the attention to and enthusiasm for education, because if you do it, you will start to like it, and you will also automatically improve. So I think it mostly concerns time and attention and interest from other people. So yes, educational career paths and your superior's attention during the annual appraisal ... all that kind of ... attention within the organisation for education. (FG3, F2)

Staff members explain that committed staff members actively seek additional sources of feedback (other than the available standard educational evaluations), for instance, by sparring with peers and by informally asking for student opinions. The student representatives add that a short staff-student distance and student opportunities to provide feedback informally are instrumental in this respect. Participants point to the importance of valuing teaching and learning through staff-student community building, which can be reached through teaching in smaller units with more room for face-to-face interaction, for example.

\section{Navigating between ownership and accountability}

According to staff members, designing teaching and learning activities based on their own insights stimulates ownership and reinforces their motivation to continuously improve. Making the (re) development of education a shared (team) task, with room for professional autonomy, affects educational quality, provided that the team is committed:

The best planning groups are teams in which extensive discussions take place, and where discussion is not avoided....There has to be commitment and a feeling of togetherness. "We are going to create something." "We are going to build something." That is how you get quality. Maybe you will sometimes cross the boundaries set by the management institute. But yes, in that case, they will blow the whistle on you anyway (FGI, F4).

Autonomy and ownership need to be linked with peer support and accountability procedures (i.e., the PDCA cycle as systematic evaluation and improvement approach). An emphasis on short-term student satisfaction and process over outcome evaluations contradicts staff's preferred focus on the longitudinal development of students. Moreover, evaluations might not be aligned to innovations or fail to capture learning effects:

You need to measure to a much larger extent if you reached your goals, and then I come back to my goal again. My goal is not to see happy students after their exam or after the semester. My goal is to see them become a great doctor. That is my goal (FG6, F5).

Students and staff members report that it is key that feedback is constructive. Herein, respondents refer specifically to the added value of narrative feedback. A lack of information and communication on the follow-up of evaluations mitigates feedback quality. Further explanation of the purposes and follow-up of evaluations can enhance the likeliness of 
students' provision of high-quality feedback. Moreover, embedding clear responsibility structures is key:

We have been trying to find out what is going on for more than a year now. There is nobody who can tell us "that person does this, that one does that, and that one gives feedback," etc. If you look at a course, it is cumbersome to improve and it will take years. But I think it should be clear from the top down that it is structured in a certain way and who is responsible for what (FG4, SI).

Complex organisational structures and involvement of many staff members in coordination and implementation roles are considered to frustrate the follow-up on evaluation results.

\section{Building on integrative leadership}

Chart I summarises how integrative leadership contributes to intertwining the tensions present within the 4 themes described previously. With regard to fostering an open systems perspective, the formation of multidisciplinary teams (including students) is considered important. Such teams allow for shared responsibilities, decision making, and the inclusion of different perspectives:

I think you should start with the group that has to perform the task. The group should not be too large, but as heterogeneous as possible ... and it should get approval from everyone within the educational organisation to perform that task (FG3, SI).

Leaders ought to stimulate connective links between the overarching (programme or organisation) goals and individual faculty members' ambitions, motivations, and specialties. Offering too much freedom to teams or individual teachers can endanger the curriculum coherence:

What you see now is that when those people [the study programme management] ignore the content, a lot of teachers develop education in their own way. Of course they do this with the best intentions, let me make that clear, but yeah, then everything becomes all jumbled (FG4, F2). 


\begin{tabular}{|c|c|c|}
\hline Tension & Integrative leadership & Tension \\
\hline $\begin{array}{l}\text { Organisational flexibility for } \\
\text { change and innovation }\end{array}$ & $\begin{array}{l}\text { Open systems perspective } \\
\text { Embedding (ad hoc, project based), } \\
\text { multidisciplinary teams }\end{array}$ & $\begin{array}{l}\text { Organisational stability for } \\
\text { effectiveness and efficiency }\end{array}$ \\
\hline $\begin{array}{l}\text { Bottom-up improvement } \\
\text { initiatives }\end{array}$ & $\begin{array}{c}\text { Stakeholder involvement } \\
\text { Fostering collaboration, transparency, and } \\
\text { open communication with staff and } \\
\text { student representatives }\end{array}$ & $\begin{array}{r}\text { Top-down improvement } \\
\text { initiatives }\end{array}$ \\
\hline Intrinsic motivation & $\begin{array}{l}\text { Valuing teaching and learning } \\
\text { Emphasis on faculty development, human } \\
\text { relations, and resources }\end{array}$ & Extrinsic motivation \\
\hline Professional autonomy & $\begin{array}{c}\text { Ownership and accountability } \\
\text { Stimulating constructive feedback and } \\
\text { feedforward }\end{array}$ & Professional control \\
\hline
\end{tabular}

Chart I Integrative leadership to overcome competing organisational orientations (tensions) in themes reflecting quality culture constituents to continuous quality improvement in undergraduate medical education. ${ }^{\mathrm{a}}$

a The 5 themes were identified in a multicentre focus group study conducted by researchers from Maastricht University, the Netherlands, in 2018; 22 staff members and 18 students from 6 medical schools in the Netherlands participated in the 6 focus groups. The centre of the chart illustrates integrative leadership required to address tensions present within the 4 other identified main themes (presented in italics) reflecting quality culture constituents to continuous quality improvement (CQI). The tensions are depicted in the lateral parts of the chart, resembling orientations that are relevant for CQI in their own respect, but at the same time represent each other's opposites.

A general framework within which teams have freedom to operate helps to establish a balance between flexibility to innovate and stability to remain effective and efficient:

Yes, the intended aims determine the framework and the framework in the end determines that you tell people, "You have leverage and a certain freedom, but within the boundaries of the provided framework" (FG6, F5).

Abilities of leaders to establish a supportive communication climate are considered important determinants of the success of improvement initiatives. Through communication processes, leaders can foster transparency on the vision behind organisational change and foster involvement: 
It could just happen to be a good vision, but then you would like to know what it entails exactly. If you share it, this vision, you have some room for errors. Then at least you know what the dot on the horizon is. It could happen that somebody forgets to send you an email, and you think, "It's okay. I know what we are working towards. I know why this needs to happen now" (FG2, F2).

The EC members provide various examples of the way leaders promote valuing of teaching and learning and trigger motivation: through support and collaborative teacher networks, establishing education career tracks, and offering additional time or reimbursement for teaching. Leaders affect the balance of ownership (and autonomy) with accountability (and control) through appreciation of education and the provision of constructive feedback.

\section{Discussion}

In this study, we identified 5 themes that in concert shape a culture for CQI in medical education. As Chart I illustrates, various tensions within organisations exist between orientations to maintain and further develop the quality of education. The integration and creation of a synergy between these competing orientations call for increased multidisciplinary collaboration, open communication, investments in faculty development and human resources, and accountability procedures focusing on quality enhancement over quality control.

An open systems perspective (Theme I) aids in promoting quality development through intensified knowledge sharing and the stimulation of creativity and innovation. Taking such a perspective aids schools in their shift from devoting to CQI efforts (resembling incremental, single-loop learning) to becoming true learning organisations (resembling modified goals, decision-making rules, or both - double-loop learning). ${ }^{30}$ To stimulate a culture for CQI, a need for change in current values of medical schools is apparent. Whereas staff members typically prefer a flexible and human centred organisation, ${ }^{31,32}$ medical schools are still often seen as conservative, hierarchical, disconnected, and discouraging humanistic orientations. ${ }^{22,33-35}$

Broad stakeholder involvement (Theme 2) is key to CQI, as diversity in knowledge, skills, and (potentially competing) values helps to address the multifaceted notion of education quality. ${ }^{36}$ However, medical professionals and academics are used to working and learning within silos (relating to their clinical service activities, departments, disciplines, etc.), which reinforce distinct attitudes, problem-solving skills, and the use of a common language. ${ }^{37}$ Moreover, physicians and researchers typically have a large degree of autonomy. They are used to taking individual responsibility and are keen to defend interests of their own discipline. ${ }^{37}$ Thorough discussions and cocreation sessions involving staff members from different backgrounds form a keystone to initiate collective improvement activities. ${ }^{38}$ Additionally, CQI entails a role change from students as clients or consumers to active members of and contributors to the organisational culture. 
In line with research on incentives and staff needs satisfaction, ${ }^{39,40}$ we found several illustrations of extrinsic motivators for CQI. The valuing of teaching and learning (Theme 3 ) through increased funding, time for development, information sharing, and faculty development initiatives influence the organisation's improvement potential. ${ }^{41,42}$ Hence, a mere promotion of ownership and accountability (Theme 4) will not lead to beneficial results if required resources to take action are lacking.

Our findings indicate that integrative leadership (Theme 5) supports further quality culture development. Leadership in medical education is changing from individual staff supervision, guidance, and support to a focus on the broader collective. Instead of attributing responsibility for CQI to strong leadership, leaders are expected to be motivators, mentors, and facilitators. In the knowledge-intensive setting of medical schools, leaders and employees co-construct meaning and solutions to organisational issues. ${ }^{43} \mathrm{CQI}$ of medical education is best served with leaders who are able to combine multiple styles and who are able to coalesce different stakeholder goals and ambitions. ${ }^{44}$

The implementation of communities of practice (CoPs) ${ }^{45}$ opens a window of opportunity to address the themes of a culture for continuous improvement. CoPs facilitate interaction between teachers from diverse disciplinary backgrounds and create opportunities to gain new perspectives. Moreover, (training) activities organized within these communities strengthen a sense of involvement and enhance competence, confidence, credibility, and connection. ${ }^{46} \mathrm{CoPs}$ form an environment in which the valuing of teaching and learning, personal development, and teacher identity building is central. Constructive peer feedback processes in teaching and learning communities help to balance ownership and accountability for educational improvement. It should be noted that an open and longitudinal character of CoPs is essential to their added value; they should go beyond the mere establishment of a temporal league of quality champions.

\section{Theoretical and practical significance}

The present study gives voice to the opinion of staff members and students that standard quality management approaches should be complemented by insights derived from the quality culture concept. The reported results have contributed to gaining a deeper insight into this theoretical notion. Our findings imply a shift from static approaches emphasising accountability toward flexible approaches with room for professional autonomy and community building. CQI requires a stronger focus on the valuing of teaching; staff motivation; and student personal, academic, and professional development.

\section{Strengths and limitations}

This study contributes to the available literature as it is one of few studies that research quality culture empirically. We gathered data from multiple institutions and took into account both 
staff and student perspectives. The findings suggest that value orientations within medical schools are highly relevant in explaining how quality management approaches and work-related psychological attitudes of staff members interact. Whereas these orientations were rather homogeneous in the participating medical schools, they might vary in other contexts. The fact that we included only medical schools from the Netherlands (6 of 8 ) should be taken into account in the interpretation and transferability of results. A further limitation is that views of EC members might differ from other important stakeholders. However, as ECs typically operate on the organisational, meso, level, we assume to have captured both management and grassroots perspectives. A third (potential) limitation is that the respondents, despite guaranteed anonymity, might have been reluctant to share particular experiences with researchers affiliated with another university.

\section{Recommendations for future research}

To pave new paths for CQI, future research on interventions that convert individual educational improvement approaches to collective endeavours would be particularly valuable. In addition, case studies on best practices relating to the 5 themes identified in this study would provide levers to initiate organisational change and development for CQI.

\section{Conclusions}

Of a medical school's 3 missions - education, research, and clinical services - education is often the slowest to recognise that quality improvement and change are necessary, with traditions being dominant. Efforts to nurture the quality cultures in medical schools will help to unfreeze this status quo.

Acknowledgments: The authors thank all participating education quality advisory committee members for their time and openness. The authors also thank Academic Medicine's anonymous reviewers for their valuable comments and suggestions.

Funding/Support: None reported.

Other disclosures: None reported.

Ethical approval: This study was approved by the Dutch Association for Medical Education (NVMO) Ethical Review Board (file number 1046) on June 6, 2018. 


\section{References}

I. Casiro, $O$ and Regehr G. (2018). Enacting pedagogy in curricula: On the vital role of governance in medical education. Academic Medicine; 93: 179-184.

2. Harden, R.M. (20I8). Ten key features of the future medical school: Not an impossible dream. Medical Teacher; 40: 1010-1015.

3. Cruickshank, M. (2003). Total quality management in the higher education sector: A literature review from an international and Australian perspective. Total Quality Management and Business Excellence; 14: II59-II67.

4. Lillis, D. (2012). Systematically evaluating the effectiveness of quality assurance programmes in leading to improvement in institutional performance. Quality in Higher Education; 18: 59-73.

5. Harvey, L. and Green, D. (1993). Defining quality. Assessment and Evaluation in Higher Education; 18: 9-34.

6. Da Dalt, L., Callegaro, S., Mazzi, A. et al. (2010). A model of quality assurance and quality improvement for post-graduate medical education in Europe. Medical Teacher; 32: e57-e64.

7. Velthuis, F., Varpio, L., Helmich, E., Dekker, H., Jaarsma, A.D.C. (2018). Navigating the complexities of undergraduate medical curriculum change: Change leaders' perspectives. Academic Medicine; 93:1503-1510.

8. Harvey, L and Newton, J. (2007). Transforming quality evaluations: Moving on. In: Westerheijden DF, Stensaker B, Rosa MJ, eds. Quality Assurance in Higher Education: Trends in Regulation, Translation and Transformation. Dordrecht, the Netherlands: Springer.

9. Ter Bogt, H.J. and Scapens, R.W. (2012). Performance management in universities: Effects of the transition to more quantitative measurement systems. European Accounting Review; 2I: 45I-497.

10. Blouin, D. and Tekian, A. (2018). Accreditation of medical education programs: moving from student outcomes to continuous quality improvement measures. Academic Medicine; 93: 377-383.

II. Barzansky, B., Hunt, D., Moineau G, et al. (2015). Continuous quality improvement in an accreditation system for undergraduate medical education: Benefits and challenges. Medical Teacher; 37: 1032-1038.

12. Bland, C.J., Starnaman, S., Wersal, L., Moorehead-Rosenberg, L., Zonia, S., and Henry, R. (2000). Curricular change in medical schools: How to succeed. Academic Medicine; 75: 575-594.

13. Kember, D., Leung, D.Y.P., Kwan, K.P. (2002). Does the use of student feedback questionnaires improve the overall quality of teaching? Assessment and Evaluation in Higher Education; 27: 4II-425.

14. Berings, D., Beerten, Z., Hulpiau, V., and Verhesschen, P. (201I). Quality culture in higher education: From theory to practice. In: Blättler A, Bollaert L, Crozier F, et al, eds. Building Bridges: Making Sense of Quality Assurance in European, National and Institutional Contexts. Brussels, Belgium: European University Association.

15. European University Association (2006). Quality culture in European universities: A bottom up approach: Report on the three rounds of the quality culture project 2002-2006. Brussels, Belgium: European University Association.

16. Schein, E.H. (1984). Organizational culture and leadership: A dynamic Vvew. San Francisco, CA: Jossey-Bass.

17. Denison, D.R. (1984). Bringing corporate culture to the bottom line. Organizational Dynamics; 13: 4-22.

18. Genn, J.M. (200I). AMEE medical education guide no. 23 (Part 2): Curriculum, environment, climate, quality and change in medical education: A unifying perspective. Medical Teacher; 23: 445-454.

19. Bendermacher, G.W.G., oude Egbrink, M.G.A., Wolfhagen, I.H.A.P., and Dolmans D.H.J.M. (2017). Unravelling quality culture in higher education: A realist review. Higher Education; 73: 39-60.

20. Yorke, M. (2000). Developing a quality culture in higher education. Tertiary Education Management; 6: 19-36.

21. Harvey, L. and Stensaker B. (2008). Quality culture: Understandings, boundaries and linkages. European Journal of Education; 43: 427-442.

22. Blouin, D., Tekian, A., Harris, I.B. (2019). Do organizational cultures of Canadian medical schools promote a quality culture? Medical Teacher; 4I: 662-667.

23. Kleijnen, J., Dolmans, D., Willems, J., and Van Hout, J. (2013). Teachers' conceptions of quality and organisational values in higher education: Compliance or enhancement? Assessment and Evaluation in Higher Education; 38: I52-166. 
24. Horine, J.E., and Hailey, W.A. (1995). Challenges to successful quality management implementation in higher education institutions. Innovative Higher Education; 20: 7-17.

25. Newton, J. (2002). Barriers to effective quality management and leadership: Case study of two academic departments. Higher Education; 44: 185-212.

26. Mir, R., and Watson, A. (2000). Strategic management and the philosophy of science: The case for a constructivist methodology. Strategic Management Journal; 24: 94I-953.

27. Stalmeijer, R.E., Mcnaughton, N. and Van Mook, W.N. (2014). Using focus groups in medical education research: AMEE guide no. 91. Medical Teacher; 36: 923-939.

28. Laan, R.F.J.M., Leunissen, R.R.M., van Herwaarden, C.L.A. (2010). The 2009 framework for undergraduate medical education in the Netherlands. GMS Z Med Ausbild; 27:Doc35.

29. King, N. (2004). Using templates in the thematic analysis of text. In: Cassel C, Symon G, eds. Essential Guide to Qualitative Methods in Organizational Research. London, UK: Sage.

30. Argyris, C. (199I). Teaching smart people how to learn. Harvard Business Review; 69: 99-109.

31. Bendermacher, G.W.G., oude Egbrink, M.G.A., Wolfhagen, I.H.A.P., Leppink, J., Dolmans, D.H.J.M. (2019) Reinforcing pillars for quality culture development: A path analytic model. Studies in Higher Education; 44: 643-662.

32. Kleijnen, J., Dolmans, D., Willems, J., Muijtjens, A., Van Hout, J. (2009) Organisational values in higher education: Perceptions and preferences of staff. Quality in Higher Education; I5: 233-249.

33. Krupat, E., Pololi, L., Schnell, E.R., and Kern, D.E. (2013). Changing the culture of academic medicine: The C-change learning action network and its impact at participating medical schools. Academic Medicine; 88: 1252-1258.

34. Pololi, L.H., Krupat, E,, Civian, J.T., Ash, A.S., and Brennan, R.T. (2012). Why are a quarter of faculty considering leaving academic medicine? A study of their perceptions of institutional culture and intentions to leave at 26 representative U.S. medical schools. Academic Medicine; 87: 859-869.

35. Ovseiko, P.V. and Buchan, A.M. (2012). Organizational culture in an academic health center: An exploratory study using a competing values framework. Academic Medicine; 87: 709-718.

36. Cameron, K. and Quinn, R. (2006). Diagnosing and Changing Organizational Culture Based on the Competing Values Framework. San Francisco, CA: Jossey-Bass.

37. Hall, P. (2005). Interprofessional teamwork: Professional cultures as barriers. Journal of Interproffesional Care; 19(suppl I): 188-196.

38. Meeuwissen, S.N.E., Gijselaers, W.H., Wolfhagen, I.H.A.P., and oude Egbrink, M.G.A. (2020). When teachers meet in interdisciplinary teams: Hangouts, distribution centers and melting pots. Academic Medicine; 95: 1265-1273.

39. Wisener, K.M. and Eva, K.W. (2018). Incentivizing medical teachers: Exploring the role of incentives in influencing motivations. Academic Medicine; 93 (II suppl): S52-S59.

40. Engbers, R., Fluit, C.R., Bolhuis, S., Sluiter, R., Stuyt, P.M., and Laan, R.F. (2015). Relations between policy for medical teaching and basic need satisfaction in teaching. Advances in Health Sciences Education; 20: 969-980.

4I. Smesny, A.L., Williams, J.S., Brazeau, G.A., Weber, R.J., Matthews, H.W., and Das, S.K. (2007). Barriers to scholarship in dentistry, medicine, nursing, and pharmacy practice faculty. American Journal of Pharmacology Education; 71: 91.

42. Edwards, R.A., Venugopal, S., Navedo, D., and Ramani S. (2019). Addressing needs of diverse stakeholders: Twelve tips for leaders of health professions education programs. Medical Teachers; 4I: 17- 23.

43. Tourish, D. (2019). Is complexity leadership theory complex enough? A critical appraisal, some modifications and suggestions for further research. Organizational Studies; 40: 219-228.

44. Lieff, S.J. and Albert, M. The mindsets of medical education leaders: How do they conceive of their work? Academic Medicine; 85: 57-62.

45. Steinert, Y. (20I0). Faculty development: From workshops to communities of practice. Medical Teacher; 32: $425-428$.

46. Jauregui, J., O'Sullivan, P., Kalishman, S., Nishimura, H., and Robins, L. (2019). Remooring: A qualitative focus group exploration of how educators maintain identity in a sea of competing demands. Academic Medicine; 94: 122-128. 
Appendix I: Focus Group Interview Guide for Study of Continuous Quality Improvement in Undergraduate Medical Education, Maastricht University, the Netherlands, 2018

\section{[OPENING]}

A. Based on previous research we know that, despite of the fact that quality management systems and procedures used in different higher education organisations are becoming more alike, differences exist with regard to their experienced effectiveness. Apparently, other elements play a role in quality improvement as well. In this research, we would like to focus on elements that promote a culture aimed at continuous educational quality improvement. We would like to start by asking you to write down what according to you are core concepts related to a culture for continuous quality improvement. Please try to keep these concepts in mind and use them in the discussion.

\section{[PLAN]}

B. The curriculum reform of your bachelor/master programme in Medicine was initiated in [year] and is by now [partly implemented/fully implemented]. What according to you are the most important factors to be successful in the (re)design phase of a curriculum or a course? What are the most important challenges?

C. In what way are students involved in the redevelopment or further development of education? What experiences do you have with this? (What are best practices? When didn't this work-out as intended?)

$D$. What is the role of the education management/the programme management (for example year coordinators, bachelor and master coordinators and directors of education) in the redevelopment and/or further development of education?

\section{[DO]}

E. An important factor impacting on quality of education is the commitment of faculty and the commitment/involvement of students. What elements contribute to creating this involvement and commitment? (Ask for examples and best practices).

F. Which characteristics of the relation between faculty and between faculty and the higher management are supportive/hampering continuous educational improvement? Why?

G. Can you elaborate on the contacts between students and faculty (concerning quality improvement of education)? Which aspects in this contact contribute in the most positive (or negative) sense to CQI? Why?

\section{[CHECK]}

$H$. Do students and faculty feel that the quality management procedures within the Medicine program are effective? Do they contribute to educational improvement? Why (not)? What can be improved?

I. How do teachers experience the evaluation of education quality by others?

\section{[ACT]}

J. What factors contribute to the formulation and realization of improvement plans, which are formulated after a course period?

\section{[CLOSURE]}

$\mathrm{K}$. Are there other matters with regard to quality improvement/nurturing a quality culture that were not discussed yet? Are there other aspects which you would like to bring under attention? Are the core concepts you have written down discussed? (Ask all participants individually). 
Appendix 2: Key Features of a Quality Culture Contributing to Continuous Educational Improvement: Coding Results of a Written Exercise Performed by Faculty and Students From 6 Medical Schools in the Netherlands, Maastricht University, 2018

At the start of each focus group session, we asked faculty and student members of the Education Committees to write down what according to them are the most important aspects of a culture for continuous educational improvement. The selection and ranking of the listed codes are based on I) the coding of the written exercises (the top ten most frequently assigned codes to faculty and student data are included), and 2 ) the assigning of a code to data of at least three different focus groups. There were 5 missing values (faculty or students who did not fill out or hand in their written exercise). We corrected for this based on the focus group transcript. The grey scales represent the code density (frequency of the codes used relative to the total number of participants $(N=40)$, Faculty $(F=22)$ and students $(S=18)$. Abbreviations: $\mathrm{N}=$ total number of participants, $\mathrm{F}=$ Faculty, $\mathrm{S}=$ Students

\begin{tabular}{|l|l|l|l|}
\hline Code & \multicolumn{1}{|l|}{ N } & F & S \\
\hline Commitment of faculty & \multicolumn{3}{|l|}{} \\
\hline General communication & & \\
\hline Openness (culture/atmosphere) & & \\
\hline Involvement/representation & & & \\
\hline Commitment of students & & & \\
\hline Readiness to change and experiment & & & \\
\hline Shared goals & & & \\
\hline Constructive feedback & & & \\
\hline Systematic PDCA & & & \\
\hline Clear responsibilities & & & \\
\hline Transparency in decision making & & & \\
\hline Community building & & & \\
\hline Time for development & & & \\
\hline$>0 \leq 20 \%$ & & & \\
\hline
\end{tabular}





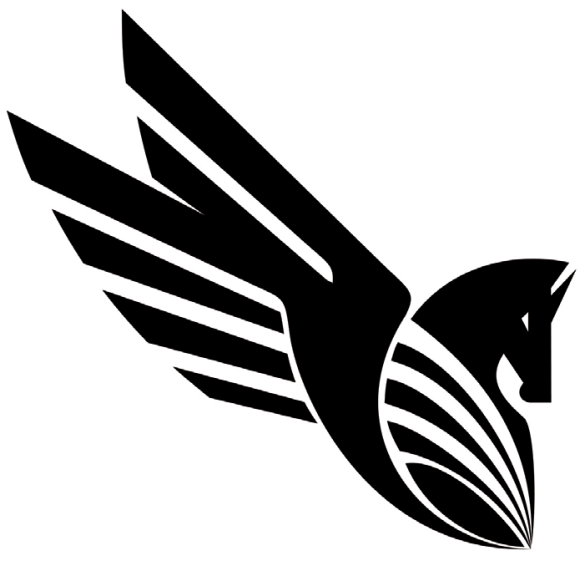

Guy Bendermacher

Diana Dolmans

Willem de Grave

Ineke Wolfhagen

Mirjam oude Egbrink

Published in:

Advances in Health Sciences Education (2020) - online publication ahead of print 
ChapterV

\section{Advancing quality culture in health professions education: experiences and perspectives of educational leaders}




\begin{abstract}
The concept of quality culture has gained increased attention in health professions education, drawing on insights that quality management processes and positive work-related attitudes of staff in synergy lead to continuous improvement. However, the directions that guide institutions from quality culture theory to educational practice have been missing so far. A prospective qualitative case study of three health professions education programmes was conducted to explore how a quality culture can be enhanced according to the experiences and perspectives of educational leaders. The data collection was structured by an appreciative inquiry approach, supported with vignette-based interviews. A total of 25 participants (a selection of course coordinators, bachelor coordinators and directors of education) reflected on quality culture themes to learn about the best of what is (Discover), envision positive future developments (Dream), identify actions to reach the desired future (Design), and determine how to support and sustain improvement actions (Destiny) within their own educational setting. The results are presented as themes subsumed under these four phases. The experiences and perspectives of educational leaders reveal that peer learning in teams and communities, attention to professional development, and embedding support- and innovation networks, are at the heart of quality culture enhancement. An emphasis on human resources, (inter)relations and contextual awareness of leaders stood out as quality culture catalysts. Educational leaders are therefore encouraged to especially fuel their networking, communication, coalition building, and reflection competencies.
\end{abstract}

\title{
Keywords
}

Appreciative Inquiry, Continuous Quality Improvement, Educational Leadership, Faculty Development, Organisational learning, Quality culture. 


\section{Introduction}

Many schools for health professions education (HPE) nowadays face the challenges of increasing student numbers, rapidly evolving educational approaches and technologies, a volatile financial environment and increased accountability pressures.' These circumstances call for an amplified focus on institutions' continuous improvement capacities. ${ }^{2}$ Since the 1990's, educational quality enhancement methods have been carried forward by waves of research on organisational culture and performance, total quality management, and an integration of both into the more topical concept of 'quality culture'. ${ }^{3,4}$ The latter concept is commonly used in higher education and originates from insights that quality management and control approaches are too technocratic and top-down and therefore fail or even have adverse effects. ${ }^{5,6}$ There is a growing consensus that an organisational culture for quality requires a more holistic approach in which quality systems and instruments, competencies, and individual as well as collective values are not seen as separate entities but are combined into one overarching concept - the concept of quality culture. ${ }^{7}$

\section{Defining quality culture}

The most often used definition of quality culture has been formulated by the European University Association (EUA). The EUA states that a quality culture is:
"an organisational culture that intends to enhance quality permanently and is characterised by two distinct elements: on the one hand, a cultural/psychological element of shared values, beliefs, expectations and commitment towards quality and on the other hand, a structural/managerial element with defined processes that enhance quality and aim at coordinating individual efforts". ${ }^{(\text {(p. } 10)}$

Rather than emphasising control, assurance and compliance to standards, a quality culture focuses on change, development and innovation. ${ }^{7}$ Positive psychological attitudes of staff (e.g. ownership and commitment) are considered working mechanisms of a quality culture, since they reinforce staff contributions to continuous improvement processes. The notion of quality culture is often captured in one breath with strategies that emphasise collaboration, shared goals and visions, stakeholder involvement, and a supportive communication climate. ${ }^{9}$

Quality cultures in HPE institutions seem to maintain an emphasis on stability and formal procedures, whereas cultures characterised by cohesiveness and motivation might be more open to engage in reflections on continuous quality improvement. ${ }^{10-12}$ Pololi and colleagues found that the values of academic staff might not be in tune with organisational values in medical education and that this is expressed in an undervaluing of tasks performed in education. ${ }^{13}$ Efforts to advance the quality culture in HPE institutions are also found to be driven by attempts to promote internal integration, and at the same time be better prepared for external (accreditation) demands. ${ }^{2,14,15}$ HPE leaders can positively contribute to building a common set of quality related values. ${ }^{16}$ Through sharing values and involving academic staff members in goal 
setting, their commitment to education can be reinforced. This is important, since in this way, a better balance could be reached between teaching roles and roles that academics also have in research and/or healthcare. ${ }^{17}$

\section{A further exploration of leadership in health professions education}

Previous studies have contributed to an increased insight in good leadership practices and desired leadership skills. For instance, Lieff and Albert concluded that medical education leaders navigate between intrapersonal (e.g. creating self-awareness), interpersonal (e.g. community building), organisational (e.g. task and goal setting) and managerial (e.g. strategy development) fields of practice. ${ }^{18}$ In a study by Bordage et al., being visionary, open-minded, and trustworthy stood out as preferred personality attributes of HPE leaders. ${ }^{19}$ Contemporary research implies that the strategic, employee-oriented and value driven processes associated with the influence of leaders do not merely depend on powerful, charismatic, or visionary leadership. ${ }^{20}$ Rather, a shift is taking place from leader-centred theories to understanding leadership impact based on shared, collaborative, and distributed approaches. ${ }^{21}$ There is increasing recognition that situational (or adaptive) leadership is required to address the complexity inherent in the academic environment. ${ }^{22}$ As leadership in HPE is multi-layered, within the reality of (medical) school hierarchies, one might be a leader and a follower at the same time. ${ }^{23}$ Moreover, instead of being mere leadership recipients, academics can steer the leadership of others and impact organisational developments through co-creation. ${ }^{24}$

\section{Research gaps}

A main challenge ahead for HPE institutions and their leaders lies in finding the stepping stones that pave the path from quality culture theory to organisational practice. ${ }^{25}$ Despite the importance attributed to quality culture and educational leadership in their own right, insights into how leaders can contribute to quality culture enhancement remain un(der)recognised by some and are either unclear or misunderstood by a good many. ${ }^{26-28}$ This lack of insight might result from a scarcity of research that takes contexts into account when studying the phenomena of quality culture or leadership. ${ }^{29-32}$ Moreover, while quality culture studies often include a strong theoretical component, many studies on educational leadership lack reference to supporting theory. ${ }^{9,33} A$ third gap in the literature concerns the fact that a majority of leadership studies concentrate on the highest management level. ${ }^{34}$

\section{Research aim}

This study aimed to bridge the quality culture theory-practice gap by addressing the question: How can a quality culture in health professions education be enhanced according to the experiences and perspectives of educational leaders? We are especially interested in how HPE leaders working at different management levels help shape a quality culture and what their preferences for further (organisational and educational) development are. We focussed on leaders as central actors influencing culture, although it should be acknowledged that leaders are influenced by subcultures themselves as well. ${ }^{35}$ 


\section{Methods}

\section{Design}

We followed the principles of a prospective qualitative case design to explore educational leader's experiences and perspectives on the advancement of a quality culture in the setting of their own organisation. This design encompassed a deductive testing of hypothetical 'ideal' situations against data gathered from three undergraduate (bachelor) programmes in HPE. ${ }^{36}$ Vignette-based interviews were used to let educational leaders reflect on professional dilemmas and to invite them to identify opportunities for further organisational development. ${ }^{37}$ Our instrumental approach to the case analysis focused on learning from similarities and redundancy across three cases (rather than on identified variety within or across cases). ${ }^{38}$

\section{Study approach}

Our study approach followed the theoretical and methodological ideas behind 'appreciative inquiry'. Grounded examples from the organisation's positive past are first identified and subsequently used to portray images of the organisation's positive future. ${ }^{39,40}$ The appreciative inquiry approach entails an exploration of four interconnected phases that together can be used to initiate and guide organisational change: Discovery (learn about 'the best of what is'), Dream (envision possibilities for the desired future), Design (identify actions to reach the desired future), and Destiny (determine how to support and sustain future development actions). ${ }^{41}$

\section{Study setting and participants}

This study was conducted from November to December 2019, at Maastricht University's Faculty of Health Medicine and Life Sciences (FHML), situated in The Netherlands. All programmes at FHML apply Problem-Based Learning (PBL). Three directors of education bear responsibility for education in the FHML domains 'Health', 'Medicine', and 'Biomedical Sciences'; each director is responsible for multiple bachelor/master programmes. Three FHML bachelor programmes, each led by a bachelor coordinator, made up the cases: I) the bachelor in Biomedical Sciences with 336 first-year students who started in 2019, 2) the bachelor in Health Sciences with 285 students who started in 2019, and 3) the bachelor in Medicine, with 32I students who started in 2019. The programmes are structured in 4-10-week thematic courses (each programme includes 25 to 35 courses). The courses are designed, implemented, and evaluated by planning groups consisting of 3-6 staff members from a variety of academic disciplines and are headed by a course coordinator. Most planning groups also include one or two student members.

\section{Participant selection and inclusion}

Our study focused on educational leadership at course, bachelor and domain level. We purposefully invited course coordinators from each year I, 2 and 3 of the programmes to participate in an individual interview. We approached those course coordinators with the highest overall average ratings for the student course evaluation items about the 'learning effect', 'quality of organisation', 'quality of learning activities', and 'alignment of different parts of the course' in the 2017-18 and 
2018-19 academic years. In total, we invited 6 coordinators from year I. Furthermore, 10 coordinators from year 2 were invited since the curricula then offer more elective/specialisation courses. For year 3, 3 coordinators were invited since the curricula then include less obligatory courses and/or a thesis period. In addition to the 19 interviews with course coordinators $(\mathrm{N}=6$ or $\mathrm{N}=7$ per programme), the bachelor coordinators $(\mathrm{N}=3)$ and directors of education $(\mathrm{N}=3)$ were interviewed, resulting in a total number of 25 interviews; 9 female (36\%); 16 male (64\%). The participants were affiliated to 15 different departments. Table I provides further information on the participants.

Table I Background information on study participants

\begin{tabular}{l|c|c|c|c|c}
\hline Management level & \multicolumn{2}{c}{ Course } & \multicolumn{1}{c}{ Bachelor } & Domain ${ }^{\text {a }}$ & \multicolumn{2}{c}{ Total } \\
\hline Participant data & N & N & N & N & $\%$ \\
\hline Female & 6 & 2 & I & 9 & $36 \%$ \\
\hline Male & I3 & I & 2 & 16 & $64 \%$ \\
\hline Total & 19 & 3 & 3 & 25 & $100 \%$ \\
\hline Position & N & N & N & N & $\%$ \\
\hline Full Professor & 4 & 2 & 2 & 8 & $32 \%$ \\
\hline Associate Professor & 6 & I & I & 8 & $32 \%$ \\
\hline Assistant Professor & 4 & 0 & 0 & 4 & $16 \%$ \\
\hline Lecturer & 5 & 0 & 0 & 5 & $20 \%$ \\
\hline Educational background ${ }^{b}$ & N & N & N & N & $\%$ \\
\hline Biomedical/Basic sciences & 9 & 2 & I & 12 & $48 \%$ \\
\hline Social sciences & 7 & I & I & 9 & $36 \%$ \\
\hline Medicine & 3 & 0 & I & 4 & $16 \%$ \\
\hline Work experience & M & M & M & M & range \\
\hline Years in role & 3 & 5 & 5 & 3 & I-6 \\
\hline Years at institution & 25 & 20 & 29 & 25 & $11-39$ \\
\hline
\end{tabular}

\section{Represented Departments}

Anatomy and Embryology, Clinical Psychology, Epidemiology, Genetics \& Cell Biology, Gynaecology \& Obstetrics, Health Promotion, Health Services Research, Human Biology, Medical Microbiology, Nutrition \& Movement Sciences, Orthopaedics, Pathology, Psychiatry \& Neuropsychology, Skills lab, Social Medicine

a A domain covers multiple bachelor/master programmes

b Refers to undergraduate education of interviewees (basic/biomedical sciences e.g. refers to pharmacology, chemistry; social sciences e.g. refers to sociology, health Sciences).

$N$ Number of participants

M Mean 


\section{Research team and reflexivity}

The first author (GB) is an educational policy advisor who is also working as a part-time PhD candidate. He has cooperated with several of the interviewed staff members in quality management procedures. WG was responsible for interviewing all participants. $\mathrm{He}$ is an educational psychologist with a broad expertise in faculty development. WG took on the interviewing task not only because of his qualitative research experience, but also because of his relatively independent relation to the participants and programmes under study. In so doing, we intended to contribute to an open character of the interviews. The research team further consisted of two educational scientists with a focus on quality assurance (IW and DD), and a medical physiologist working as professor of medical education (ME). Two team members (IW and ME) hold senior management positions at the FHML Institute for Education (as vice-director and scientific director, respectively). We are aware that the experiences derived from our different roles and positions have shaped our perspectives. The diversity in our backgrounds however also helped us to broadly reflect on the data.

\section{Creation of vignettes and interview guide}

All participants were interviewed with the use of five vignettes. These vignettes were designed by the first author (and thereafter reviewed and approved by the other team members) based on previous quality culture research in medical schools. ${ }^{15}$ For four of the vignettes, a card that summarised the main concepts was provided. In the fifth vignette, main concepts were marked in bold. An interview guide developed by GB and WG supported the discussion of the vignettes (see Appendix). This guide was structured according to the "4-D" phases of appreciative inquiry. The interview guide also included a sensitising opening question on the study programme culture. To prevent social desirability bias from affecting results, we did not ask course coordinators to evaluate higher management in their own educational domain or vice versa. The vignettes and interview guide were tested by GB and WG in interviews with a former director of education and a former bachelor and course coordinator of FHML's Medicine programme. No changes to the vignettes were deemed required after the pilot interview sessions. Changes made to the interview guide were the incorporation of an open question on personal leadership style and an integration of the questions on the design and delivery stages of appreciative inquiry.

\section{Data collection and management}

All interviews (average duration 73 minutes, all held in Dutch) were conducted by WG. The audiotaped interviews were then transcribed verbatim and pseudonymised by $G B$. The audio files and interview transcripts were stored on GB's secured personal research drive (only accessible by the data manager of Maastricht University's School of Health Professions Education). To check for the adequacy of transcripts, all participants were asked to review these and provide their approval. After the participant's approval of the transcripts, the audio recordings were deleted. Participants during the transcript review stage could inform GB should they want to omit, alter or further explain transcript parts. Such changes or additions were made for five participants. An authorised translator ensured the quality of the selected quote translations from Dutch to English. 


\section{Data analysis}

Data were analysed via the six steps of thematic analysis as described by Braun and Clarke (see Figure I).$^{42}$ In the first step, GB transcribed the audio files in order to gain familiarity with the data. Please note that all interviewees have provided their written consent for GB's direct access to audio files. To ensure further anonymity, other team members did not have access to the audio files. GB and WG repeatedly read transcripts and marked salient quotes: a process already initiated during the data collection (simultaneous interviewing and transcribing) phase, in order for WG and GB to be able to discuss their first impressions. In the second step (code generation), GB and WG independently coded all interviews by means of a combined structured and open coding approach. The structured approach included coding of illustrative context examples per case (study programme), appreciative inquiry phases, and vignette themes. Simultaneous open coding allowed for a broader interpretation of the data. ${ }^{43}$ In the third step (theme search), GB and WG met to discuss, merge, and refine codes and identify subthemes. Subsequently, in the fourth step (theme review), the outcomes of the previous steps were shared with the full research team. The team members that had not been involved in the previous steps reviewed the selection of anonymised salient quotes that were clustered per case (a total of 186 quotes were reviewed). The subthemes identified by GB and WG were checked against these extracts and further refined based on group discussions. GB then checked whether the identified subthemes adequately covered the entire dataset. In the fifth step (defining themes), the team identified themes that overarched the cases based on subtheme agglomeration and cross-case comparisons. We did not identify particular subthemes that stood out in only one of the cases. Through several team discussions, we reached consensus on the interpretation of findings. In the sixth and final step (article writing), the team members contributed to the manuscript in various iterations. The analysis was supported by ATLAS.ti software application (version 8.3, GmbH, Berlin, Germany).

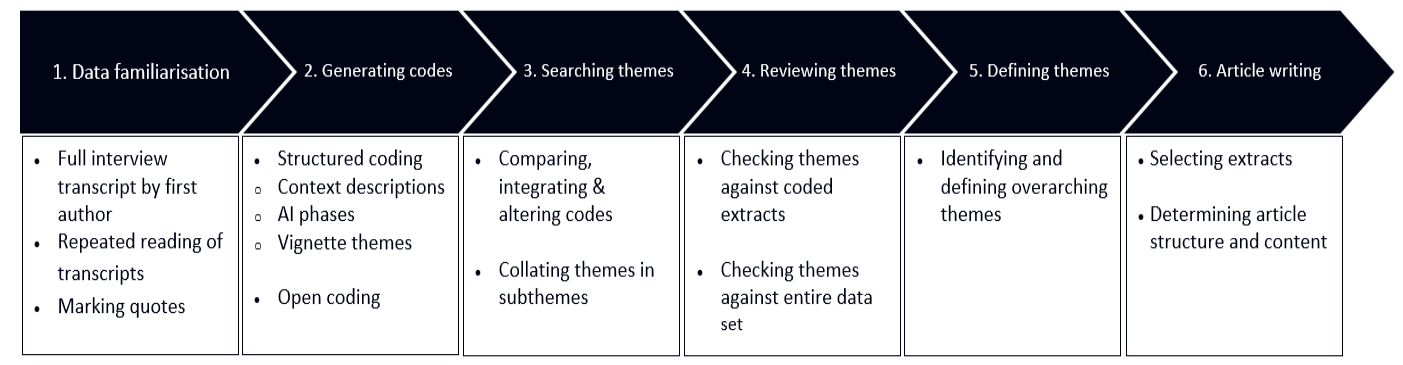

Figure I Six phases of thematic analysis (Based on Braun and Clarke. ${ }^{42}$ )

\section{Ethical considerations}

This study was approved by Maastricht University's Health Medicine and Life Sciences Ethical Review Committee (FHML-REC/2019/042). 


\section{Results}

Based upon the qualitative analysis, twelve themes were identified which are structured under the four phases of appreciative inquiry: I) Discover: stimulating expertise based selection and creativity, reinforce multidisciplinary learning, collect and act upon multisource feedback, 2) Dream: foster external perspectives for curriculum alignment, establish staff learning communities with and without students, enhance teacher appreciation and identity building, 3 ) Design: Implement longitudinal education roles, encourage peer coaching and interactive education, pay attention to quality of work experience, and 4) Destiny: intertwine departmental and educational HRM policies, invest in support and innovation networks, further educational leadership expertise (see figure 2).

It should be noted that themes described under the Dream and Design phases might already be present (to a limited degree) in the current situation, yet interviewees reported that these aspects should receive more emphasis to enhance the quality culture. Quotes of interviewees, included after each theme description, illustrate the findings. The quotes by bachelor coordinators and directors of education are presented as ' $P C^{n}$ ', which stands for programme coordinator, number I to 6 (randomly assigned for pseudonymisation purposes), whereas course coordinators are referred to as $\mathrm{CC}^{\mathrm{n}}$, and the cases are randomly coded as PI, P2, and P3.

\section{Discovering the best of what is - appreciating}

Stimulating expertise-based selection \& creativity

Interviewees explained that the benefits reaped from working in course planning groups build on expertise-based selection and room for staff to use this expertise in creative ways. A main area of leadership attention focuses on safeguarding that 'the right people are in the right place' to cover and deliver the content of the programme. An urge of staff to be involved in education that matches their professional interest was considered key to their motivation to engage in educational development. In addition, a sharing of interests and educational values served as oil for the motor of educational development. Leaders can encourage staff by letting them lead in their own competency domains:

"Linked to that [course theme], I started searching for the relevant people; those who were... yeah... very enthusiastic about it. I really noticed they were keen to contribute and were creative. The course is genuinely constructed and advanced based on their inner passion [...]. Yes, it strongly connects to their core expertise" $\left(\mathrm{P} 3, \mathrm{CC}^{\prime}\right)$.

"I put a lot of effort into inviting people to deepen their talents and deploy their passion. I try to offer them a lot of space in areas they feel challenged and competent in [...]. They are in the lead... they are in the lead" (P2, CC $\left.{ }^{2}\right)$. 
Reinforcing multidisciplinary team learning

Multidisciplinary teacher teams were seen as an important asset of education at FHML. According to respondents, collaboration and knowledge exchange within diversely composed planning groups (with senior and junior staff, multiple departments, and both genders represented) provided levers for team learning. The interviewees indicated that they particularly appreciated reflection with team members on development opportunities. As leaders, they also tried to optimise contributions of team members by sharing responsibilities, connecting different points of view, and fortifying joint efforts:

"Then you keep on developing... Just by asking questions [...], by engaging in this reflection cycle with the three of us and asking everyone 'what did you think of it, and how would you like to see it changed'? Then I offer them the leeway to do it that way and we can discuss afterwards, like: 'well, did it improve or not?'” $\left(\mathrm{PI}, \mathrm{CC}^{4}\right)$.

"I explicitly do not act as a hierarchical leader. I always ask members of the planning group for their input. It is something that is achieved through joint effort, also with a joint awareness that we must execute it in a good way. I am someone who shares responsibilities, someone who wants to connect people and engage them" $\left(\mathrm{P} 2, \mathrm{CC}^{\prime}\right)$.

Collecting and acting upon multisource feedback

A multitude of information sources is available through which coordinators collect feedback on educational quality (e.g. student review panels, tutors, lecturers, course evaluation surveys, accreditation committees, national surveys, etc.). Most coordinators expressed their appreciation for narrative and just-in-time feedback as opposed to quantitative evaluations. Additionally, participants emphasised the importance of conducting executive roles themselves. They felt that direct contact with students allowed them to receive richer information and feed forward. By being visible and approachable, coordinators collected informal feedback first-hand and were able to act on and react to evaluations more rapidly:

"There are numerous points of view, ranging from accreditation panels to staff members, from people in management positions to students. That is important: to bring these different perspectives together and try to at least maintain and preferably improve education continuously" $\left(P I, P C^{6}\right)$.

"The connecting element is often the autonomous nervous system. That was not sufficiently recognised by students. [...] You do not notice that yourself, until you meet them and ask for feedback. 'This is what we intended; did it land this way?' No, we didn't get that'. Well, then you do something about it" (P3, CC $\left.{ }^{3}\right)$. 


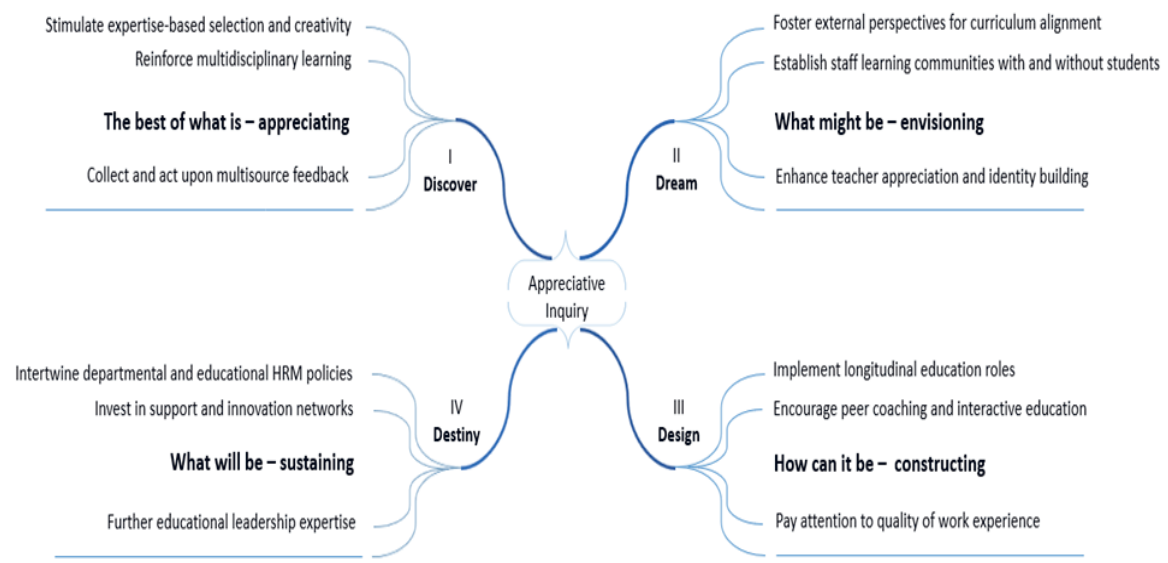

Figure 2 Overview of themes structured under the four phases of appreciative inquiry

The figure presents four interconnected phases of appreciative inquiry: energising and strength-based experiences (I-Discover) form foundations of the envisioned positive future (II-Dream). The vision can be operationalised through aligned actions (III-Design), while organisational strategies and policies support and sustain improvement actions in the longer run (IV-Destiny).

\section{Unveiling dreams - envisioning what might be}

Foster external perspectives for curriculum alignment

When asked how they envisaged the ideal situation, respondents referred to several present 'tensions'. One of these tensions concerned having an internal orientation (e.g. focusing on one's own course) versus an external orientation (taking in a broader perspective to improve alignment and quality of the whole programme). Moreover, the increased attention to an external perspective also related to flexibility and anticipating on dynamics outside the programme; to align with subsequent master programmes, the labour market and broader developments in academia and the society at large:

"That you know the content of all other courses... You should also be ready to change things within your own course to create that alignment [...]. Because course coordinators often do what they think is right, but that does not have to be aligned with what was already there or with what is happening in other courses" $\left(\mathrm{P} 3, \mathrm{CC}^{6}\right)$.

"You should have a way to... we have student evaluations...but what societal and research developments should we connect to and how do we translate these into course improvements? The reflex is to directly go from the evaluation to... perhaps you should build that [external perspective] into the course evaluation $\left(\mathrm{PI}, \mathrm{CC^{2 }}\right)$. 
Establish staff learning communities with and without students

A second tension experienced by the staff members we interviewed related to a focus on educational organisation and process aspects versus more content-based discussions on how to improve the programme. Building on their appreciation for peer collaboration, respondents envisioned the establishment of learning communities in which staff regularly meets to discuss personal experiences, challenges and exchange expertise. A staff dream was to also extrapolate the learning that already took place by the cooperation with students in planning groups to a broader level. By means of open and communication with students, staff-student learning communities could be created. The quotes below refer to both these communities:

"It's important that course coordinators see each other on a regular basis. That they tell each other about challenges they face. What goes well and what could be improved. That we learn from each other.That is very useful I believe [...] That is making use of the expertise of the [course coordinator] group" $\left(\mathrm{P} 3, \mathrm{CC}^{\prime}\right)$.

"You could very well ask a student: "Which teachers perform exceptionally well and why are these people exceptionally good?' 'What makes them better than someone else who is average or below average?'. [...]. We do take note of it, say 'great', but leave it at that. [...] We never ask, "how do you actually do that?"' (P2, CC4).

\section{Enhance teacher appreciation and identity building}

A third 'vision on what might be' relates to a tension in valuing research, healthcare, and educational roles. According to respondents, the appreciation for conducting teaching roles could be amplified to come to par with the appreciation of achievements in research. Interviewees verbalised that offering career tracks in education (and giving education an equal status to research) could endorse the teacher identity. Furthermore, respondents also related identity building to a sense of staff to contribute to and being part of a greater whole. The sharing of study programme successes could play a role in this:

"That people can make a career in education from the start. Often it is like: 'then you aren't good at research or something must have failed [...]'. That feeling is still present. I think you can only get this right by giving education and research the same status" $\left(P 2, P C^{2}\right)$.

"I think the sharing of successes. That you say, 'this is what we have achieved, in this way'. Yes, that would be a good thing. Rather than saying 'this is what I have achieved with course [...]', you say 'this is what we have achieved as a bachelor' (P3, CC $)$. 


\section{Designing how it can be - constructing}

\section{Implement longitudinal education roles}

The envisioned themes for further development are related to follow-up actions in the 'design' phase. Respondents indicated that fostering external perspectives for curriculum alignment could be put into practice by implementing longitudinal (or recurring) education roles. An example provided concerned the role of mentor. In this role, staff guide students during their study career which respondents deem valuable since they can follow and contribute to the student's development and at the same time gain in-depth knowledge of the programme. By creating a pool of teachers that conduct the role of tutor, trainer or planning group member for multiple years, the identification and support of the programme's mission can be strengthened as well. At the same time, regular job rotation (within such a fixed pool of staff in executive roles) was suggested to stimulate innovation:

"You receive a lot more feedback on the curriculum from students than you normally do... The students tell us 'this is what we faced' or 'that really was an excellent course'. I am not in that course... As a mentor, you learn way more about how the curriculum is actually constructed" (P3, $\left.P C^{3}\right)$.

"We have colleagues that also perform care tasks and have a background in clinical education. They can play an important part in skills trainings. We have the in-house expertise, but since roles are scattered it is difficult to secure sufficient trainers each year. [...] [In the planning group] we should perhaps move to a system with annual rotations, to exchange knowledge and expertise, but at the same time maintain the dynamics to innovate" $\left(\mathrm{PI}, \mathrm{CC}^{6}\right)$.

\section{Encourage peer coaching and interactive education}

The vision of establishing staff (-student) learning communities links to opportunities for peer coaching. For instance, respondents explained that new staff members could be guided by senior staff or 'buddies' who provide tips and act as a coach. Also in the context of courses, opportunities were identified to pair senior with junior staff in education activities. The interviewees further reported that establishing a learning community also depended on the creation of learning situations where staff and students benefit from small-scale interactive education (e.g. in small research projects). An increased interaction can be reinforced by longitudinal roles (the previous theme). Staff illustrated that opportunities for interaction with students formed an important motivator for them to teach:

“I can help this new person with tips. Like:'I wouldn't do that' or 'you should pay attention to that'.Try to transfer my expertise. Every tutor approaches the task in his or her own way. There isn't one absolute, good way, but you can exchange tricks and ... try to coach someone else" (P2, $\left(C^{5}\right)$. 
"There, education and research are closely linked, and we are thinking as a sort of mini team: 'how could we do this?'Then it is not about appreciation, but I get satisfaction out of the fact that I can do nice things [...].You suddenly see the student thinking: 'I know what it's about, great, and I can participate'! Then, education is very real" $\left(\mathrm{P} 3, \mathrm{CC}^{4}\right)$.

Pay attention to quality of work experience

The vision of enhancing teacher appreciation and identity building links to providing attention to the quality of work experience. Interviewees explained that leadership attention to the individual situation of staff forms a keystone to uphold the quality of work experience: some interviewed leaders already did this by taking into account talent development, stimulating learning on the job, and trying to prevent that teaching demands exceeded the manageable workload. This required that leaders invest in personal approaches to maintain connections with the teaching staff in executive roles:

"An element that seems to be neglected in the entire policy... seems to be neglected, is the quality of work and work experience [...] The entire subject of educational quality isn't seen in terms of human qualities and the quality of their work [...].The work they do should also produce quality for themselves so to say" $\left(\mathrm{PI}, \mathrm{CC}^{\prime}\right)$.

"That [conversation with individual teachers] resulted from the workload discussion... what is it that really matters to the individual teacher, what does he run into and what would he want in his teaching career? [...] I notice that teachers highly appreciate it when you sit down and talk with them about their individual situation" $\left(\mathrm{PI}, \mathrm{PC} \mathrm{C}^{4}\right)$.

\section{Fostering a sustainable destiny - what will be}

Intertwine departmental and educational HRM policies

Respondents explained that human resources management (HRM) policies are important to sustain attention to individual, team and collective (study programme) development. Interviewees mentioned that, to this end, recruitment, retention and promotion policies in departments should be intertwined with the faculty's strategic aims of education. Departments and programmes require leverage to link teaching, research and care tasks tailored to the capacities and ambitions of staff. Another important prerequisite to sustain development is that resources (budget and time) are protected for teachers and teacher teams to further education. Some respondents indicated that their department's policy to appoint several staff members that are dedicated $100 \%$ to teaching (these staff members hold a position fully based on their involvement in education), contributed to their dedication to grow:

“'What suits you now and what is your zone of proximal development?' [...] 'What are your opportunities for development and what constitutes your challenge?' [...] perhaps also alter 
periods; [Make sure] that 50/50 [research/education] is dispersed over multiple years, because sometimes there are research projects that need a lot of attention, but you still have to teach $50 \% "\left(P I, C C^{2}\right)$.

"I now have a full teaching allocation which gives me the chance to fully develop [...] I also think [they should] give space to people who are very committed to education and reward these people. That motivates. That [teacher] prize also motivated me to perform even better" $\left(\mathrm{P3}, \mathrm{CC}^{3}\right)$.

Invest in support and innovation networks

Interviewees mentioned that embedding innovation networks would allow educational leaders to stimulate innovation. Participants for instance pointed to trying out new educational approaches on a small scale in pilot projects which could later be transferred to a larger scale. Teacher network events were mentioned as supportive to peer learning. Moreover, the teaching coordinators stated that they profited from their investments in constructing an (informal) network with both academic and support staff. To facilitate networking, coordinators reflected that they would benefit from a physical proximity to teaching and support staff, which is a challenge in large programmes with staff from many different departments involved:

"By prototyping and trying things out you make a better version. We collectively discover what works and what does not [...]. A couple of times it did not work, but, still, we got a lot of information out of it. Next time, you come up with something else that does work. That is fun" $\left(P 2, P C^{\prime}\right)$.

"That you take a moment and start looking: 'where lies the expertise and who can you ask for that?' [...] That could be people from block support [...] or people from the planning department [...] That you know who are working for you and who are performing things for you, the practical training and lab supervisors, that you know who they are" $\left(P 3, P C^{3}\right)$.

Further educational leadership expertise

The interviewees reflected that educational leadership training is key to sustain good practices but also to continuously improve in their own role as leaders. The respondents explained that they did not necessarily gain their leadership positions because of their educational expertise: experience in education, job rotations, and commitment to educating future professionals set paths to leadership positions as well. According to respondents, the sustainability of future educational innovations and improvement actions would benefit from increased attention to feedback on educational leadership on different levels, through leadership development tracks and learning by means of co-leadership:

"A lot of research is done, and many new ideas are generated by you [department of educational research], but also outside this university. I would appreciate it if more attention 
would be paid to that. A refresher course for coordinators: 'these are new developments in the field, consider if you can use that'” $\left(P 3, C C^{2}\right)$.

"Leadership development does not receive the attention it deserves [...] I believe that, across the board, more attention could be paid to that. Nobody ever told me how to lead such a planning group. What is expected, and if you perform well in that sense. They do review the course, but they do not evaluate my functioning within the course" $\left(P 2, C^{\prime}\right)$.

\section{Discussion}

This study sought to increase insights into how a quality culture can be enhanced according to the experiences and perspectives of educational leaders. The findings highlight that peer learning in multidisciplinary teams and communities as well as attention to continuous professional development form the core of a quality culture. Leaders can play a key role in these spheres of capacity building by initiating learning across teacher networks, and providing room to staff to use their expertise while gradually increasing their responsibilities in education. Educational leaders indicated that attention to quality of work experiences, appreciating and rewarding staff teaching performance, and stimulating room for creativity, nurture quality culture conditions. Overall, the experiences and perspectives of interviewees strongly relate to human interrelations- and human resources as drivers of the organisational quality culture. An increased fit between leadership practices and preferences for educational and organisational development, HRM strategies, support \& innovation networks, and leadership training programmes is required to sustain a quality culture in HPE in the long run.

Typical strengths and visions for improvement found in our case study link to investments made in integrated, multidisciplinary courses and close staff, and staff-student interactions. Our findings furthermore resonate with research on conditions for positive teacher team performance. I.e. these conditions can be nurtured by stimulating co-creation, sharing responsibilities and decision making, and through the enhancement of psychological safety in teams by educational leaders. ${ }^{4-46}$ Leaders of educational programmes often cannot influence the broader organisational HRM policies, but if leadership efforts and HRM practices are not fully aligned (e.g. in staff recruitment and promotion policies), opportunities for HRM and leadership to act in synergy are not used to an optimal degree. ${ }^{47}$ Hence, strategic investments, incentives and accounting for the professional development of staff are needed to support the educational mission. ${ }^{48,49}$ Our study also underscores that a lot is still to be gained from levelling appreciation of education roles to roles in research and healthcare as this could allow for a more swift merger of professional identities..$^{50,51}$

It should be acknowledged that the curriculum integration approaches, longitudinal education roles, alternative reward structures and other forms of governance proposed by interviewees 
might form only part of the way to advance quality cultures in HPE. As organisations regularly change strategies and processes to adapt to changing circumstances, it can be argued that leadership, relationships, ownership and trust are at the heart of a quality culture, rather than strategies and systems. ${ }^{52}$ Agreements between educational leaders and academics that precede decision making, based on a reached state of shared educational principles, norms and values, could aid to adopt a quality culture and go beyond implementing quality strategies. ${ }^{53}$ Four main characteristics attributed to successful leadership are of the essence in this respect. Leaders can I) articulate inspiring visions for the future, 2) stimulate new ways of thinking, 3) attend to 'follower's' needs and concerns, and 4) act as a role model. ${ }^{54}$ For academics to become involved in quality culture enhancement, however, non-leader-centered approaches are also more required. Such approaches are characterised by interaction, a creation of trust, listening, a people focus, and a style of 'management by walking around'. ${ }^{55}$ Hence, non-leader-centered approaches do justice to the dependency of HEl individual staff contributions and their functioning as teams. In this study, we found multiple examples of distributed (but coordinated) leadership. ${ }^{56}$ Such approaches reflect a balanced quality culture that highlights opportunities to reach organisational goals, while taking individual staff aspirations into consideration to push or pull goals and quality improvement work into the desired direction.

Our findings underscore the importance of collective workplace learning and communities of practice. ${ }^{57,58}$ The good practices reported upon by interviewees surfaced where networking and a sharing of ideas were fostered. Leaders reported to be strongly embedded in such networks, which they also use to their benefit to create support for change. The finding that leadership is considered to influence quality culture enhancement indirectly, through networks and influencing values, is in line with studies that advocate a human relation orientation. 11,59 Their indirect influence explains why leaders may "resemble the abominable snowman whose

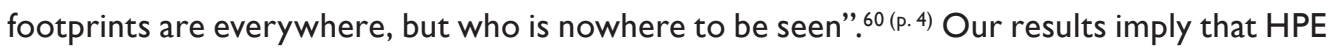
institutions benefit from those (leaders) who shift from a focus on isolated, role based actions of individuals to the influences of contexts on processes, behaviours, and outcomes. ${ }^{61}$ Leaders that are able to adopt a such a contextual perspective might be more inclined to recognise the importance of crossing boundaries of departments and subcultures in order to nurture a shared educational quality culture. These often are experienced staff members that possess the competencies to balance tensions (e.g. relating to internal control versus external dynamic demands) and use these tensions to drive improvement. ${ }^{62}$

This study adds to the field of quality culture and leadership research by including views from leaders working on different levels. In addition to their focus on human relations, leaders' experiences on quality culture enhancement encompassed management aspects and organisational structure issues. Rules, policies, procedures, and accountability, are also needed for a quality culture to take root. The balancing of structures and systems with staff values requires coalition building, negotiation and mediating for resources. ${ }^{63}$ We noticed that in the 
interviews, especially bachelor coordinators and directors of education mentioned the influential role of management structures, strategic issues and systems for accountability. The same holds for visions to enhance curriculum alignment. Course coordinators appeared to focus more on improvement of content and team learning aspects. These differences can logically be explained by role characteristics which range from more team-focused behaviours on course level to political and strategic behaviour on the overarching domain level. As competencies to use different frames of leadership add to the organisation's adaptability, it is worthwhile to offer training in domains HPE leaders are not that accustomed to. ${ }^{64,65}$ This is not to say that human relations approaches should be abandoned (on the contrary). However, training that allows (future) leaders to consider the wider context can fuel opportunities to eventually change these contexts, not only the individuals within it. In this sense, the legacy of HPE leaders for quality culture enhancement also entails the imprint they make at the end of their tenure by leaving many good leaders behind who can go even further. ${ }^{66}$

In addition to the gaps our study addresses, the added value of our research is to be found in the application of appreciate inquiry. So far, the use of this approach in HPE research is limited. ${ }^{40}$ Several participants expressed to value the focus on the positive and energising aspects our research method encompassed. The combination of appreciative inquiry with the use of vignettes aided to stimulate dialogue and reflection, which in a natural way led to the generation of insights and new ideas.

\section{Limitations}

The fact that this research is conducted in the setting of three study programmes offered within one organisation should be taken into account in the interpretation of the results. Our results are not necessarily generalisable or transferable to other populations or settings due to the relatively small sample size. The insights we gained are very relevant for hypothesis generation and further research on quality culture enhancement in HPE, but similar research in other organisations is required to further underpin our conclusions. A second limitation concerns the fact that our results represent self-reports and perceptions of educational leaders. In-depth questions on how interviewees experienced their own situation, and probes to illustrate these with examples and anticipated effects of organisational developments, aided to provide a truthful picture. Nevertheless, a triangulation on the experiences and perspectives of leaders and their qualities by students and/or other teaching staff members are required to gain a holistic perspective on quality culture enhancement and the specific contributions of leaders herein. A quality culture stresses the importance of a broad stakeholder feedback and involvement in order for improvement and innovation to thrive.

\section{Future directions}

Some of the main challenges of HPE institutions today lay in crafting curriculum alignment, fostering professional development of teaching staff and anticipating on external demands to 
continuously evolve. The results of this study reveal that these challenges should be addressed by placing human resources and interrelations central as the institution's greatest assets for quality culture enhancement. Educational leadership alone will not be sufficient to advance the quality culture. However, by focussing on networking, communication, and coalition building, leaders can stimulate the quality of study programmes to exceed the sum of their individual parts. Educational research and faculty development training that focus on learning leadership in context ('on the job'), with room for reflection on personal views, experiences, and competencies, are needed to remain fit for the future.

\section{Acknowledgements}

The author team wishes to thank the course coordinators, bachelor coordinators and directors of education who participated in this study. The first author in particular wants to thank Dries Berings (Catholic University of Leuven) and Gea van Zutven (Fontys University of Applied Sciences, $(\mathrm{NL})$ ) for several discussions that provided inspiration for this research, and Angelique van den Heuvel for her help in editing the manuscript. 


\section{Appendix Interview guide and vignettes}

\section{Opening question}

1. What are typical characteristics of the study programme culture $(1 / 2 / 3)$ ? For instance consider the way in which staff (collectively) engage in quality improvement of education.

\section{Good and inspiring practices}

2. How do you stimulate the situation as described in the vignette within your course/study programme? What is working well at this moment? What are good practices? What are your best experiences? What do you find most important? What do you value/appreciate most?

\section{Effect good and inspiring practices}

3. Do you notice in practice that the situation as described in the vignette has a positive effect on staff and attention to quality of education? (If so, how?).

\section{Vision on development}

4. Which aspects related to the vignette would you like to see further developed? How would the ideal future situation look like? Which situation or circumstances would you like to see changed?

\section{Creation / Sustainability}

5. In which way could you make the situation as described in the vignette concrete? What should be organised differently? Which resources are required?

\section{Leadership}

6. How would you describe your personal leadership style? What is the effect of your particular style?

7. Do you recognise the importance of 'integrative leadership' as described in the vignette? I am curious as to how you (could) put this to practice on the course/programme level. Could you elaborate on this?

\section{Closing question}

8. Are there good practices that you could not fit within one of the five themes? Did you miss a subject that is important for stimulating the development of a culture for continuous quality improvement? 


\begin{tabular}{|l|}
\hline Open systems perspective \\
\hline $\begin{array}{l}\text { - Openness and external } \\
\text { orientation }\end{array}$ \\
- Freedom to experiment \\
and innovate \\
- Internal and external \\
alignment \\
- Adaptivity, creativeness \\
\& flexibility
\end{tabular}

\begin{tabular}{|l|}
\hline Stakeholder involvement \\
\hline - Shared goal orientation \\
- Creation of support for \\
educational change \\
initiatives \\
- Balancing top-down and \\
bottom-up approaches \\
- Sharing best practices
\end{tabular}

\begin{tabular}{|l|}
\hline \multicolumn{1}{|c|}{ Valuing teaching and } \\
learning
\end{tabular}

\begin{tabular}{|c|}
\hline $\begin{array}{c}\text { Ownership and } \\
\text { accountability }\end{array}$ \\
\hline $\begin{array}{c}\text { - Professional autonomy } \\
\text { and peer support }\end{array}$ \\
- Constructive feedback \\
- Systematic evaluation and \\
improvement approaches \\
- Clear responsibility \\
structure
\end{tabular}

\section{Vignette I: Open systems perspective}

Within the course/programme, there is a lot of attention to formal and informal feedback with regard to quality of education. Coordinators have an 'external perspective' and feel free to experiment and innovate in education.

A characteristic of the course/programme is that attention is provided to internal alignment (within and between courses) and external alignment (with developments and demands from the field).

\section{Vignette 2: Stakeholder involvement}

Within the course/programme diverse stakeholders (students and staff members) are closely involved in (continuous) educational development. As a result, diverse scenarios, challenges and opportunities can be considered. Within the course/the programme, there is a lot of attention to the formulation and working towards a shared goal, expectancy management and obtaining support for educational innovation.

\section{Vignette 3: Valuing teaching and learning}

The attention and valuing of the quality of education within the course/programme stimulates the commitment of teachers. Staff members have a reflective attitude. The creation of a community (of teachers, but also between students and teachers) is being promoted. The development of staff members involved in education and students is a key topic of attention.

Vignette 4: balancing ownership and accountability

The planning group(s) of this course/within this programme have a lot of freedom and autonomy to develop education according to their own insights. Staff members have a strong sense of ownership and the freedom they have stimulates their motivation. Continuous improvement of education is seen as a shared task. At the same time, staff is aware of the importance of accountability procedures and educational evaluations. This involves making adequate agreements on responsibilities.

\section{Vignette 5: Reflecting on "integrative" leadership}

Previous research has suggested that integrative leadership in particular contributes to the further development of a quality culture. Integrative leadership refers to styles directed towards sharing responsibilities, the promotion of collaboration and connecting goals and ambitions of individual staff members, with goals aspired to by the study programme or organisation. 


\section{References}

I. Frenk J, Chen L, Bhutta, Z.A, et al. (2010). Health professionals for a new century: transforming education to strengthen health systems in an interdependent world. Lancet; 376: 1923-1958.

2. Blouin, D. and Tekian, A. (2018). Accreditation of medical education programs: Moving from student outcomes to continuous quality improvement measures. Academic Medicine; 93: 377-383.

3. Harvey, L., and Williams, J. (2010). Fifteen years of quality in higher education. Quality in Higher Education; 16: 3-36.

4. European University Association (2012). Examining Quality Culture Part III: From self-reflection to enhancement. Brussels: EUA.

5. Newton, J. (2000). Feeding the Beast or Improving Quality?: Academics' perceptions of quality assurance and quality monitoring. Quality in Higher Education; 6: 153-163.

6. Lomas, L. (2004). Embedding quality: The challenges for higher education. Quality Assurance in Education: An International Perspective; 12: 157-165.

7. Ehlers, U.D. (2009). Understanding quality culture. Quality Assurance in Education: An International Perspective; 17: 343-363.

8. European University Association (2006). Quality culture in European universities: A bottom-up approach. Report on the three rounds of the quality culture project 2002-2006. Brussels: EUA.

9. Bendermacher, G.W.G., oude Egbrink, M.G.A., Wolfhagen, I.H.A.P., and Dolmans, D.H.J.M. (2017). Unravelling quality culture in higher education: a realist review. Higher Education; 73: 39-60.

10. Blouin, D. (2019a). Quality improvement in medical schools: vision meets culture. Medical Education; 53 : II00-III0.

II. Blouin, D., Tekian A., and Harris, I.B. (2019b). Do organizational cultures of Canadian medical schools promote a quality culture? Medical Teacher; 4I: 662-667.

12. Ovseiko, P.V. and Buchan, A.M. (2012). Organizational culture in an academic health center: an explanatory study using a competing values framework. Academic Medicine; 87: 709-718.

13. Pololi, L., Kern, D.E., Carr, P., Conrad, P., and Knight, S. (2009). The Culture of Academic Medicine: Faculty perceptions of the lack of alignment between individual and institutional values. Journal of General Internal Medicine; 24: 1289-1295.

14. Al-Shehri, A.M. and Al-Alwan I. (2013). Accreditation and culture of quality in medical schools in Saudi Arabia. Medical Teacher; 35: S8-SI4.

15. Bendermacher, G.W.G., de Grave, W., Wolfhagen, I.H.A.P., Dolmans, D.H.J.M., and oude Egbrink, M.G.A. (2020). Shaping a culture for continuous quality improvement in undergraduate medical education. Academic Medicine; 95: 1913-1920.

16. Bland C.J. and Wersal L. (2002). Effective leadership for curricular change. In: Norman G.R. et al. (eds) International Handbook of Research in Medical Education. Springer International Handbooks of Education, vol 7. Springer, Dordrecht

17. Cantillon, P., D'Eath, M., De Grave, W., and Dornan, T. (2016). How do clinicians become teachers? A communities of practice perspective. Advances in Health Sciences Education; 21: 991-1008.

18. Lieff, S. and Albert, A. (2012). What do we do? Practices and learning strategies of medical education leaders. Medical Teacher; 34: 312-319.

19. Bordage, G., Foley, R., and Goldyn, S. (2000). Skills and attributes of directors of educational programmes. Medical Education; 34: 206-210.

20. Sandhu, D. (2019). Healthcare educational leadership in the twenty-first century. Medical Teacher; $4 \mathrm{I}$ : 148-618.

21. McKimm, J. and Lieff, S.J. (2013). Medical education leadership (In: Dent, J., Harden, R.M. \& Hunt, D. (Eds.) A practical guide for medical teachers (pp. 343-35I). London: Churchill Livingstone-Elsevier).

22. Velthuis, F.,Varpio, L., Helmich, E., Dekker, H., and Jaarsma, D. (2018). Navigating the complexities of undergraduate medical curriculum change: change leaders' perspectives.Academic Medicine; 93: 1503-15I0.

23. McKimm, J. and O'Sullivan, H. (2016). When I say ... leadership. Medical Education; 50: 896-897. 
24. Uhl-Bien, M. (20I4). Followership theory: a review and research agenda.The Leadership Quarterly; 25:83-I04.

25. Kottman, A., Huisman, J., Brockerhoff, L., Cremonini, L., and Mampaey, J. (2016). How can one create a culture of quality enhancement? Center for Higher Education Policy Studies (CHEPS), University of Twente, The Netherlands.

26. Scott, G. Coates, H., and Anderson, M. (2008). Learning leaders in times of change. Academic Leadership Capabilities for Australian Higher Education. University of Western Sydney and Australian Council for Educational Research.

27. Bryman, A. (2007). Effective leadership in higher education: A literature review. Studies in Higher Education; 32: 693-710.

28. Lieff, S.J. and Yammarino, F.J. (2017). How to lead the way through complexity, constraint and uncertainty in academic health science centers. Academic Medicine; 92: 614-62I.

29. Mohelska, H. \& Sokolova, M. (2014). Organisational culture and leadership-joint vessels? Social and Behavioral Sciences; 171: 1011-1016.

30. Harvey, L. and Stensaker, B. (2008). Quality culture: Understandings, boundaries and linkages. European Journal of Education; 43: 427-442.

31. Uhl-Bien, M. (2006). Relational leadership theory: exploring the social processes of leadership and organizing. The Leadership Quarterly; 17: 654-676.

32. Hallinger, P. (2018). Bringing context out of the shadows of leadership. Educational Management Administration and Leadership; 46: 5-24.

33. Dopson, S., Ferlie, E., McGivern, G., Fischer, M.D., Mitra, M., Ledger, J. \& Behrens, S. (2019). Leadership development in higher education: A literature review and implications for programme redesign. Higher Education Quarterly; 73: 218-234.

34. Bolden, R., Gosling, J., \& O'Brien, A. (2012). Academic leadership: Changing conceptions, identities and experiences in UK higher education. London: Leadership foundation for higher education.

35. Bland, C.J., Starnaman, S., Wersal, L., Moorhead-Rosenberg, L., Zonia, S., and Henry, R. (2000). Curricular change in medical schools: how to succeed. Academic Medicine; 75: 575-594.

36. Bitektine, A. (2008). Prospective case study design: Qualitative method for deductive theory testing. Organizational Research Methods; II: 160-180.

37. Bernabeao, E.C, Holmboe, E.S, Ross, K, Cheskuk, B., and Ginsburg, S. (2013). The utility of vignettes to stimulate reflection on professionalism: theory and practice. Advances in Health Sciences Education; 18: 463-484.

38. Stake, R.E. (2008). Qualitative case studies (In Denzin, N.K. \& Lincoln, Y.S. (Eds.), Strategies of qualitative inquiry (3rd ed., pp. I19-150). Thousand Oaks, CA: Sage.

39. Cooperrider, D.L. and Whitney, D. (1999). Appreciative inquiry: A positive revolution in change. Published in Cooperrider, D.L., Whitney, D. (1999) (Holman, P., Devane, T., Eds.). San Francisco, CA: Barrett-Koehler Communications, Inc.

40. Sandars, J. and Murdoch-Eaton, D. (2017). Appreciative inquiry in medical education. Medical Teacher; 39 : 123-127.

4I. Stavros, J.M, Godwin, L.N., and Cooperrider, D.L. (2015). Appreciative inquiry: organization development and the strengths revolution (In: Rothwell, W.J., Stavros, J., \& Sullivan, R.L. (Eds.) Practicing organization development: leading transformation and change (chapter 6). New York: Wiley and Sons).

42. Braun, V. and Clarke, V. (2006). Using thematic analysis in psychology. Qualitative Research in Psychology; 3: 77-10I.

43. Saldana. J. (20I3). The coding manual for qualitative researchers (London: Sage).

44. Meeuwissen, S., Gijselaers, W., Wolfhagen, I.H.A.P. \& oude Egbrink, M.G.A. (2019). How teachers meet in interdisciplinary teams. Academic Medicine (in press). DOI I0.1097/ACM.0000000000003II5.

45. Meeuwissen, S.N., Gijselaers, W.H., Wolfhagen, I.H. \& oude Egbrink, M.G.A. (2020). When I say... team learning. Medical Educaction; 54: 784-785.

46. Koeslag-Kreunen, M.G.M., Van der Klink, M.R., Van den Bossche, P., and Gijselaers, W. (2018). Leadership for team learning: the case of university teacher teams. Higher Education; 75: 191-207.

47. Leroy, H., Segers, J., van Dierendonck, D., and den Hartog, D. (2018). Managing people in organizations: 
Integrating the study of HRM and leadership. Human Resource Management Review; 28: 249-257.

48. Love, L.M., Haggar, F.L., McBrien, S.B., Buzalko, R.J., Hartman, T.L., Shope, R.J., and Beck Dallaghan, G.L. (2018). Supporting the professional identity of medical science educators: Understanding faculty motivations for quality improvement in teaching. Medical Science Educator; 28: 655-665.

49. Engbers, R., Fluit, C.R.M.G., Bolhuis. S., de Visser, M., and Laan, R.F.J.M. (2017). Implementing medical teaching policy in university hospitals. Advances in Health Sciences Education; 22: 985-1009.

50. Hall, P. (2005). Interprofessional teamwork: Professional cultures as barriers. Journal of Interprofessional Care; SI: 188-196.

5I. Thomas, L.R., Roesch, J., Haber, L., Rendon, P., Chang, A., Timm, C., Kalishman, S., and O'Sullivan, P. (2020). Becoming outstanding educators: What do they say contributed to success? Advances in Health Sciences Education (in press). DOI 10.1007/s 10459-019-09949-7.

52. Kezar, A. (2004) What Is More Important to effective governance: Relationships, trust, and leadership, or structures and formal Processes? New Directions for Higher Education; 127: 35-46

53. Stensaker, B., and Vabø, A. (2013). Re-inventing shared governance: Implications for organisational culture and institutional leadership. Higher Education Quarterly; 67: 256-274.

54. Siangchokyoo, N. Klinger, R.L. and Campion, E.D. (2020). Follower transformation as the linchpin of transformational leadership theory: A systematic review and future research agenda. The Leadership Quarterly; 31: I-18.

55. Knight, P.T. and Trowler, P.R. (2000). Department-level cultures and the improvement of learning and teaching. Studies in Higher Education; 25: 69-83.

56. Mehra, A., Smith, B.R., Dixon, A.L., and Robertson, B. (2006). Distributed leadership in teams: The network of leadership perceptions and team performance. The Leadership Quarterly; 17: 232-245.

57. Elmberger, A., Björck, E., Liljedahl, M., Nieminen, J., and Bolander Laksov, K. (2019). Contradictions in clinical teachers' engagement in educational development: an activity theory analysis. Advances in Health Sciences Education; 24: 125-140.

58. Cruess, R.L., Cruess, S.R., and Steinert, Y. (2018). Medicine as a community of practice: Implications for medical education. Academic Medicine; 93: 185-191.

59. Bendermacher, G.W.G., oude Egbrink, M.G.A., Wolfhagen, I.H.A.P., Leppink, J., and Dolmans, D.H.J.M. (2019). Reinforcing pillars for quality culture development: a path analytic model. Studies in Higher Education; 44: 643-662.

60. Bennis, W. G. and Nanus, B. (1997). Leaders: The strategies for taking charge. Cambridge, MA: Harvard Business Review Press.

6I. Lichtenstein, B.B., Uhl-Bien, M., Marion, R., Seers, A., Orton, J.D., and Schreiber, C. (2006). Complexity leadership theory: An interactive perspective on leading in complex adaptive systems. Emergence: Complexity and Organization; 8: 2-12.

62. Hill, F. and Stephens, C. (2005). Building leadership capacity in medical education: developing the potential of course coordinators. Medical Teacher; 27: 145-149.

63. Bolman, L.G. and Deal. T.E. (2003). Reframing organizations. Artistry, choice, and Leadership (third ed.). San Fransisco, CA: Jossey-Bass.

64. Sasnet, B. and Clay, M. (2008). Leadership styles in interdisciplinary health science education. Journal of Interprofessional Care; 22: 630-638.

65. Bearman, M., Tai, J., Kent, F., Edouard, V., Nestel, D., and Molloy, E. (2018). What should we teach the teachers? Identifying the learning priorities of clinical supervisors. Advances in Health Sciences Education; 23: 29-4l.

66. Fullan, M. (2005). Leadership and sustainability. Thousand Oaks, CA: Corwin Press. 


ChapterVI

Discussion 


\section{Quality culture: a new area in higher education policy and research}

Quality management strategies have gained an indelible place on the agenda of higher education institutions (HEls). However, the contributions of these strategies to the actual improvement of education have increasingly been contested.' There is a growing awareness that quality management approaches alone do not suffice to improve the quality of teaching and learning. ${ }^{2}$ Investments in quality management might even have counterproductive effects, since 'managerialism' tends to emphasise control and accountability, which may clash with staff preferences for flexibility and autonomy. ${ }^{3,4}$ In response to this critique, the concept of quality culture has been introduced in HEl's policy and research. ${ }^{5-7}$ According to this notion that is very much in vogue today, to attain quality we should nurture two dimensions: a structural/managerial dimension with defined processes, including coordinated individual improvement efforts, and a cultural/psychological dimension of shared quality values, beliefs, and expectations. ${ }^{5}$ When wellaligned, values that relate to educational quality, and quality management approaches, are expected to lead to educational improvement in synergy. ${ }^{8}$

Alongside this enhanced attention to quality culture, governance philosophies (mainly in the West) have started to place more trust in HEls' capacities to embed approaches to safeguard quality. ${ }^{9}$ Moreover, continuous improvement of education is expected to be driven by distinctive institutional ambitions, and a sound involvement of stakeholders. ${ }^{10} \mathrm{HEls}$ already possess some form of quality culture, thus initiatives to foster it do not start from scratch. Existing quality cultures are grounded in conceptions of staff members and in improvement practices that relate to disciplinary, departmental, or programme-specific traditions. ${ }^{11,12}$ What is new in bringing quality culture to the forefront of policy and research is that such endeavour is aimed at initiating change and organisational development. Despite the positive connotation attached to quality culture, however, there is a lack of insight in what its most important elements are. ${ }^{13,14}$ Hence, just as management structures in HEls have increasingly become alike,' likewise research must seek to paint a congruent picture of the institutional characteristics, values, motivating factors and behaviours that support improvement.

\section{A recap and contemplation of the main findings of this dissertation}

The overarching aims of this dissertation were to: I) explore the most important features of a quality culture and investigate their interrelationships; and 2) provide insights into how a culture of continuous educational quality improvement can be promoted.

Our literature review (Study I) served to identify the key constituents of a quality culture. To allow institutions to work on quality improvement, strategies, policies, procedures, responsibilities and the instalment of evaluation systems are considered basic structural/managerial requirements. On the other hand, shared values, a focus on innovation and flexibility, and human relations, are 
regarded key cultural/psychological quality culture features. The literature review demonstrated that leadership and communication play a crucial binding role. Leaders act as central 'drivers' of quality improvement efforts through resource allocation, clarification of roles and responsibilities, creation of partnerships and motivating of staff members. Communication is essential to distribute quality improvement strategies, evaluation outcomes, responsibilities, and good practices. The literature review brought forward empirically supported claims that staff knowledge, empowerment, ownership and commitment are associated with staff/student learning and development outcomes, staff/student satisfaction, and improvement of educational processes. Although some authors have argued that quality cultures are contextually dependent, ${ }^{15-17}$ we were able to identify several aspects that quality cultures have in common; these findings tie in with other subsequent studies that flagged participation, a mutual value orientation, trust and responsibility structures as key quality culture features, ${ }^{6,7,18}$ and with earlier studies that advocate for the key role of leadership and communication. 5,19,20

A path analytic model (Study 2) served to explore the interrelations between organisational context features, work-related psychological attitudes, and quality improvement practices. Rational goal values (emphasising planning, goal attainment and efficiency) were found to directly affect these practices. Moreover, the path analysis revealed that human relation values (e.g. collaboration, concern for staff morale and involvement) influenced empowerment, commitment and - albeit indirectly - ownership. In turn, ownership leads to increased contributions to improvement efforts. Positive work-related psychological attitudes should be considered just as important in their own right, since they are postulated to predict extra efforts by staff, beyond their formal tasks, for the good of the organisation. ${ }^{21-23}$ Commitment, empowerment and ownership were also likely to impact informal approaches to improve education (i.e. approaches that were not captured by our path model). ${ }^{24} \mathrm{~A}$ number of recent quality culture studies indeed revealed that relations (either direct or indirect) exist between quality culture features such as commitment, involvement and ownership and positive outcomes such as job satisfaction, increased responsiveness, attention to process management and, in general, a better overall organisational performance..$^{25-28}$

The subsequent two studies explored ways to enhance a quality culture. Five themes were constructed (in Study 3) representing staff and student views on quality culture features in relation to the Plan-Do-Check-Act cycle: I) fostering an open-systems perspective, 2) enlarging stakeholder involvement, 3) valuing teaching and learning, 4) balancing ownership and accountability, and 5) being devoted to integrative leadership. Tensions or competing values were found across four themes: flexibility for change vs stability for effectiveness, bottom-up vs top-down initiatives, intrinsic and extrinsic staff motivators and a focus on professional autonomy vs control. Balancing organisational tensions and competing values, however challenging, provides levers to learn and develop. ${ }^{29-30}$ Hence, by introducing different approaches to address quality, diverging value orientations variously affect effectiveness criteria. HEls need these multiple orientations to be able to react to contextual changes. ${ }^{31}$ 
Leaders can contribute to quality culture enhancement by wielding their assertive, participative and value-influencing behaviours to address the said competing values and tensions. ${ }^{32}$ The findings of Studies 3 and 4 show that leaders do this by promoting collaboration, by creating a supportive communication climate, by stimulating new ways of thinking based on appealing visions, and by paying attention to staff's individual concerns and quality of work experience. The members of quality advisory committees and educational leaders pointed out that we need open-systems perspectives to fuel innovation and to bring study programmes into better alignment. In addition, valuing teaching and learning was seen as a driver of educational quality improvement efforts. This finding bears similarities to current growing ambitions across European universities to review and reconsider academic recognition and reward systems and to work towards a larger appreciation for education. ${ }^{33}$

Our studies led us to conclude that we need a closer fit between strategies for innovation, staff development and supportive networks. Investing in the selection and training of educational leaders would be an important step in this direction. Moreover, a larger emphasis on human capital and interrelations is needed. The furthering of human resources management, especially in areas of competency and educational career building, will contribute to the sustainability of HEls' improvement capacity. ${ }^{34}$ Communities of practice could also help to catalyse individual and collective learning, peer support and HEls' innovation potential. ${ }^{35}$ In attempting to sail from the status quo to an enhanced quality culture, HEls should pay attention to the following three main areas: the connection between quality structures and values, the relation between quality, culture and change, and educational leadership development. These three topics will be further discussed in the following paragraphs.

\section{Walking the quality structure - quality values tightrope}

The structural/managerial and cultural/psychological dimension of a quality culture form a tightrope that stakeholders in HEls have to walk while maintaining balance. Students, academics, managers and support members hold different views on 'quality' and its aspects that should be promoted; their commitment to quality depends on whether quality management efforts focus on the quality attributes they deem important. ${ }^{36}$

Many studies on quality culture in $\mathrm{HEl}$ (including the studies in this dissertation) take the quality culture definition that is formulated by the European University Association as a point of departure. The statement that in addition to a structural/managerial dimension, a cultural/ psychological dimension contributes to 'quality culture' might come across as tautological. In this respect, the added value of the approach adopted in this dissertation, to relate quality culture to theory on subcultures and competing value orientations in organisations, becomes apparent; within an institute multiple cultures coexist, which are overlapped by an educational quality culture. ${ }^{29,31}$ Yet, dividing quality culture into two main dimensions can be helpful to analyse the concept. It is of note that the two dimensions are not purely self-contained. More 
specifically, structural approaches include elements of assessment/evaluation and accountability, but also serve learning and development aspirations. Existing organisational values that are internally and control-oriented, on the other hand, reflect a preference for structures, stability, planning and procedures.

There is a wealth of literature that criticises quality management implementation in HEls. e.g. ${ }^{37-41}$ The respondents in our research on quality management practices, however, held quite positive views. According to these stakeholders, structural and managerial approaches were indispensable to increase awareness of teaching quality issues. In contrast, there was less agreement among the study subjects on the contributions of quality management processes to innovation, experimentation and actual educational improvement. Rather, they felt that shared educational values, self- and shared reflections, team collaboration, and commitment to education were more important in their efforts to learn and develop than were formal processes. A reason why quality management fails to deliver its potential in improving education might be that instruments lack information on contexts, emergent processes, and the achievement of intended learning goals. For staff concerned with educational improvement, however, such information is essential. Hence, ideally evaluations should not only assess whether a programme worked, but also how it worked, why it did or did not work and what (else) happened. ${ }^{42}$

Academics are generally supportive of evaluations that include constructive feedback for continuous educational improvement. ${ }^{43}$ Cognitive exercises that stimulate dialectical thinking (to handle seeming contradictions and inconsistencies in organisations) could help stakeholders to disclose their core values and work on solutions that better align values and procedures. ${ }^{16}$ Moreover, by empowering teaching staff to co-design quality management approaches, their involvement in these practices might be further increased. Open and tailored evaluation formats, that are complemented with an open dialogue, can help to re-shift the focus from 'whether things are being done well', to 'whether the right things are being done'. ${ }^{44}$ The participants in our studies regularly referred to staff 'openness' and 'boundary crossing' as important determinants of creativity and improvement. A challenge lies ahead for HEls to nurture these attitudes and thereby move from organisational stability and incremental improvement (single-loop learning) to flexibility and changing underlying decision-making principles, if so required, for the enhancement of education (double-loop learning). ${ }^{45}$

\section{Quality, culture and change}

As described in the Introduction to this dissertation (Chapter I), the topics of 'quality' and 'quality culture' in higher education are elusive, since the way in which they are interpreted depends on the points of view of the stakeholders concerned. These different perspectives make it hard to address quality and quality culture. It seems relevant to address educational issues from a linear perspective (the structural/managerial dimension of a quality culture), as -assuming that an institution is able to accurately diagnose emerging problems-this would offer 
a straightforward response to existing shortcomings. ${ }^{46}$ In practice, however, issues of quality in higher education tend to have multiple causes which are difficult to pinpoint and are hard to tackle since they relate to complex, social issues. ${ }^{47}$ The four studies we conducted underscored the need to shift the emphasis from formal definitions and quality management approaches towards context-dependent discussions and deeper understandings of quality determinants. In other words, to identify adequate strategies for quality improvement, HEls must first seek to identify and interconnect the priorities of stakeholders.

It was also pointed out that quality culture enhancement requires HEls to become more flexible, open, and change oriented. However, HEls accommodate strong subcultures that typically embrace quality improvement practices only if these resonate with their own perspectives and ambitions. ${ }^{48}$ It is important to realise that quality improvement is foremost future oriented, but staff's improvement perspectives and abilities are shaped by existing concepts, values and norms. This is where a dilemma surfaces: learned concepts, values, and norms are likely to have positive effects, but might lead to a situation where improvement is only habit driven and imitative, rather than rationally driven and outcome focused. ${ }^{49}$

Our studies suggest that HEls would benefit from opening new lines of communication that address quality issues and stimulate individual learning, shared learning, and organisational action. ${ }^{50}$ The improvement capacity of HEls is reliant on stakeholders that come together to review existing practices, consider new knowledge, and revise definitions of quality issues. ${ }^{51}$ Such get-togethers can lead to new conceptual concepts, and alternative values and norms. Moreover, they can contribute to an increased awareness that to cope with the dynamic demands in their environment, HEls need approach improvement from a systems perspective. ${ }^{52}$ Educational leadership plays an essential role in nurturing the learning conditions that relate to educational quality, existing subcultures, and organisational change.

\section{Furthering educational leadership development}

Insights into the influence of leadership on quality culture have appeared difficult to transfer to higher education, due to the complexity of this particular setting. ${ }^{32,53,54}$ Consistent with other studies in the domain of academic health professions education, our findings suggest that the significance of leadership is manifested in shared, collaborative and distributed instead of 'strong' or 'heroic' leadership approaches. ${ }^{55,56}$ Although all our studies suggest that leadership is an important constituent to quality culture, a large part of the influence of leaders seems to be exerted in indirect or covert ways.

It can be argued that the importance of 'horizontal' leadership in health professions education originates from the bounded authority that leaders have. Although educational leaders have received an external, formal mandate from higher management, they also need an internal, informal mandate from the teachers they work with. ${ }^{57}$ The internal mandate in particular 
deserves further cultivation, since learning and development in HEls is largely dependent on the participation of academics in change and improvement processes. ${ }^{58}$ The results of our studies imply that leaders require support to obtain and reinforce their internal mandate. I.e. as one educational leader stated: "leadership development does not receive the attention it deserves [...] more attention could be paid to that. Nobody ever told me how to lead such a planning group, what is expected, and if you perform well". Leadership development approaches would ideally address dilemma's concerning educational quality, subcultures, and organisational change. ${ }^{59}$ These dilemma's involve choices to use a directive approach or provide leeway, to stimulate top-down or bottom-up improvement, to balance internal and external perspectives, and to be a visionary, while leaving room for involvement. Such matters require leaders to stimulate dialogue and take into account specific contexts.

HEI policies appear to hamper leader's opportunities to allot positive incentives to staff members who carry out tasks in a successful manner. ${ }^{60}$ In addition, professional development for quality culture enhancement, implies a larger attention to human resources management for educational (leadership) positions. ${ }^{61}$ An eye should be kept on the fact that demands on academics to keep abreast with what is happening in their discipline are already overwhelming. ${ }^{62}$ Professional development of teachers and educational leaders therefore seems best served by approaches that are situated in disciplinary and local contexts. Departmental education coordinators could play an important role as 'brokers' that match staff interests, ambitions of study programmes, and strategies for continuous improvement. To support this role, closer links between departmental and programme policies are required.

\section{Methodological strengths and limitations}

Various methodological strengths and limitations inherent to the performed research should be considered. A first strength is that all the studies we conducted are theoretically wellembedded. To disentangle quality culture, insights from the organisational sciences, e.g. 29-31 organisational psychology, e.g. 29-31 approaches to quality management, e.e. 2,4,17 and topical studies that argued for quality culture enhancement, e.g. $13,15,63$ served as points of departure. Whereas the quality culture concept had hitherto been mainly approached from a political and educational policy perspective, our studies used insights from different scholarly fields. In addition to departing from the perspectives offered by the literature, our studies contributed in their own ways to the further development of theory on quality culture in higher education.

A second strength is the innovative character of this dissertation. More specifically, our studies were among the first to empirically research quality culture. The dissertation travels from quality culture theory, to in situ perspectives on the phenomenon. We applied a combination of complementary approaches: a literature review, quantitative, and qualitative studies. The use of methods such as a 'realist review' (Study I) and 'appreciative inquiry' (Study 4) are relatively rare in higher education and could serve as examples to other researchers in the field. ${ }^{64,65}$ 
A third strength is that we incorporated perspectives of various stakeholders. Our literature review included articles in which data derived from staff, students and policy makers were included. Additionally, we involved student \& staff representatives that act in an advisory capacity on the organisational 'meso' level, and educational leaders who are working on different hierarchical levels (the latter has also seldom been done in higher education research). ${ }^{66}$

One of the limitations of this dissertation is that the data for three studies were gathered in universities offering health professions education in the Netherlands. The context features of Dutch academic education have therefore influenced the findings. For example, Maastricht University (UM), where we conducted two particular studies, is characterised by multidisciplinary staff collaborations, thematically structured curricula, and small staff-student distances due to the Problem-Based Learning format in place. These characteristics might be present in a less explicit manner in other HEls. Furthermore, the setting of health professions education is distinct from other settings since a substantial number of staff members are involved in potentially interfering research, education and healthcare tasks. Some caution should therefore be taken to overgeneralise findings to other settings.

A second important limitation is that the dissertation's results are mainly based on self-reports. Although experiences and perceptions are a direct source of information and are very relevant in organisational culture research, they might not entirely reflect institutional reality due to a social desirability bias. Another implication of this limitation is that our research did not incorporate comparative or outcome measurements of the impact that quality culture enhancement has on educational improvement: the studies refrained from making a 'hard' (quantitative) evaluation of quality culture benefits.

\section{Suggestions for further research}

To address the limitations of this dissertation, we offer several recommendations for future studies. First, we invite researchers to capture insights into quality cultures not only across institutions but also internationally. Moreover, studies that include multiple educational domains and involve other stakeholders (e.g. student and teacher populations at large, administrative staff, labour market representatives) can enrich our knowledge on quality culture(s). Furthermore, studies that explicitly relate quality culture features to outcome measures would justify investments in quality culture enhancement by providing evidence of their beneficial effects. Quality culture(s) could be related to measures of student and staff satisfaction or results of external programme reviews. Lastly, we welcome additional studies into whether and how staff and staff-student interactions affect quality cultures. A social network analysis of staff members involved in educational improvement and/or longitudinal observation studies (e.g. on team learning and staff-student community building) could advance our understanding of the organisational conditions that stimulate important contributors to quality culture enhancement, such as boundary crossing and peer learning. 


\section{Practical implications}

This dissertation contributes to higher education research and policy advancement in several ways. First, our studies provide support for the theory that there's more to working on educational quality improvement than merely implementing quality systems and processes. Although frequently made, this presupposition has lacked empirical support. ${ }^{57}$ The results suggest that, to make quality improvement work, a shift is needed from accountability and control towards more trust in professional expertise and enhanced professional ownership. Efforts to shape continuous improvement should be based on a dialogue between students, teaching staff and the management. If future improvement approaches are aligned with staff and students' quality values, it is more likely that the most pressing issues impacting quality will be addressed and that evaluations will be adequately acted upon. ${ }^{67}$

The finding that human relation values enhance positive work-related psychological attitudes implies that HEls should invest more in HRM strategies. The need for more appreciation for teaching and learning stood out as a key quality culture element in this research; yet, it has not been sufficiently institutionalised. ${ }^{68,69}$ Adapting educational policies and practices to incorporate more appreciation of educational achievements and experience could serve as stimuli for staff development. The expanded emphasis on shared educational quality values, collectiveness, interrelatedness and peer learning, can be combined with ambitions to further internal and external alignment (in line with an open systems perspective). In this respect, the findings also highlight collective workplace learning and the establishment of communities of practice which foster the exchange of expertise and ideas for educational innovation. ${ }^{70}$

More attention should be paid to strengthening the competencies of today's and tomorrows' educational leaders. Leadership development goes hand in hand with quality culture enhancement, provided such endeavours include reflection processes, expertise and knowledge sharing and ways to nurture teacher team safety and trust relations, besides stimulating contextual awareness. ${ }^{71-74}$ Educational leaders would benefit especially from training in systems thinking, team learning, and decision making based on a situational sensitivity. ${ }^{75}$ 


\section{References}

I. Harvey, L. and Williams, J. (2010). Fifteen years of quality in higher education (Part Two). Quality in Higher Education; 16: 81-II3.

2. Kleijnen, J., Dolmans, D., Willems, J., and Van Hout, H. (2012). Does internal quality management contribute to more control or to improvement of higher education? A survey on faculty perceptions. Quality Assurance in Education; 19: 141-155.

3. Davies, J., Douglas, A., and Douglas, J. (2007). The effect of academic culture on the implementation of the EFQM excellence model in UK universities. Quality Assurance in Education; I5: 382-40I.

4. Horine, J.E. and Hailey, W.A. (1995). Challenges to successful quality management implementation in higher education institutions. Innovative Higher Education; 20: 7-17.*

5. European University Association (2006). Quality culture in European universities: A bottom-up approach. Report on the three rounds of the quality culture project 2002-2006. Brussels: EUA.

6. Alzafari, K. and Kratzer, J. (2019). Challenges of implementing quality in European Higher Education: an expert perspective. Quality in Higher Education; 25: 26I-288.

7. Hildesheim, C. and Sonntag, K (2019). The quality culture inventory: a comprehensive approach towards measuring quality culture in higher education. Studies in Higher Education; 45: 892-908.

8. Berings, D., Beerten, Z., Hulpiau, L.V. and Verhesschen, P. (2010). Quality culture in higher education: from theory to practice. Proceedings of the 5th European Quality Assurance Forum, Lyon, France. Brussels: EUAYorke, M. (2000). Developing a quality culture in higher education. Tertiary Education and Management; 6: 19-36.

9. Nederlands-Vlaamse Accreditatie Organisatie (2018). Beoordelingskader accreditatiestelsel hoger onderwijs Nederland: vertrouwen in kwaliteit. Retrieved September 9th 2020, from: https:/www.nvao.net/files/ attachments/.89/Beoordelingskader_accreditatiestelsel_hoger_onderwijs_Nederland_2018.pdf.

10. Brennan, J., and Shah, T. (2000). Quality assessment and institutional change: Experiences from 14 countries. Higher Education; 40: 331-49.

II. Knight, P.T. and Trowler, P.R. (2000). Department-level cultures and the improvement of learning and teaching. Studies in Higher Education; 25: 69-83.

12. Austin, A.E. (1990). Faculty cultures, faculty values. New Directions for Institutional Research; 68: 61-74.

13. Kottman, A., Huisman, J., Brockerhoff, L., Cremonini, L., and Mampaey, J. (2016). How can one create a culture of quality enhancement? Center for Higher Education Policy Studies (CHEPS), University of Twente, The Netherlands.

14. Lanarès, J. (2009). Tracking the development of a quality culture: Is the discourse translated into action? Paper presented at the Fourth European Quality Assurance Forum, Copenhagen, Denmark.

15. Harvey, L. and Stensaker, B. (2008). Quality culture: understandings, boundaries and linkages. European Journal of Education; 43: 427-42.

16. Berings, D. and Grieten, S. (2012). Dialectical reasoning around quality culture. Paper presented at the seventh European Quality Assurance Forum (EQAF) of the European University Association (EUA), Tallinn. Nov 22-24.

17. Bollaert, L. (2014). A manual for internal quality assurance in higher education with special focus on professional higher education. Brussels: European Association of Institutions in Higher Education.

18. Sattler, C. and K. Sonntag. (2018). Quality cultures in higher education institutions. In Knowledge and Space Vol. 12 - Geographies of the University, edited by P. Meusburger, M. Heffernan \&, and L. Suarsana, 313-27. Heidelberg: Springer.

19. Flumerfelt, S. and Banachowski, M. (20II). Understanding leadership paradigms for improvement in higher education. Quality Assurance in Education; 19: 224-247.

20. Thornhill, A., Lewis, P., and Saunders, M.N.K. (1996). The role of employee communication in achieving commitment and quality in higher education. Quality assurance in education; 4: 12-20.

21. Gordon, G. (2002). The roles of leadership and ownership in building an effective quality culture. Quality in Higher Education; 8: 97-106.

22. Spreitzer, G.M. (1995) Psychological empowerment in the workplace: Dimensions, measurement and validation." Academy of Management Journal; 38: 1442-1465. 
23. Meyer, J.P., Stanley, D.J., Herscovitch, L., and Topolnytsky, M. (2002). Affective, continuance, and normative commitment to the organization: A meta-analysis of antecedents, correlates, and consequences. Journal of Vocational Behaviour; 61: 20-52.

24. Wilkinson, A. (2004) Quality and the Human Factor. Total Quality Management \& Business Excellence: I5; 1019-1024.

25. Rifa'i, A.A., Permana, J., and Komariah, A. (2019). The Influence of Internal Quality Assurance and Quality Culture on Performance of Higher Education Institution. Advances in Social Science, Education and Humanities Research; 258:274-278

26. Soria-García, J. and Martínez-Lorente, Á.R. (2020). The influence of culture on quality management practices and their effects on perceived service quality by secondary school students. Quality Assurance in Education; 28: 49-65.

27. Idris, I. (2019). Exploring organizational culture, quality assurance, and performance in higher education. Management and Economics Journal; 3: 166-I8I.

28. Han, Y., Kumar, V., Tuyeết Trương, N., \& Ngoc Hoang, N. Y. (2019). The impact of culture of quality (COQ) on the organizational performance. In: Proceedings of the 9 th International Conference on Operations and Supply Chain Management, Vietnam.

29. Berings, D. (200I). Dealing with competing values as a condition for the development of integral quality management in higher vocational education in Flanders. [Omgaan met concurrerende waarden als voorwaarde tot de ontwikkeling van integrale kwaliteitszorg in het hogescholenonderwijs in Vlaanderen.] (PhD Thesis), K.U. Leuven, EHSAL, Brussel.

30. Smart, J. (2003). Organizational effectiveness of 2-year colleges: the centrality of cultural and leadership complexity. Research in Higher Education; 44: 673-703.

31. Cameron, K.S. and Quinn, R.E. (1999). Diagnosing and changing organisational culture based on the competing values framework. Reading MA: Addison-Wesley.

32. Jauregui, J., O'Sullivan, P., Kalishman, S., Nishimura, H., and Robins, L. (2019). Remooring: A qualitative focus group exploration of how educators maintain identity in a sea of competing demands. Academic Medicine; 94: 122-128.

33. Association of Universities in the Netherlands (2020). Position Paper: Recognition \& Rewards. Retrieved on September $29^{\text {th }}, 2020$, from: https://www.vsnu.nl/recognitionandrewards/.

34. Fullan, M. (2005). Leadership and sustainability. Thousand Oaks, CA: Corwin Press.

35. Buckley, H., Steinert, Y., Regehr, G., and Nimmon, L. (2019). When I say ... community of practice. Medical Education; 53: 763-765.

36. Giertz, B. (2000). The quality concept in higher education. Paper presented at the TQM for Higher Education Institutions II, Verona, Italy, 30-3I August.

37. Newton, J. (2000). Feeding the beast or improving quality? Academics' perceptions of quality assurance and quality monitoring. Quality in Higher Education; 6: 153-163.

38. Anderson, G. (2006). Assuring Quality/Resisting Quality Assurance: Academics' responses to 'quality' in some Australian universities. Quality in Higher Education; 12: 161-173.

39. Cardoso, S., Rosa, M.J. and Stensaker, B. (2016). Why is quality in higher education not achieved? The view of academics. Assessment \& Evaluation in Higher Education; 41: 950-965.

40. Huusko, M. and Ursin, J. (2010). Why (Not) Assess? Views from the Academic Departments of Finnish Universities. Assessment \& Evaluation in Higher Education; 35: 859-869.

4I. Haji, F., Morin, M.P., and Parker, K. (20I3). Rethinking programme evaluation in health professions education: Beyond 'did it work'? Medical Education; 47:342-35I.

42. Bloch, C., Degn, L., Nygaard, S., and Haase, S. (2020). Does quality work work? A systematic review of academic literature on quality initiatives in higher education. Assessment \& Evaluation in Higher Education. Online publication ahead of print.

43. Cardoso, S., Rosa, M.J., Videira, P., and Amaral, A. (2019). Internal quality assurance: A new culture or added bureaucracy? Assessment \& Evaluation in Higher Education; 44; 249-262.

44. Cartwright, M.J. (2007). The rhetoric and reality of 'quality' in higher education. An investigation into staff perceptions of quality in post- 1992 universities. Quality Assurance in Education; 15: 287-30I. 
45. Argyris, C. and Schön, D.A. (1996). Organizational learning II: Theory, method \& practice. Reading: Addison Wesley.

46. Newton, J. (2010). A tale of two 'qualitys'. Reflections on the quality revolution in higher education. Quality in Higher Education; 16: 5I-53.

47. Hawick, L., Cleland, J., and Kitto, S. (2017). Getting of the carousel: Exploring the wicked problem of curriculum reform. Perspectives on Medical Education; 6: 337-343.

48. Mårtensson, K., Roxå, T., and Stensaker, B. (20I4). From quality assurance to quality practices. An investigation of strong microcultures in teaching and learning. Studies in Higher Education; 39: 534-545.

49. Edmondson, A. and Moingeon, B. (1998). From organizational learning to the learning organization. Management Learning; 29: 5-20.

50. Wong, B.M. and Headrick, L.A. (2020). Application of continuous quality improvement to medical education. Medical Education; 00: I-10.

5I. Avdjieva, M. and Wilson, M. (2002). Exploring the development of quality in higher education; 12: 372-383.

52. Krause, K.L. (2012). Adressing the wicked problem of quality in higher education: theoretical approaches and implications. Higher Education Research \& Development; 31: 285-297.

53. Bryman, A. (2007). Effective leadership in higher education: A literature review. Studies in higher education; 32: 693-710.

54. Ovseiko, P.V. and Buchan, A.M. (2012). Organizational culture in an academic health center: An exploratory study using a competing values framework. Academic Medicine; 87: 709-718.

55. Sandhu, D. (2019). Healthcare educational leadership in the twenty-first century. Medical Teacher; 4I: 148-618.

56. McKimm, J. and Lieff, S.J. (20I3). Medical education leadership (In: Dent, J., Harden, R.M. \& Hunt, D. (Eds.) A practical guide for medical teachers (pp. 343-35I). London: Churchill Livingstone-Elsevier).

57. Mårtensson, K. and Roxå, T. (2016). Leadership at a local level $\square$ Enhancing educational development. Educational Management, Administration \& Leadership; 44: 247-262.

58. McKimm, J., Redvers, N., El Omrani, O., Parkes, M.W., Marie Elf, M., and Woollard, R. (2020) Education for sustainable healthcare: Leadership to get from here to there. Medical Teacher. Online publication ahead of print.

59. Sundberg, K., Josephson, A., Reeves, S., and Nordquist, J. (2017). Power and resistance: Leading change in medical education. Studies in Higher Education; 42: 445-462.

60. Marshall, S.J., Orrell, J., Cameron, A., Bosanquet, A., and Thomas, S. (20II). Leading and managing learning and teaching in higher education. Higher Education Research \& Development; 30: 87-103.

61. Mårtensson, K., Roxå, T., and Olsson, T. (201I). Developing a quality culture through the scholarship of teaching and learning. Higher Education Research \& Development; 30: 5I-62.

62. Ehlers, U.D. (2010). Moving from control to culture in higher education quality. In: Ehlers, U,D., Schneckenberg, D. (eds) Changing cultures in higher education. Berlin, Heidelberg: Springer.

63. Harvey, L. and Stensaker, B. (2008). Quality culture: understandings, boundaries and linkages. European Journal of Education; 43: 427-42.

64. Sandars, J. and Murdoch-Eaton, D. (2017). Appreciative inquiry in medical education. Medical Teacher; 39: 123-127.

65. Berg, R.C. and Nanavati, J. (2016). Realist review: Current practice and future perspectives. Journal of Research Practice; I2: RI.

66. Bolden, R., Gosling, J., \& O’Brien, A. (2012). Academic leadership: Changing conceptions, identities and experiences in UK higher education. London: Leadership foundation for higher education.

67. Kleijnen, J. (20I2). Internal quality management and organisational values in higher education. Conceptions and perceptions of teaching staff. [PhD Thesis]. Maastricht: Universitaire Pers.

68. Engbers, R., Caluwé, L.I.A., de., Stuyt, P.M.J., Fluit, C.R.M.G., and Bolhuis, S. (2013). Towards organizational development for high-quality medical teaching. Perspectives on Medical Education; 2: 28-40.

69. Bligh, J., and Brice, J. (2010). Leadership in medical education. The British Medical Journal; 340: c235I

70. Cruess, R.L., Cruess, S.R., and Steinert, Y. (2018). Medicine as a community of practice: Implications for medical education. Academic Medicine; 93: 185-191. 
7I. Meeuwissen, S.N.E., Gijselaers, W.H., Wolfhagen, I.H.A.P., and oude Egbrink, M.G.A. (2020). When teachers meet in interdisciplinary teams: Hangouts, distribution centers and melting pots. Academic Medicine; 95: 1265-1273.

72. Edmondson, A.C., Dillon, J.R., Roloff, K.S. (2007) Three perspectives on team learning. Academy of Management Annals; I: 269-3I4.

73. Hill, F. and Stephens, C. (2005). Building leadership capacity in medical education: developing the potential of course coordinators. Medical Teacher; 27: 145-149.

74. Meeuwissen, S.N., Gijselaers, W.H., Wolfhagen, I.H. \& oude Egbrink, M.G.A. (2020). When I say... team learning. Medical Educaction; 54: 784-785.

75. Nordquist, J. and Grigsby, R.K. (20II). Medical schools viewed from a political perspective: how political skills can improve education leadership. Medical Education; 45: II74-II80. 



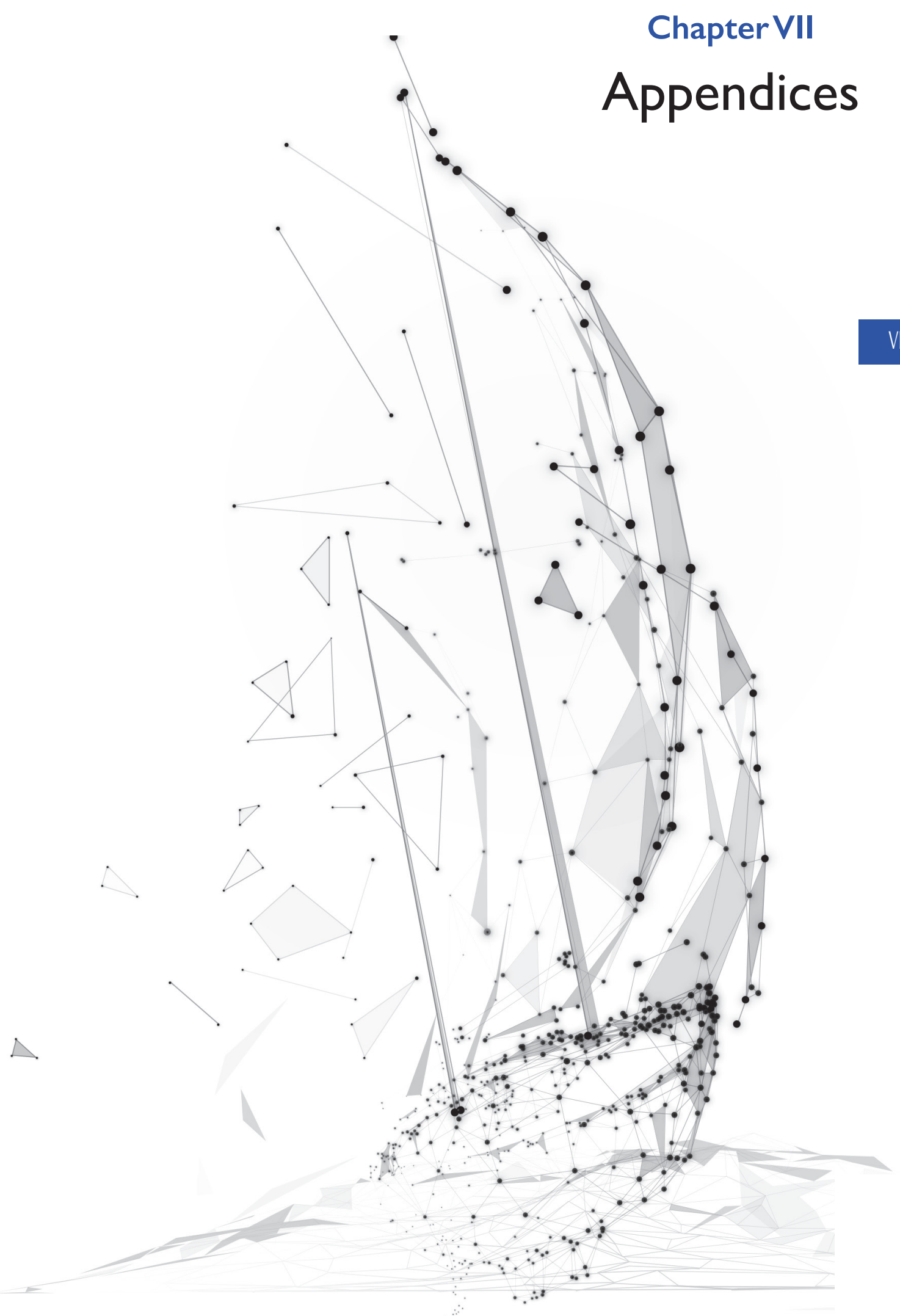




\section{Summary}

Chapter I, the introduction of this dissertation, sketches the history and relevance of the quality culture concept. The chapter starts with a description of the momentum that quality management in higher education institutions (HEls) had gained in the 1990's. The importance attributed to quality management at that time coincided with rising student numbers, intensified competition, rapid advances in educational technology, expanded pressures on funding, and growing public demands for accountability. Quality management was seen as a panacea to propel effectiveness, efficiency and transparency. Despite its encompassed advantages, quality management increasingly became subject to criticism. Foremost, since there was (and still is) inconclusive agreement on whether quality management actually leads to improved education. A second major critique concerns the technocratic and control oriented character of quality management which can contrast with staff values of professionalism and autonomy. Earlier research on the relationship between organisational cultures and effectiveness implies that values and attitudes of organisational members also impact performance. The notion of 'quality culture' embraces the idea that quality management should be in line with staff values, so that they can reciprocally reinforce each other. Despite the positive connotation of the quality culture notion, a sound conceptualisation of the construct is still missing. This lack of insight might stem from quality and quality culture being elusive concepts: they mean different things to different stakeholders. Empirical research is needed that brings these multiple perspectives to the surface and provides a clearer picture on what a quality culture exactly entails. This research gap led to formulation of two overarching research questions that underpin our studies:

I. What are the most important features of a quality culture and how do these features interrelate?

2. How to promote a culture of continuous quality improvement?

Chapter II describes the results of a realist review that focuses on the identification of inhibiting and promoting organisational context elements that impact quality culture, to explore a quality culture's working mechanisms, and to map its associated outcomes. A systematic literature search was performed in seven electronic databases which cover different disciplinary fields. An initial and iterative search and the application of multiple exclusion criteria resulted in the inclusion of 31 articles. The structural/managerial dimension and cultural/psychological dimension as included in the definition of quality culture formulated by the European University Association served to frame promoting and inhibiting elements. Strategies, policies, procedures, responsibilities and the instalment of evaluation systems, are considered basic structural/ managerial requirements to work on educational quality improvement. On the other hand, shared values, a focus on innovation and flexibility, and human relations, are regarded key cultural/psychological quality culture features. Inhibiting structural/managerial elements of a quality culture comprise the counterparts of the promoting elements described above, e.g. a 
lack of staff and student involvement and a lack of clear policies, procedures, and responsibilities. The sense of belonging to a subculture with its own educational values, working ethos and commitment, can hamper the development of an overall quality culture as well. Moreover, the emphasis of quality management on 'control' rather than on 'improvement' is generally reported as a factor inhibiting the development of a quality culture. Leadership and communication include both 'structural/managerial' and 'cultural/psychological' attributes and act as binding elements between these two dimensions. Based on an analysis of quality management interventions, propositions were formulated on working mechanisms of a quality culture. These mechanisms include commitment and ownership as determinants of staff agency, and staff knowledge and empowerment as elements that are closely linked to human relations. The four mechanisms, in turn, are associated with outcomes of staff/student learning and development, staff/student satisfaction, and educational process improvement. This study contributed to a more comprehensive understanding of quality culture and resulted in a conceptual framework that is backed by results from empirical studies. The study outcomes call for increased attention to leadership and communication, as these might be easier to address than other structure/ management and culture/psychological elements.

Chapter III explores the interrelations between the key quality culture concepts that were identified in our first study. Informed by literature from the field of organisational psychology, a hypothetical path model was construed. The measured concepts were represented in a configuration of internal context characteristics (competing value orientations, leadership and communication), work-related psychological attitudes of staff members (empowerment, commitment and ownership), and quality enhancement practices. A quality culture survey that included the before mentioned concepts was constructed by combining subscales of existing questionnaires, incorporating items of original questionnaires, and item/scale development by the research team. The data to test the hypotheses was collected from coordinators involved in four bachelor's programmes of Maastricht University's (NL) Faculty of Health, Medicine and Life Sciences. Eighty nine responses were collected (a response rate of $72 \%$ ). The study findings particularly highlighted the importance of a 'human relation' value orientation. This orientation influences empowerment, commitment and communication satisfaction. Moreover, out of the four value orientations, human relation values were found to have the strongest correlation with positive leadership. Additionally, rational goal values and ownership were found to be positively related to quality enhancement practices. Counter to the hypotheses, no relation was identified between leadership and staff's experienced empowerment, commitment and ownership. Based on the findings, it is advocated that institutional policies and strategies for quality enhancement should aim at a promoting ownership, while leadership should especially be directed to nurturing human relation values.

Chapter IV presents the results of a qualitative study among students and staff members who hold a representative role in education quality advisory committees. By means of this inter- 
institutional study we aimed to gain further insights into the perspectives of students and staff members on quality culture and its relation with educational improvement. Participants were 22 staff members and 18 student representatives affiliated to 6 medical schools in the Netherlands. The conducted focus group interviews concentrated on quality culture characteristics in relation to optimising educational development, implementation, evaluation, and further improvement (the Pan-Do-Check-Act cycle). Template analysis, a stepwise type of thematic analysis, was applied to analyse the data. Five main themes resembling quality culture constituents to continuous improvement were identified: (I) fostering an open systems perspective, (2) involving stakeholders in educational (re)design, (3) valuing teaching and learning, (4) navigating between ownership and accountability, and (5) building on integrative leadership. A supportive communication climate, which can be fuelled by the organisation's leaders, contributes to and is integrated within the first 4 themes. The themes relate to tensions between flexibility for change vs. stability for effectiveness, bottom-up vs. top-down improvement initiatives, intrinsic and extrinsic staff motivators, and a focus on professional autonomy vs. professional control. The assertive, participative and value-influencing behaviours of leaders can contribute to quality culture enhancement by addressing the four tensions. This study provided new insights in the link between theory and practice of continuous quality improvement. Specifically, the study revealed that staff's professional autonomy, collaboration with peers and students, and the valuing of teaching and learning need to be amplified. The results suggest a shift away from static quality management approaches toward more flexible, development-oriented approaches focusing on the five themes of a culture for continuous quality improvement.

Chapter $V$ focuses on the question how a quality culture can be enhanced according to the experiences and perspectives of educational leaders. Interviews were conducted with educational leaders of three health professions education programmes offered at Maastricht University (NL). The data collection was structured by an appreciative inquiry approach, and supported with vignettes that were informed by our previous study (each vignette resembled one of the five quality culture themes). A total of 25 participants (course coordinators, bachelor coordinators and directors of education) reflected on the themes to learn about the best of what is (Discover), envision positive future developments (Dream), identify actions to reach the desired future (Design), and determine how to support and sustain the improvement actions (Destiny). Based upon a thematic analysis, twelve subthemes were identified under the four phases of appreciative inquiry: I) Discover: stimulating expertise based selection and creativity, reinforce multidisciplinary learning, collect and act upon multisource feedback, 2) Dream: foster external perspectives for curriculum alignment, establish staff learning communities with and without students, enhance teacher appreciation and identity building, 3) Design: implement longitudinal education roles, encourage peer coaching and interactive education, pay attention to quality of work experience, and 4) Destiny: intertwine departmental and educational HRM policies, invest in support and innovation networks, further educational leadership expertise. 
The experiences and perspectives of educational leaders revealed that peer learning in teams and communities, attention to professional development, and embedding support- and innovation networks, are at the heart of quality culture enhancement. An emphasis on human resources, (inter)relations and whole systems thinking stood out as quality culture catalysts. Based on the findings, leaders are encouraged to fuel their networking, communication, coalition building, and reflection competencies.

Chapter VI includes a discussion on the outcomes of the four studies. In this chapter, answers are provided to the two overarching research questions; we first present a recap of the results and interpret their meaning in relation to the existing literature. Thereafter, three topics are discussed that HEls should consider in attempts to enhance their quality culture: the balancing of quality structures and values, the relation between quality, culture and change, and the furthering of educational leadership. Our studies lead to the overall conclusion that to enhance a quality culture, strategies for innovation, staff development, and establishing teacher \& teacher-student networks, need to be linked. Moreover, a larger emphasis on human capital and interrelations is needed. The main strengths of this dissertation encompass that; I) all studies are theoretically well-embedded in literature derived from different scholarly fields, 2) our studies were among the first to empirically research quality culture, and 3) perspectives of various stakeholders were incorporated. The dissertation's limitations relate to the context in which the studies were performed and the fact that the results of three studies are based on self-reports. Future research is recommended to gather insights in quality culture across institutions at an international level. Moreover, including multiple educational domains and other stakeholders will enrich the knowledge on quality culture. Studies that relate quality culture features in an explicit way to outcome measures would justify the beneficial effect of investing in quality culture enhancement. Lastly, additional studies are suggested that increase insights into staff, and staff-student interactions that affect a quality culture. Implications of this dissertation are that a) quality improvement requires a shift from accountability and control toward trust in professional expertise and ownership, b) the importance of work-related psychological attitudes implies a need to invest in HRM strategies, and c) more attention should be provided to strengthening competencies of educational leaders: leadership development goes hand in hand with quality culture enhancement. 


\section{Samenvatting}

Hoofdstuk I, de inleiding van deze dissertatie, schetst de geschiedenis en relevantie van het concept kwaliteitscultuur. Het hoofdstuk start met een beschrijving van het momentum dat kwaliteitsmanagement in hoger onderwijsinstellingen verkreeg in de jaren '90. Het belang dat werd gehecht aan kwaliteitsmanagement vond tegelijkertijd plaats met een aantal andere belangrijke ontwikkelingen, zoals snel stijgende studentaantallen, een toenemende concurrentie tussen universiteiten, snelle ontwikkelingen in onderwijstechnologieën, een toenemende druk op financiering en een grotere publieke verantwoordingsvraag. Kwaliteitszorg werd gezien als een middel om de effectiviteit, efficiëntie en transparantie van het hoger onderwijs te bevorderen. Ondanks de vooronderstelde voordelen van kwaliteitsmanagement groeide de kritiek. Dit kwam vooral doordat er (tot op heden) niet is aangetoond dat kwaliteitsmanagement bijdraagt aan een daadwerkelijke verbetering van onderwijs. Een tweede punt van kritiek betrof het technocratische en controlegeoriënteerde karakter van kwaliteitsmanagement. Deze staan in contrast met waarden van stafleden die eerder gericht zijn op professionaliteit en autonomie. Eerder onderzoek naar de relatie tussen de cultuur en effectiviteit van organisaties laat zien dat waarden en attitudes van organisatieleden van invloed zijn op het presteren. Het begrip 'kwaliteitscultuur' operationaliseert het idee dat kwaliteitsmanagement verbonden moet zijn met de waarden van stafleden, zodat deze elkaar wederzijds kunnen versterken. Ondanks de positieve connotatie van het begrip kwaliteitscultuur, ontbreekt tot nu toe een gedegen conceptualisering. Dit gebrek aan inzicht heeft waarschijnlijk zijn oorsprong in het gegeven dat kwaliteit en kwaliteitscultuur beiden veelomvattend en ongrijpbaar zijn: ze worden op uiteenlopende wijze, door verschillende stakeholders, geïterpreteerd. $\mathrm{Er}$ is empirisch onderzoek nodig dat de verschillende perspectieven op kwaliteitscultuur zichtbaar maakt en dat een duidelijker beeld schetst van het concept kwaliteitscultuur. Deze kennislacune leidde tot de formulering van twee overkoepelende onderzoeksvragen die ten grondslag liggen aan de uitgevoerde studies die zijn opgenomen in deze dissertatie:

I. Wat zijn de belangrijkste kenmerken van een kwaliteitscultuur en hoe zijn deze kenmerken aan elkaar gerelateerd?

2. Hoe kan een cultuur van continue kwaliteitsverbetering worden bevorderd?

Hoofdstuk II beschrijft de resultaten van een realist review die gericht isop het identificeren van belemmerende en bevorderende context elementen van een kwaliteitscultuur, het verkennen van haar werkende mechanismen en het in kaart brengen van de gerelateerde uitkomsten. Zeven elektronische databases die diverse disciplines en onderzoeksvelden representeren werden op systematische wijze doorzocht. Op basis van een primaire en een aanvullende zoekactie en de toepassing van diverse exclusiecriteria werd een totaal van 31 studies geselecteerd voor verdere analyse. De structuur/management dimensie en cultuur/ psychologische dimensie zoals beschreven in de definitie van kwaliteitscultuur (opgesteld door 
de European University Association) werden gebruikt om de bevorderende en belemmerende factoren in te kaderen. Uit de review bleek dat strategieën, beleid, procedures, verantwoordelijkheden en het implementeren van evaluatiemethodieken behoren tot structuur/ management basisvoorwaarden om aan kwaliteitsverbetering van onderwijs te kunnen werken. Daarnaast bleken gedeelde waarden, een focus op innovatie, flexibiliteit en werkrelaties cultureel/psychologische kernkarakteristieken van een kwaliteitscultuur. Belemmerende structuur- en managementelementen van een kwaliteitscultuur bestaan uit de tegenhangers van de eerder beschreven bevorderende karakteristieken, bijvoorbeeld een gebrek aan staf- en studentbetrokkenheid en een gebrek aan duidelijk beleid, procedures en verantwoordelijkheden. Het behoren tot een subcultuur met specifieke onderwijswaarden, een specifiek arbeidsethos en een bepaald (ontbrekend) commitment voor onderwijs, kan de ontwikkeling van een kwaliteitscultuur ook in de weg staan. Daarbij wordt de nadruk van kwaliteitsmanagement op 'controle' in plaats van 'verbetering' gezien als een belemmerende factor voor de ontwikkeling van een kwaliteitscultuur. Leiderschap en communicatie hebben zowel structuur/management als cultuur/psychologische kenmerken en fungeren als verbindende elementen tussen deze twee dimensies. Op basis van een analyse van managementinterventies werden de werkende mechanismen van een kwaliteitscultuur geïdentificeerd. Deze mechanismen bestaan uit commitment en eigenaarschap als determinanten van de inzet door stafleden. Daarnaast zijn kennis en empowerment mechanismen die sterk verbonden zijn met interpersoonlijke (werk) relaties. De vier mechanismen zijn op hun beurt verbonden met het leren en de ontwikkeling van staf- en studenten, staf/student tevredenheid en de verbetering van onderwijsprocessen. Deze studie droeg bij aan een beter begrip van kwaliteitscultuur en resulteerde in een conceptueel model dat gebaseerd is op de resultaten van empirische studies. De uitkomsten van het onderzoek impliceren dat er meer aandacht nodig is voor leiderschap en communicatie, omdat deze elementen van een kwaliteitscultuur waarschijnlijk gemakkelijker te adresseren zijn dan andere structuur/management en cultuur/psychologische elementen.

Hoofdstuk III gaat in op relaties tussen de belangrijkste karakteristieken van een kwaliteitscultuur die in onze eerste studie werden geïdentificeerd. Op basis van literatuur uit de organisatiepsychologie werd een hypothetisch model geconstrueerd. De geanalyseerde concepten bestonden uit een configuratie van interne organisatiecontextkarakteristieken (conflicterende waardeoriëntaties, leiderschap en communicatie), werkgerelateerde psychologische attituden van stafleden (empowerment, commitment en eigenaarschap) en praktijken voor kwaliteitsverbetering. Deze concepten werden opgenomen in een vragenlijst over kwaliteitscultuur, die werd samengesteld op basis van sub-schalen van bestaande vragenlijsten, items van andere vragenlijsten en items/schalen die werden ontworpen door het onderzoeksteam zelf. De gegevens om de hypothesen te testen werden verzameld onder coördinatoren van vier bachelorprogramma's van de Faculty of Health, Medicine, and Life Sciences, Universiteit Maastricht. Negenentachtig reacties werden ontvangen (een responspercentage van $72 \%$ ). De bevindingen van deze studie benadrukken het belang van 
een mensgerichte/interpersoonlijke waardeoriëntatie. Deze oriëntatie is van invloed op empowerment, commitment en communicatietevredenheid. Van de vier waardeoriëntaties bleken mensgerichte/interpersoonlijk waarden ook het sterkst te correleren met positief leiderschap. Rationele doel waarden en eigenaarschap lieten ook een positief verband zien met de uitvoering van praktijken gericht op onderwijsverbetering. In tegenstelling tot de geformuleerde hypotheses kon er geen relatie worden aangetoond tussen leiderschap en door stafleden ervaren empowerment, commitment en eigenaarschap. Op basis van deze bevindingen kan worden beargumenteerd dat instellingen hun strategie en beleid voor kwaliteitsverbetering meer moeten richten op het bevorderen van eigenaarschap, terwijl leiders zich met name moet focussen op het bevorderen van mensgerichte/interpersoonlijke waarden.

Hoofdstuk IV presenteert de resultaten van een kwalitatieve studie onder studenten en stafleden die een vertegenwoordigende rol vervullen in opleidingscommissies (commissies met als belangrijkste taak te adviseren over aangelegenheden die de onderwijskwaliteit beïnvloeden). Het doel van deze studie was meer inzicht te krijgen in de perspectieven van studenten en stafleden op kwaliteitscultuur en de relatie met onderwijsverbetering. Deelnemers aan de studie waren 22 staf-en 18 studentvertegenwoordigers van 6 Nederlandse geneeskundeopleidingen. In de uitgevoerde focusgroep-interviews werd ingezoomd op karakteristieken van een kwaliteitscultuur in relatie tot onderwijsontwikkeling, implementatie, evaluatie en verdere verbetering (de Plan-Do-Check-Act cyclus). Template analyse, een stapsgewijze methode van thematische analyse, werd gebruikt om de data te analyseren. Vijf hoofdthema's werden geïdentificeerd die de bijdrage van een kwaliteitscultuur aan continue verbetering representeren: (I) bevorderen van een open systeem perspectief, (2) betrekken van stakeholders in het (her)ontwerpen van onderwijs, (3) waarderen van onderwijs en leren, (4) navigeren tussen eigenaarschap en accountability, en (5) integratief leiderschap. Een ondersteunend communicatieklimaat, dat kan worden gestimuleerd door leiders in de organisatie draagt bij aan- en is geïntegreerd in- de eerste vier thema's. De thema's zijn gerelateerd aan spanningen binnen de organisatie tussen flexibiliteit voor verandering en stabiliteit ten behoeve van effectiviteit, bottom-up en top-down verbeterinitiatieven, intrinsieke en extrinsieke factoren die stafleden motiveren en een focus op professionele autonomie versus professionele controle. Het assertieve, betrokken en waarden-beïnvloedende gedrag van leiders kan bijdragen aan de kwaliteitscultuur door in te werken op de vier spanningen. Deze studie biedt nieuwe inzichten in de relatie tussen de theorie en praktijk van kwaliteitsverbetering. De studie laat zien dat de professionele autonomie van stafleden, samenwerking met vakgenoten en studenten, en het waarderen van onderwijs en leren versterkt moeten worden. De resultaten suggereren dat een verschuiving nodig is van statische kwaliteitsmanagementbenaderingen naar flexibele en ontwikkelingsgerichte benaderingen die zich focussen op de vijf thema's van een cultuur voor continue kwaliteitsverbetering. 
Hoofdstuk V gaat in op de vraag hoe een kwaliteitscultuur kan worden versterkt volgens de ervaringen en inzichten van onderwijsleiders. Er werden interviews gehouden met coördinatoren van drie opleidingen uit het gezondheidsdomein van de Universiteit Maastricht. De datacollectie werd gestructureerd door een 'waarderend onderzoeken benadering' en door het gebruik van vignetten die gebaseerd zijn op onze vorige studie (ieder vignet staat voor een van de vijf thema's van kwaliteitscultuur die beschreven zijn in het hoofdstuk IV). Een totaal van 25 participanten (blokcoördinatoren, bachelor coördinatoren en opleidingsdirecteuren) reflecteerde op de thema's om bestaande best practices te ontdekken (Discover), om een visie vast te stellen die bijdraagt aan een positieve doorontwikkeling van de organisatie (Dream), om acties te identificeren die bijdragen aan het realiseren van deze visie (Design) en om inzicht te geven in hoe verbeteracties duurzaam kunnen worden ingezet (Destiny). Op basis van een thematische analyse werden twaalf subthema's geïdentificeerd die onder de vier fasen van waarderend onderzoeken zijn ondergebracht: I) Discover: het stimuleren van op expertise gebaseerde selectie en creativiteit, het versterken van multidisciplinair leren, het verzamelen van multi-source feedback en op basis hiervan acteren, 2) Dream: bevorderen van een extern perspectief voor curriculumintegratie en afstemming, instellen van leergemeenschappen van stafleden, met- en zonder studenten, het vergroten van waardering voor onderwijsgevers en de ontwikkeling van een onderwijsidentiteit, 3) Design: het implementeren van longitudinale onderwijsrollen, bevorderen van peer coaching en interactief onderwijs, aandacht besteden aan de ervaren kwaliteit van werk, 4) Destiny: het integreren van Human Resource Management beleid van vakgroepen en onderwijsbeleid, investeren in ondersteunende-en innovatie-netwerken en het stimuleren van leiderschapsexpertise. De ervaringen en perspectieven van de geïnterviewde onderwijscoördinatoren laten zien dat het van elkaar leren in teams en gemeenschappen, aandacht voor professionele ontwikkeling en het inbedden van ondersteunings-en innovatienetwerken bijdragen aan de versterking van een kwaliteitscultuur. Tevens vormen human resources, (inter)relaties en systeemdenken katalysatoren van een kwaliteitscultuur. Op basis van de resultaten wordt aan blok-programma-en domeincoördinatoren geadviseerd hun netwerk, communicatie en reflectievaardigheden verder te ontwikkelen, alsmede te werken aan hun leiderschapscompetenties die bijdragen aan het vormen van leergemeenschappen.

Hoofdstuk VI bevat een discussie over de vier studies. In dit hoofdstuk wordt antwoord gegeven op de twee overkoepelende onderzoeksvragen. Er wordt eerst teruggeblikt op de resultaten. Vervolgens worden deze in het licht van de bestaande literatuur geïnterpreteerd en bediscussieerd. Hierna komen drie onderwerpen aan bod die hoger onderwijsinstellingen in ogenschouw moeten nemen in hun pogingen om de kwaliteitscultuur te bevorderen: het balanceren van kwaliteitsstructuren en organisatiewaarden, het verband tussen kwaliteit, cultuur en verandering, en het bevorderen van leiderschapsexpertise. Onze studies leiden tot de conclusie dat strategieën voor innovatie, docentprofessionalisering en het instellen van docent \& docent-student gemeenschappen moeten worden geïntegreerd. Daarnaast is er een grotere nadruk gewenst op human resources en werkrelaties binnen de onderwijsorganisatie. 
De sterke punten van deze dissertatie zijn dat; I) alle studies goed zijn ingebed in de literatuur, die diverse vakgebieden beslaat, 2) de studies zich in de voorhoede bevinden van empirisch onderzoek naar kwaliteitscultuur, 3) de perspectieven van diverse stakeholders zijn meegenomen. De beperkingen van de dissertatie zijn gerelateerd aan de context waarbinnen de studies zijn uitgevoerd en het feit dat de resultaten van drie studies zijn gebaseerd op zelfrapportages. Toekomstig onderzoek wordt aanbevolen zich toe te spitsen op kwaliteits-culturen binnen diverse organisaties op een internationaal niveau. Daarbij zou de inclusie van meerdere opleidingsdomeinen en stakeholders de kennis over kwaliteitscultuur verder kunnen verrijken. Studies die kwaliteitscultuur op een expliciete manier relateren aan uitkomstmaten zouden de meerwaarde voor het investeren in een kwaliteitscultuur nog beter kunnen verantwoorden. Tenslotte worden toekomstige studies aanbevolen die meer inzicht geven in staf en staf-student interacties die van invloed zijn op de kwaliteitscultuur. Implicaties van deze dissertatie zijn dat a) kwaliteitsverbetering van onderwijs vraagt om een verschuiving van verantwoording en controle naar vertrouwen in professionele expertise en eigenaarschap, b) het belang van werkgerelateerde psychologische attituden impliceert dat nadere investeringen nodig zijn in HRM strategieën, c) dat er meer aandacht uit zou moeten gaan naar het versterken van leiderschapscompetenties: de ontwikkeling van leiderschap binnen het hoger onderwijs gaat hand in hand met het bevorderen van een kwaliteitscultuur. 


\section{Impact addendum}

In this addendum, a reflection is provided on the societal and scientific impact that the performed studies have had, and are further expected to have in the future. This impact relates both to the way in which the research questions were addressed, as well as to the implications and follow-up of the main findings. Throughout the addendum, references are made to the way in which multiple target groups benefit from the results. The addendum concludes by elaborating on past and future activities to disseminate and valorise the findings.

\section{Societal impact}

The attention to the quality of higher education is growing in countries across Europe and beyond. This development fits in with the increased importance that is attributed to higher education because of its potential to contribute to national economies. Moreover, higher education receives a great deal of societal attention because it concerns both personal and population-wide aspirations for optimal talent development. In attempts to answer the question how the quality of education can best be assured and improved, the concept of quality culture is used more and more often.

Despite of the popularity of the concept, an in-depth understanding of what a quality culture exactly entails has been lacking so far. Insights are needed in what the key features of a quality culture are. Then, in a next step, approaches can be developed through which these positive quality culture features can be nurtured. The studies in this dissertation deal with this exploration and potential enhancement of quality culture. Specific attention is spent to ways in which higher education institutions can promote continuous educational improvement, which is characterised by flexibility, openness, a collective commitment and motivation to change, and a promotion of shared educational values. A quality culture resonates with staff and student opinions on how to improve and is assumed to lead to more positive effects than cultures that overemphasise standardisation and bureaucratic control measures. The dissertation's outcomes are relevant on three levels, which involve multiple stakeholders:

(Inter) national policy level: towards a shift in governing higher education quality

The significance of developing a quality culture in higher education institutions has often been stressed in politics and is also often referred to in (inter)national policy documents. In the Netherlands' Strategic Agenda for Higher Education and Research 2015-2025, one can for instance read that the government aims to change its steering philosophy: instead of focusing on inspection and control of higher education quality, investments are deemed required in a quality culture that is characterised by trust between different stakeholders, transparency, and room for institutions to set their own improvement agendas.' Especially the literature review included in this dissertation (Chapter II) has contributed to policy debates on the conceptualisation of quality culture. The literature synthesis and developed quality culture framework have served as input for various policy publications that support investments in quality culture 
development. ${ }^{\text {e.g. } 2,3,4}$ Also internationally, our review study is regularly referred to in publications that address current governance policies and advocate for a shift (e.g. in external review procedures) toward a larger emphasis on the evaluation and development of institutional quality culture(s). ${ }^{5-7}$

Institutional level: nurturing preconditions for quality culture enhancement Higher Education Institutions can influence the preconditions for developing a quality culture in several ways. The results of our studies provide multiple insights in this respect. The institution's Human Resource Management could for instance focus more on reward and recognition of education, e.g. by implementing career tracks based on achievements in education. Staff networks (referred to in this dissertation as 'communities of practice') could promote opportunities for individual and collective staff learning, can help staff members to gain a broader perspective on ongoing developments in education, and can contribute to a better alignment between courses in a programme. A quality culture builds on an increased involvement of stakeholders (staff and students) in decision-making procedures, and highlights the added value of exchanging good practices that fuel innovation. By focusing on networking, communication, and coalition building, leaders can stimulate quality culture development. Faculty development programmes are suggested to focus on learning leadership 'on the job', with room for reflection on personal experiences and competencies. Leaders should be trained to: articulate inspiring visions for the future, stimulate new ways of thinking, attend to staff needs \& concerns, and act both as collaborator and role model.

The dissertation outcomes can also be used by Higher Education Institutions that want to incorporate the quality culture concept into educational evaluation and improvement policies. For example, informed by our research, the Royal Academy of Music in the Hague developed a quality culture approach in which links between internal and external quality assurance, educational quality performance standards, and the Plan-Do-Check-Act phases are enhanced. ${ }^{8}$ The Catholic University of Leuven also translated quality culture insights into its institution-wide approach for quality evaluation and improvement (our studies contributed to these insights, as became clear in a review of KU Leuven's institutional quality policy in which the author participated). ${ }^{9}$ Also in Maastricht University's position paper "The do's, don'ts and don't knows of teaching and learning", several references are made to our work, indicating its relevance to the university community. ${ }^{10}$ Furthermore, our study findings served as input for ongoing discussions at UM on altering educational recognition and reward approaches.

Study programme level: implications for teaching staff and students

The studies in this dissertation voice the opinion of faculty and students that standard approaches for educational quality improvement should be complemented by insights derived from the quality culture concept. The study findings imply that a shift is needed from quality 
improvement approaches that emphasise control and accountability toward more open approaches with more room for professional autonomy and staff-student community building. The research findings highlight that continuous quality improvement requires a stronger focus on the valuing of teaching and learning, the job satisfaction and motivation of teaching staff members, and student personal, academic, and professional development. These aspects should ideally be incorporated in educational (re)design approaches and become embedded in daily procedures that relate to educational quality improvement.

\section{Scientific impact}

A google scholar search with the terms 'quality culture' and 'higher education' learns that the scientific attention to the topics covered in this dissertation is mounting. The search (performed in November 2020) returned 426 hits for the period I99I-2000, increasing to 2320 hits for the period 200I-20I0, and growing to even 6650 hits for 201I-2020. Despite this indication of an increased scholarly attention, the systematic literature review that we conducted in 2017 revealed that studies on quality culture which are based on gathered, analysed, and interpreted data (e.g. interviews, questionnaires) are still scarce. The innovative character of this dissertation is grounded in the fact that we were among the first to conduct a series of data-based studies on quality culture. Additionally, our studies have contributed to the theoretical development of the quality culture construct by combining insights from the organisational sciences, organisational psychology, and (quality) management sciences. The use of methods such as a 'realist review' (Chapter II) and 'appreciative inquiry' (Chapter IV) are still relatively rare in higher education and could serve as examples to other researchers. ${ }^{11,12}$

\section{Other dissemination and valorisation activities}

The four studies from this dissertation are available as published manuscripts in journals that address a broad audience in the field of higher (medical and health sciences) education. Over the past years (in 2013, 2017 and 2018), the visibility of several of our studies has been enhanced by presentations and workshops provided at the largest platform for discussion, professional development and exchange of experiences in quality assurance in Europe (the European Quality Assurance Forum, EQAF). This forum is attended by rectors and vice-rectors responsible for quality assurance, quality assurance officers, students, quality assurance agency staff and researchers working on higher education or the quality assurance field. Moreover, several paper presentations and workshops were provided at (medical) education conferences: the conferences of the Association for Medical Education in Europe, AMEE (in 2016 and 2019), conferences of the Netherlands Association for Medical Education (NVMO, in 2015 and 2019), the Educational Research Days (2017), and the Higher Education Conference (2019). The realist review approach was highlighted in a workshop facilitated by GB at the annual conference of the NVMO in 2017. For an overview of peer-reviewed conference papers please refer to the author's biography. 
Future dissemination and valorisation activities are projected in several areas: a) the author will be involved in the writing of an AMEE guide on quality assurance and quality culture development, b) he is furthermore working on a follow-up publication that targets at bringing the subject of quality culture under the further attention of those involved in medical education, $c$ ) as part of a general practitioner training programme of the School for Health Professions Education, GB will participate in organising a training in quality assurance, $d$ ) contributions to workshops and educational programmes are foreseen in several areas that the quality culture construct addresses (e.g. institutional quality culture reflection exercises that make use of competing values instruments, and leadership development programmes). 


\section{References}

I. Ministerie van Onderwijs, Cultuur en Wetenschap (2015). De waarde(n) van weten. Strategische agenda hoger onderwijs en onderzoek 2015-2025. Den Haag: Directie Hoger Onderwijs en Studiefinanciering.

2. Huisman, J. (2017). Kwaliteitscultuur: invloedrijke factoren (en de kleine lettertjes). Presentation at the congress of the Netherlands-Flanders Accreditation Organisation. Rotterdam: 23 February.

3. Vd Vegt, A.L., Middelbeek, L., and Suijkerbuijk, A. (2020). Duurzame kwaliteitscultuur in het onderwijs: Den Haag: Nationaal Regieorgaan Onderwijsonderzoek en de kennisrotonde voor het ministerie voor onderwijs, cultuur en wetenschap.

4. Reviewcommissie Hoger Onderwijs en Onderzoek (20I7). Prestatieafspraken: het vervolgproces na 2016.

5. Kottman, A., Huisman, J., Brockerhoff, L., Cremonini, L., and Mampaey, J. (2016). How can one create a culture of quality enhancement? Report commissioned by the Norwegian Agency for Quality Assurance in Education. University of Twente: Center for Higher Education Policy Studies.

6. Nguyen, C.H. and Shah, M. Quality assurance in Vietnamese Higher Education (2019). Policy and Practice in the $2 I^{\text {st }}$ century. Cham: Springer.

7. Alzafari, K. and Kratzer, J. (2019). Challenges of implementing quality in European higher education: an expert perspective. Quality in Higher Education, 25; 3: 26I-288.

8. Ravenhorst, J. and Prchal, M. (2018). De lemniscaat van continue verbetering. Hoger Onderwijs Management, thema accreditatie; 4: 14-18.

9. KU Leuven (2015). COBRA. Cooperatie, Reflectie en Actie, Checks and Balances. Een nieuwe kwaliteitszorgmethode voor de KU Leuven. Retrieved I5 November 2020, from: https://www.kuleuven. be/onderwijs/nieuwsbrief/archief/onderwijsontwikkelingen/bestanden/brochurecobra.

10. EDLAB, Maastricht University (2018). EDview position paper: the do's, dont's, and don't knows of teaching and learning at Maastricht University. Retrieved I5 November 2020, from: https://edlab.nl/wp-content/ uploads/2018/10/EDview_Dos-Donts-and-Dont-Knows.pdf.

II. Berg, R.C. and Nanavati, J. (2016). Realist review: current practice and future prospects. Journal of Research Practice; 12: I-28.

12. Sandars, J. and Murdoch-Eaton, D. (2017). Appreciative inquiry in medical education. Medical Teacher; 39 : 123-127. 


\section{Dankwoord (acknowledgements)}

Met het schrijven van dit dankwoord komt dan toch echt het einde in zicht van een uitdagende, maar vooral ook zeer leerzame onderzoeksperiode. Er zijn twee personen die ik alvast met stip bij de opening van dit hoofdstuk wil noemen. Mariëtte \& Ineke, heel hartelijk dank dat jullie mij hebben gestimuleerd om een promotietraject binnen SHE op te starten. Veel dank ook voor jullie uitgesproken vertrouwen vanaf het eerste uur en voor de geboden mogelijkheid om als beleidsmedewerker tevens onderzoek te kunnen doen!

Ineke, jij speelde ook een heel belangrijke rol binnen het promotieteam. Naast het feit dat je een autoriteit bent op het gebied van kwaliteitszorg van onderwijs, heb ik vooral mogen profiteren van je enthousiasme, toegankelijkheid en inzet die zich uitten in het op allerlei mogelijke manieren meedenken en mee (net)werken. Wanneer een teammeeting dreigde te eindigen met een ongewisse uitkomst -of lichte migraine als gevolg van onze groepsdiscussie- was jij vaak diegene die erop hamerde dat er knopen werden doorgehakt. Je weet je echt goed te verplaatsen in de nukken en noden van een promovendus en dat heb ik erg gewaardeerd! Dan over naar Diana. Wat een luxe is het om jou als begeleider gehad te mogen hebben! Bij iedere studie heb ik geprofiteerd van al je expertise en ervaring. Zo heb je mij vanaf het begin steeds gestimuleerd om de studies goed af te bakenen, terwijl ik daarbinnen juist veel vrijheid genoot. De diverse manuscripten zijn steeds beter geworden door jouw kritische feedback (al deed het soms pijn om passages waar ik lang op had zitten zwoegen, toch te moeten elimineren). Je hebt me altijd gestimuleerd om het onderzoek te promoten op (inter)nationale congressen. Veel dank hiervoor en voor de morele support die je steevast gaf voorafgaande aan een presentatie. Mirjam maakte mijn dreamteam van begeleiders compleet. Ik wil jou vooral ontzettend bedanken Mirjam voor je minutieuze wijze van feedback geven en de intelligente oplossingen die je dan aandroeg voor een veelvoud aan uitdagingen. Waar ik met name nog met plezier aan terugdenk zijn jouw positieve reacties op de commentaren die we van journals ontvingen, terwijl deze toch echt aangaven dat er nog wel flinke revisies nodig waren. "Dit gaat zeker lukken" of "Dit kan je snel opnieuw indienen" zijn (ongeveer) je woorden die mij motiveerden op momenten dat ikzelf dat hele revisieproces nog niet zo zag zitten. Ineke, Diana en Mirjam, superveel dank voor het feit dat jullie deur altijd openstond en voor alle tijd die jullie hebben gestoken in het lezen en becommentariëren van alle stukken in deze dissertatie. Ik prijs me zeer gelukkig met jullie begeleiding en onze samenwerking!

Het verhaal over de geboden begeleiding en onderzoekssamenwerking kan zelfs nog ietsjes mooier. Bij studie numero 2 was namelijk Jimmie nauw betrokken voor het nodige statistische advies. Veel dank Jimmie voor je geduldige uitleg en enthousiaste meedenken bij de onderzoeksopzet, waarna je ook nog op heel constructieve wijze bijdroeg aan het manuscript. Daarenboven mocht ik bij de uitvoering van onze twee laatste studies rekenen op de inzet van Willem. Hartelijk dank Willem voor alles wat ik van je geleerd heb op het gebied van kwalitatief onderzoek, voor de literatuur waarmee je mij steevast bombardeerde en voor de uitgebreide discussies over de onderzoeksresultaten die we tijdens enkele lange treinreizen voerden. Ik wens je een goed 
'pensioen' toe. 'Pensioen' tussen aanhalingstekens, omdat ik hoop je nog vaak op faculteit tegen te komen, wanneer je nog 'hobbyt' in het onderwijs en/of onderzoek.

Vanaf de start van mijn promotietraject heeft het werk van Dries Berings mij geïnspireerd. Ik meen dat wij elkaar voor het eerst uitvoerig hebben gesproken over onze gezamenlijke onderzoeksinteressen tijdens het EQAF in Riga. Daarna is er steeds een uitwisseling gebleven en kwam ik via Dries ook in contact met Gea van Zutven. Ik wil jullie beiden, Dries en Gea, hartelijk danken voor de inspirerende discussies die we op de KU Leuven Campus in Brussel, de Fontys University of Applied Sciences Campus in Eindhoven en op locatie te Maastricht, hebben gevoerd. Deze discussies hebben o.a. geresulteerd in enkele mooie workshops die ik samen met jullie met veel plezier heb mogen ontwikkelen en geven. Hopelijk komen we er in de nabije toekomst ook aan toe om samen een artikel over kwaliteitscultuur te schrijven!

Even terug naar FHML en wel naar mijn collega's van Strategie \& Beleid. Het is wellicht wat vreemd om je leidinggevende te complimenteren, maar ik doe het toch: Mariëtte, nogmaals veel dank voor de kans die je mij hebt geboden, voor al je professionele adviezen en meer in het algemeen voor de heel prettige wijze waarop je al jaren leiding geeft. Mensen die iets willen leren over goed leiderschap binnen een onderwijsorganisatie zou ik zeker aanbevelen wat weekjes met jou mee te lopen! Tom, over jouw positieve benadering van het beleidswerk valt denk ik een aparte dissertatie te schrijven. Veel dank voor alle wijze lessen (vaak op klassieke leest geschoeid) op schrijfgebied en m.b.t. bijvoorbeeld projectorganisatie. Lessen die zeer zeker ook van pas kwamen in het werk als PhD Student! Dank ook voor de mooie anekdotes van jou (en Eva) waarmee je de S\&B afdeling iedere dag van de eerste lockdown periode met een glimlach deed opstaan. Albertine, dankjewel voor de nauwe samenwerking in diverse projecten. Heel fijn dat we de afgelopen jaren soms onze smart konden delen, daar waar het onderzoek opstarten en uitvoeren in weinig beschikbare tijd betrof. Nog mooier is het dat uiteindelijk de opbrengsten van al die inspanningen nu zichtbaar worden. Heel veel succes met jouw promotietraject! Kamergenoot Koen: dank voor de fijne samenwerking op velerlei vlakken. Dank voor je interesse in mijn onderzoek en dat je af en toe als luisterend oor wilde fungeren wanneer ik wat frustratie moest uiten. Ook dank aan de S\&B collega's waarmee ik inhoudelijk iets minder intensief samenwerk; Marcel, ik stel het zeer op prijs dat je regelmatig binnenliep om even te sparren over hoe het er voorstond met mijn onderzoek. Tamara, veel dank voor je hulp bij de vertaling van quotes en taalverbeteringen in artikelen! Nathalie en Nicole, een simpel maar welgemeend dankjewel voor jullie fijne collegialiteit.

Graag wil ik ook SHE's Angelique hartelijk danken voor de Engelse taal correcties van diverse delen van dit proefschrift (inc. enkele onderdelen van artikels). Ik vroeg om een 'light' correctie, maar wat ik steeds terugkreeg was een sterk verbeterd product waar ik zeer blij van werd!! Dames van het secretariaat van SHE; hartelijk dank voor al jullie hulp op het praktische en planningsgebied. Paul van O\&O, veel dank voor je vlotte en vakkundige hulp bij het maken van de selectie van blok coördinatoren die werden uitgenodigd voor deelname aan de vierde studie. 
Thanks to all my fellow $\mathrm{PhD}$ candidates at SHE. I learned a lot from our article discussions during the $\mathrm{PhD}$ platform meetings and had a great time during several international conferences and social get-togethers! Serge \& Stephanie, dank voor de fijne samenwerking gedurende ons gezamenlijke voorzitterschap van datzelfde PhD platform. Daarnaast ook speciale dank aan Serge en Derk voor het lesje 's'nacht een broodje kebab bestellen' tijdens de AMEE in Wenen. Cindy \& Juliët, hartelijk dank voor de samenwerking bij de organisatie van het PhD-uitje: wat mij betreft was dat heel erg goed geslaagd!!

Stephanie, jou wil ik nog even aanvullend en apart bedanken voor het feit dat je mij als parttime promovendus hebt betrokken bij diverse SHE activiteiten. Heel erg bedankt ook voor je feedback op diverse manuscripten, alle 'social support' die je daarnaast gaf en voor hetgeen dat ik mocht leren van jouw artikelen en presentaties!

Vriendenclub met de Gulpense roots (Bjorn, Mike, Wouter, Felipe, Herold), we zien elkaar wat minder tegenwoordig vanwege het feit dat een aantal van jullie druk zijn met recente gezinsuitbreiding en/of carrière-moves. Desondanks, erg bedankt voor de interesse die jullie steeds toonden en nog tonen in de voortgang van mijn onderzoek, al is het maar omdat ook jullie reikhalzend uitkijken naar dat eindfeestje.

Gijs, Niek, Maurice, Swenne, met name bedankt voor al die geweldig mooie reizen die we de afgelopen jaren hebben gemaakt en voor de diverse gelegenheden waarbij ik jullie dan even lastig mocht vallen met wat gezeur over mijn promotietraject. Als 'Dottore' kan het niet anders dan dat ook mijn toep-en pokerkunsten automatisch nog zullen verbeteren, dus wees gewaarschuwd. Verder bedank ik ook nog graag alle leden van het 'Neubourg bouwoverleg' voor de welkome vrijdagmiddag afschakelmomentjes. Mannen van FC Gulpen 2, allemaal wel bedankt voor al jullie bijdragen aan dit vriendenteam waarin naast voetbal als uitlaatklep een ruime aandacht is voor eenieders persoonlijke \& professionele ontwikkeling ;)!!

Pap en mam, Niek, Myrthe \& Ivo, danke voor al jullie support, advies en hulp door de jaren heen die niet in woorden zijn uit te drukken. Ik kijk met veel genoegen terug op de woensdagavondetentjes waarbij er regelmatig een brainstorm over stellingen voor mijn onderzoek op gang kwam. Helaas hebben al die Franse en Italiaanse spreekwoorden de eindselectie toch niet doorstaan. Superveel dank ook voor al jullie inzet bij diverse succesvolle verbouwingen onder leiding van Ivo aan de Dorpstraat en Kantonhof waardoor ik deze woorden mag tikken met een zowel letterlijk als figuurlijk zeer mooi perspectief in zicht!!

Tot slot, nogmaals een hartelijk woord van dank aan alle docenten en studenten die aan onze studies hebben deelgenomen en aan alle ondersteunende stafleden, binnen en buiten FHML, die er mede voor zorgden dat de organisatie \& planning rondom de studies zo vlotjes liep!! 


\section{About the author}

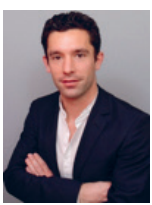

Guy Bendermacher (Heerlen, March IIth, 1985) studied Health Sciences and Public Health (2003-2008) at Maastricht University (UM). He completed the master specialisations in 'Health Policy, Economics and Management', and 'Work and Health'.

After his graduation, Guy worked for a short period at the Human Resources Department of the European Institute for Public Administration. As of 2009, he joined UM's Faculty of Health, Medicine and Life Sciences as educational policy advisor.

In the academic year 2013/2014, Guy partook in the course 'writing a PhD research proposal' offered by the School of Health Professions Education. Thereafter, he was granted the opportunity to work in part-time on his $\mathrm{PhD}$ project. The main areas in which he aspires to continue his professional career concentrate on the intersections between educational policy -organisation, education, and management sciences-and educational quality improvement. 


\section{Conference papers \& presentations}

- Bendermacher, G.W.G., oude Egbrink, M.G.A., Wolfhagen, I.H.A.P., and Dolmans, D.H.J.M. (20I3). Toward a multi-perspective model of quality culture in higher education institutions? Paper presented at the $8^{\text {th }}$ European Quality Assurance Forum (EQAF), University of Gothenburg: 21-23 November.

- Bendermacher, G.W.G., oude Egbrink, M.G.A., Wolfhagen, I.H.A.P., and Dolmans, D.H.J.M. (20I5). PhD onderzoek: Toward a multi-perspective model of quality culture in higher education institutions. Paper Presented at the $10^{\text {th }} \mathrm{PhD}$ student Day organised by the Netherlands Association for Medical Education (NVMO), University of Utrecht: 17 November.

- Bendermacher, G.W.G., oude Egbrink, M.G.A., Wolfhagen, I.H.A.P., and Dolmans, D.H.J.M. (2016). Unravelling quality culture in higher education institutions: a realist review. Paper presented at the annual conference of the Association for Medical Education in Europe (AMEE), University of Barcelona: 27-3I August.

- Bendermacher, G.W.G., oude Egbrink, M.G.A., Wolfhagen, I.H.A.P., and Dolmans, D.H.J.M. (2017). Reinforcing pillars for quality culture development: a path-analytic model. Paper presented at the $12^{\text {th }}$ European Quality Assurance Forum (EQAF), University of Latvia, Riga: 23-25 November.

- Bendermacher, G.W.G., oude Egbrink, M.G.A., Wolfhagen, I.H.A.P., and Dolmans, D.H.J.M. (2017). Versterken van een kwaliteitscultuur: een pad-analytisch model. Paper presented at the Educational Research Days (ORD), University of Antwerp: 28-30 June.

- Bendermacher, G.W.G., de Grave, W., oude Egbrink, M.G.A., Wolfhagen, I.H.A.P., and Dolmans, D.H.J.M. (2019). Werken aan een cultuur voor continue verbetering van medisch onderwijs. Paper presented at the annual congress of the Netherlands Association for Medical Education (NVMO), Rotterdam: 21-22 November.

\section{Workshops}

- Bendermacher, G.W.G., Querido, S., and Dolmans, D.H.J.M. (2016). Een review studie opzetten: hoe doe je dat? Workshop delivered at the annual congress of the Netherlands Association for Medical Education (NVMO), Egmond aan Zee: 17-18 November.

- Berings, D., Bendermacher, G.W.G., and van Zutven, G. (2018). Exploring the supporting potential of two reflection instruments to concretise a vision and strategy on quality culture development. Workshop delivered at the $13^{\text {th }}$ European Quality Assurance Forum (EQAF), University of Vienna, I5-17 November.

- Bendermacher, G.W.G., van Zutven, G., Dolmans, D.H.J.M., and Berings, D. (2019). Translating quality culture theory to (best) practice: multi-stakeholder perspectives as stepping stones for organisational development. Workshop delivered at the Higher Education Conference (HEC), Amsterdam: 28-29 October.

- Stalmeijer, R.E., Whittingham, J.R.D., Strand, P., Bendermacher, G.W.G., and Dolmans, 
D.H.J.M. (2019). Quality culture, not a quality straightjacket. Workshop delivered at the annual conference of the Association for Medical Education in Europe (AMEE), University of Vienna: 24-28 August.

- Bendermacher, G.W.G., Dolmans, D.H.J.M., and Meeuwissen, S.N.E. (202I). Advancing a quality culture through educational leadership. Workshop to be delivered at the International Conference on Faculty Development in the Health Professions of the Association for Medical Education in Europe (AMEE): 28 August.

\section{Poster pitch}

- Bendermacher, G.W.G., oude Egbrink, M.G.A., Wolfhagen, I.H.A.P., and Dolmans, D.H.J.M. (2015). Unravelling elements of quality culture(s) in higher education. Poster presented at the $4^{\text {th }}$ Research in Medical Education (RIME) Conference, Munich: 19-2I March.

\section{Miscellaneous}

- Bendermacher, G.W.G., oude Egbrink, M.G.A., Wolfhagen, I.H.A.P., and Dolmans, D.H.J.M. (2014). Research Proposal: Quality culture in higher education. School of Health Professions Education presents: 14 March.

- Bendermacher, G.W.G. (2018). Quality culture in Higher Education Institutions. Lunch Lecture FHML Department of Educational Research and Development: 6 February.

- Bendermacher, G.W.G. (2018). Reinforcing pillars for quality culture development. Lecture delivered at the 'Education afternoon' of the FHML Department of Health Education and Promotion: II June.

- Bendermacher, G.W.G. and Meeuwissen, S.N.E. (2020). Advancing a Quality Culture in Health Professions Education through Leadership Development. Lunch Lecture FHML Department of Educational Research and Development: 8 December. 


\section{SHE Dissertation Series}

The SHE Dissertation Series publishes dissertations of PhD candidates from the School of Health Professions Education (SHE) who defended their PhD theses at Maastricht University. The most recent ones are listed below.

For more information go to: https://she.mumc.maastrichtuniversity.nl

2020

- Oudkerk Pool, A. (06-II-2020) Competency-based portfolio assessment - Unraveling stakeholder perspectives and assessment practices.

- Geel van, K. (05-II-2020) Lifelong learning in radiology: all eyes on visual expertise.

- Stammen, L. (16-10-2020) Pursuing - High-Value, Cost-Conscious Care - The Role of Medical Education.

- Meulen van der, M. (15-10-2020) Assessment of physicians' professional performance using questionnaire-based tool.

- Matsuyama, Y. (05-10-2020) Contextual attributes fostering self-regulated learning in a teacher-centered culture: learner's professional identity formation is a trigger.

- Rovers, S. (16-09-2020) Growing knowledge, supporting students' self-regulation in problem-based learning.

- Bourgeois-Law, G. (03-09-2020) Conceptualizations of remediation for practicing physicians.

- Giuliani, M. (19-05-2020) A Critical Review of Global Curriculum Development, Content and Implementation in Oncology.

- Schreurs, S. (20-03-2020) Selection for medical school; the quest for validity.

- Schumacher, D. (19-03-2020) Resident Sensitive Quality Measures: Defining the Future of Patient-Focused Assessment.

- Sehlbach, C. (2I-02-2020) To be continued.... Supporting physicians' lifelong learning.

\section{9}

- Kikukawa, M. (17-12-2019) The situated nature of validity: Exploring the cultural dependency of evaluating clinical teachers in Japan.

- Kelly, M. (10-12-2019) Body of knowledge. An interpretive inquiry into touch in medical education.

- Klein, D. (06-II-2019) The performance of medical record review as an instrument for measuring and improving patient safety.

- Bollen, J. (0I-II-2019) Organ donation after euthanasia: medical, legal and ethical considerations.

- Wagner-Menghin, M. (25-09-2019) Self-regulated learning of history-taking: looking for predictive cues.

- Wilby, K. (02-07-2019) When numbers become words: Assessors' processing of performance data within OSCEs. 
- Szulewski, A. (20-06-2019) Through the eyes of the physician: Expertise development in resuscitation medicine.

- McGill, D. (29-05-2019) Supervisor competence as an assessor of medical trainees; Evaluating the validity and quality of supervisor assessments.

- Van Rossum, T. (28-02-2019) Walking the tightrope of training and clinical service; The implementation of time variable medical training. 